\title{
Copyright
}

by

Issam Mounir Srour

2005 
The Dissertation Committee for Issam Mounir Srour Certifies that this is the approved version of the following dissertation:

\section{A Linear Programming Approach to Optimize Strategic Investment in the Construction Workforce}

\section{Committee:}

Carl T. Haas, Supervisor

Richard L. Tucker

David P. Morton

John D. Borcherding

Zhanmin Zhang 


\title{
A Linear Programming Approach to Optimize Strategic Investment in the Construction Workforce
}

\author{
by \\ Issam Mounir Srour, B.S.; M.S. \\ Dissertation \\ Presented to the Faculty of the Graduate School of \\ The University of Texas at Austin \\ in Partial Fulfillment \\ of the Requirements \\ for the Degree of \\ Doctor of Philosophy
}

The University of Texas at Austin

May, 2005 


\section{Dedication}

Dedicated to my parents, Mounir and Hassiba for believing in me. They have sacrificed a lot so that I could pursue this dream. 


\section{Acknowledgements}

This dissertation is the outcome of a long journey that started many years ago. I would like to thank my supervisor, Dr. Carl Haas for his continuous feedback and support. I would like to extend my thanks to Dr. Richard Tucker for his help and guidance, Dr. Morton for his valuable help with the model formulation, Dr. Borcherding, Dr. Zhanmin Zhang, Dr. Robert Glover, and Dr. Keith Byrom for their great feedback. Special thanks to my fellow graduate students on the workforce research team for making the past three years enjoyable, namely Mike Pappas who shared with me the good and bad days. Finally, I would like to thank my wife Faith Jordan Srour for helping me edit this document and for her great support, my sister Nadine Srour, my brother Ghassan Srour, Dr. Salim Jazzini, and Dr. Souheil Srour for their infinite support.

I would like to acknowledge the Center for Construction Industry Studies and the Alfred P. Sloan Foundation for funding this research effort.

To God, most of all, I am grateful. 


\title{
A Linear Programming Approach to Optimize Strategic Investment in the Construction Workforce
}

\author{
Publication No. \\ Issam Mounir Srour, Ph.D. \\ The University of Texas at Austin, 2005
}

Supervisor: Carl T. Haas

Construction workforce management practice needs optimization techniques to better address the issue of investment in the workforce. This dissertation presents a linear programming model developed to provide an optimization-based framework for matching supply and demand of construction labor most efficiently through training, recruitment, and allocation. The developed model, entitled Optimal Workforce Investment Model (OWIM), was applied on data obtained from the CII Model Plant, a hypothetical \$140-million petro-chemical project to be built in the Gulf Coast region, and a recent survey conducted by the Center for Construction Industry Studies (CCIS) and the Construction Industry Institute (CII). The input data to the model consist of a certain available labor pool, cost figures for training workers in different skills, the cost of hiring workers, hourly labor wages, and estimates of affinities between the different considered skills. The output of the OWIM includes the number of construction workers to be hired and the number of construction workers to be trained in order to meet a job-site demand pattern over a certain period of time in the most cost-effective fashion. Use of the model not only helps to alleviate problems of skilled labor shortages in the US construction industry but also provides firms costs savings by reducing hiring, training, and retainage costs. 


\section{Table of Contents}

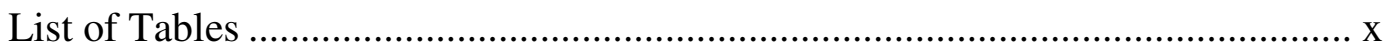

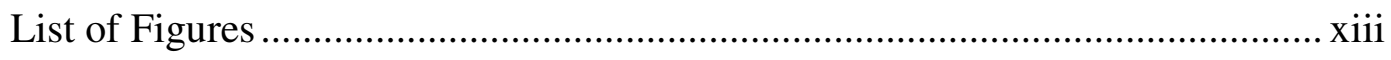

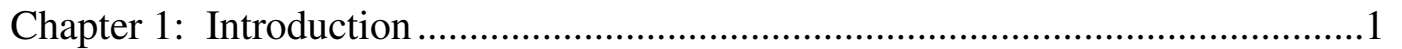

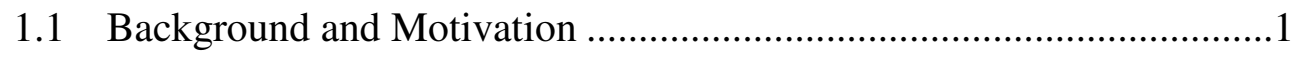

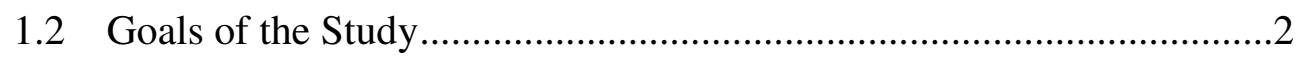

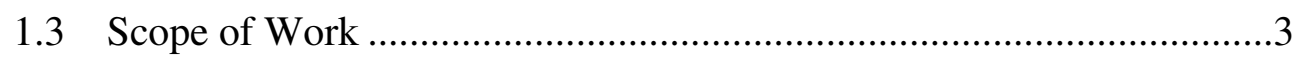

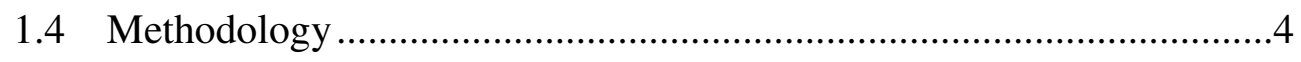

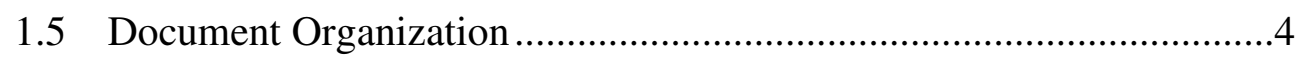

Chapter 2: Review and Synthesis of the Body of Knowledge in the Construction

Workforce Arena ……...........................................................................

2.1 Introduction: The US Construction Industry ......................................

2.2 Current State of the US Construction Workforce .................................11

2.2.1 Demographics ......................................................................11

2.2.2 What Does the Industry Value in its Workers? ..........................18

2.3 Skilled Labor Shortage: A Major Challenge ………...........................25

2.4 Previous Strategic Planning Efforts ....................................................

2.5 Optimization: A Historical Background ………………………............35

2.6 Use of Relevant Optimization Techniques Outside Construction ........36

2.7 Need for Optimization Techniques to Address the Issue of Strategic Investment in the Construction Workforce............................................38

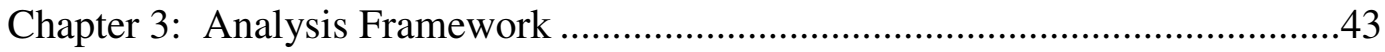

3.1 Introduction: Main Objective of the Study ………………………......43

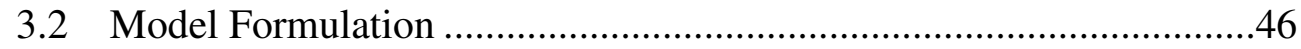

3.2.1. Type of Model and Solution Algorithm....................................47

3.2.2. Main Assumptions ...................................................................50

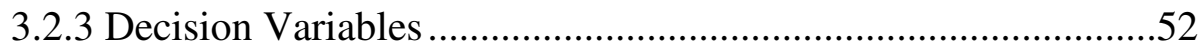

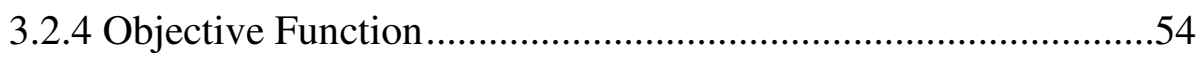

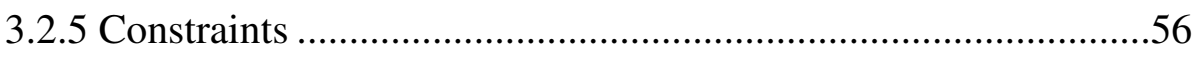


3.2.6 Full Formulation .........................................................................

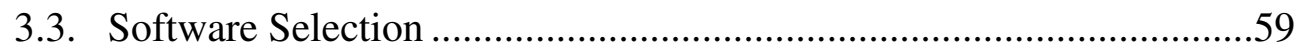

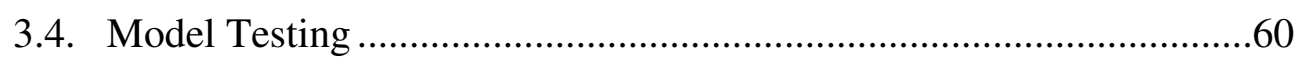

Chapter 4: Application of the OWIM on the CII Model Plant ..............................61

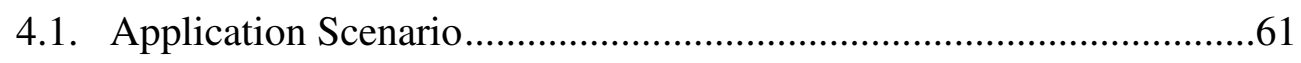

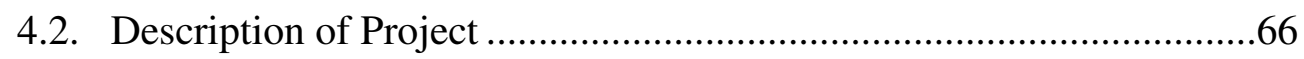

4.3. Labor Demand Requirements ………………….............................67

4.4. Available Workforce.......................................................................

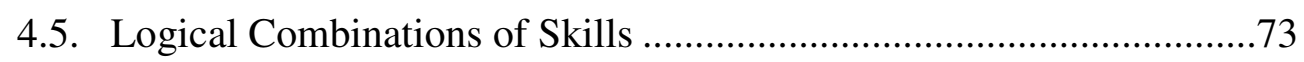

4.5.1. CII/CCIS Survey …………………………............................

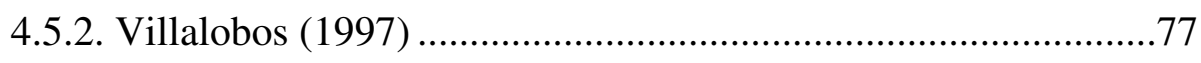

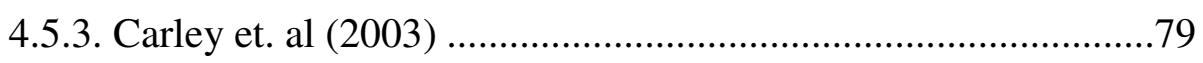

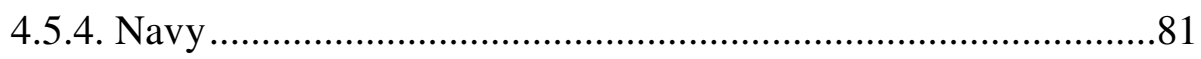

4.5.5. Other Industry Practices............................................................ 82

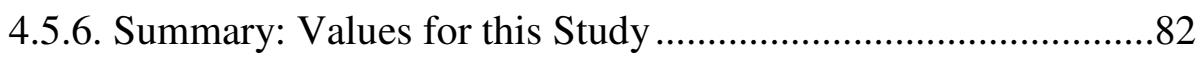

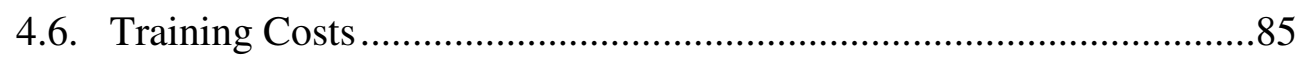

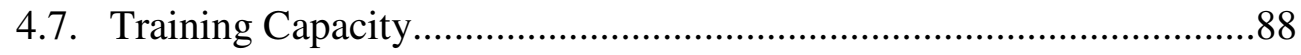

4.8. Hiring Costs ...................................................................................... 89

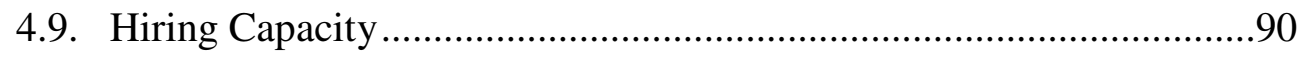

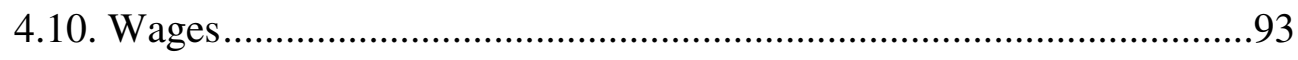

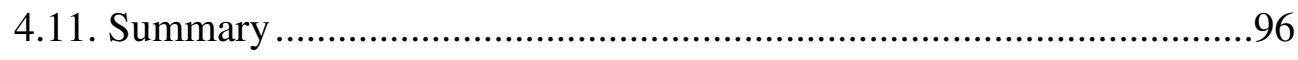

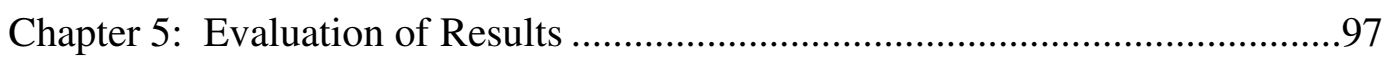

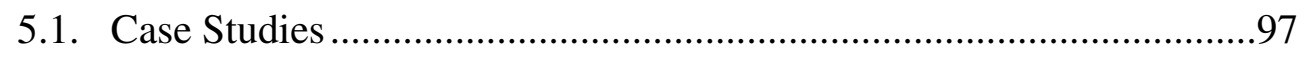

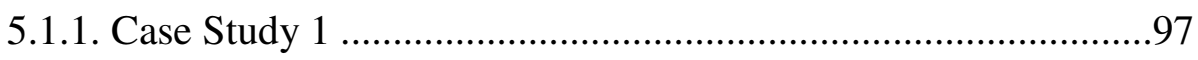

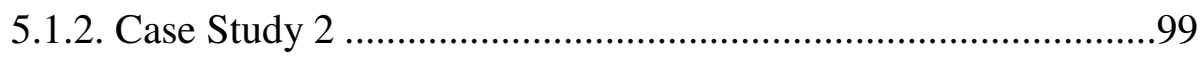

5.1.3. Case Study 3 ......................................................................... 101

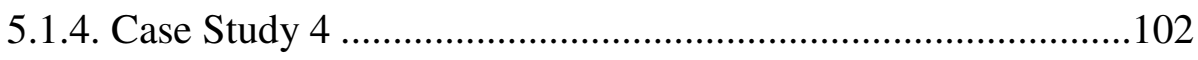

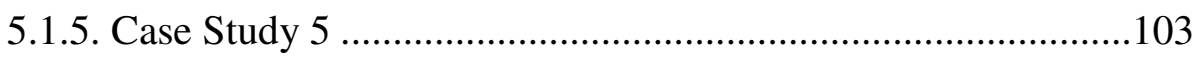

5.1.6. Summary of Five Cases .........................................................105

5.2. Sensitivity Analyses..........................................................................107 
5.2.1. Sensitivity to Training Costs....................................................107

5.2.2. Sensitivity to Hiring Costs ..........................................................110

5.2.3. Sensitivity to Wages ..............................................................113

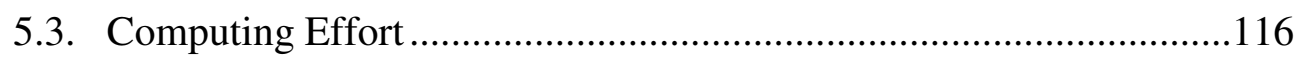

Chapter 6: Benefits and Costs of Implementing the OWIM..................................118

6.1. Benefits of Implementation..............................................................118

6.1.1. Solution Using Approach 1 .......................................................120

6.1.2. Solution Using Approach 2 ..................................................120

6.1.3. Solution Using the OWIM .....................................................122

6.1.4. Comparison between OWIM and Approaches 1 and 2 ...........123

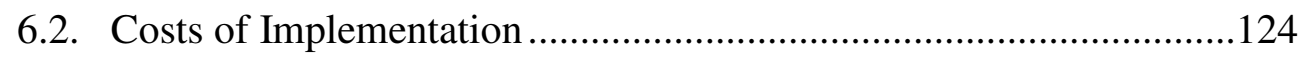

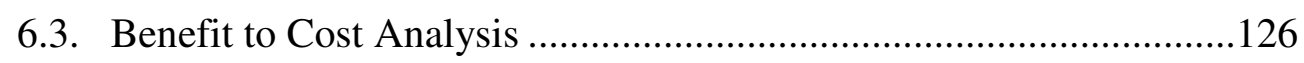

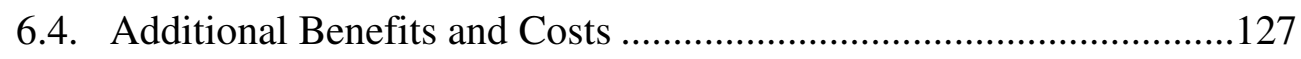

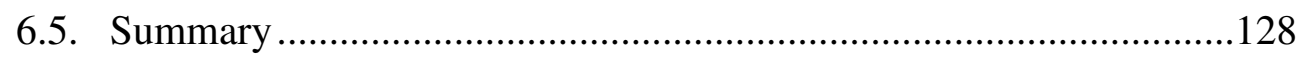

Chapter 7: Conclusions and Recommendations ............................................129

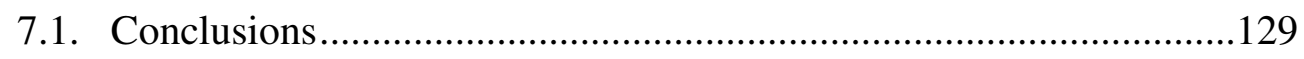

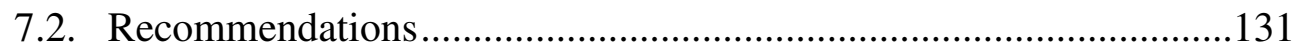

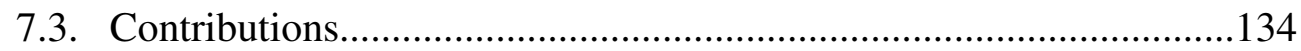

Appendix A: Workforce Assessment Package Questionnaires .............................135

Appendix B: Case Study 1-An Example Formulation of the WOIM in GAMS .141

Appendix C: Sample Output of Worker Assignment Resulting from Running the WOIM on Case Study 1 ........................................................................147

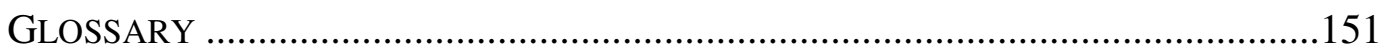

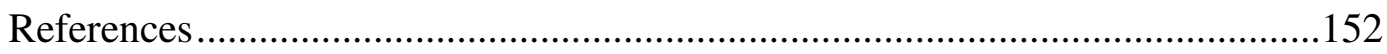

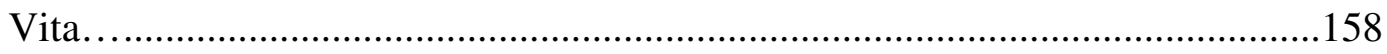




\section{List of Tables}

TABLE 2.1. OCCUPATIONAL CLASSIFICATION AND DISTRIBUTION IN CONSTRUCTION (CPWR 2002) 10

TABLE 2.2. AVERAGE HOURLY WAGES IN THE DIFFERENT CRAFTS (CII/CCIS SURVEY VERSUS BLS DATA)....... 15

TABLE 2.3. DEMOGRAPHIC STATISTICS OF SURVEYED WORKERS. 16

TABLE 2.4. BIVARIATE CORRELATION BETWEEN HOURLY WAGES AND WORKERS CHARACTERISTICS.

TABLE 2.5. BIVARIATE CORRELATION BETWEEN ANNUAL INCOME AND WORKERS

CHARACTERISTICS 21

TABLE 2.6. REGRESSION OF HOURLY WAGES AGAINST KEY WORKER ATTRIBUTES. ........ 24

TABLE 2.7. REGRESSION OF ANNUAL INCOME AGAINST KEY WORKER ATTRIBUTES........ 25

TABLE 2.8. EXCESS SUPPLY OF CONSTRUCTION WORKERS IN ALBERTA IN PERCENT (CWDFC 2002) 30

TABLE 2.9. NUMBER OF AVAILABLE WORKERS IN ALBERTA IN 2002 (CWDFC 2002)........ 31

TABLE 4.1: CII MODEL PLANT WORKFORCE (BURLESON ET. AL 1998), .................................... 62

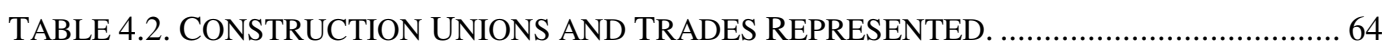

TABLE 4.3. CRAFTS AREAS AS SPECIFIED BY THE NATIONAL CENTER FOR CONSTRUCTION

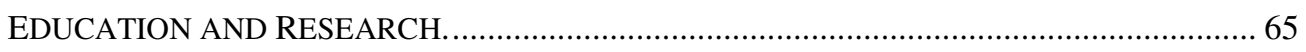

TABLE 4.4. LABOR DEMAND OVER THE ANALYSIS PERIOD (KEY CRAFTS ARE HIGHLIGHTED). 68

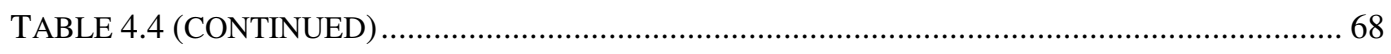

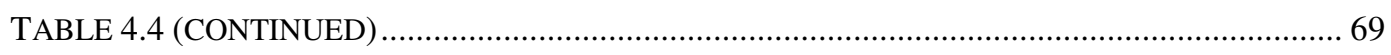


TABLE 4.5. NUMBER OF SINGLE-SKILLED WORKERS AVAILABLE AT THE BEGINNING OF THE PROJECT. 71

TABLE 4.6. NUMBER OF AVAILABLE WORKERS WITH TWO SKILLS AT THE BEGINNING OF THE PROJECT. 72

TABLE 4.7. MULTISKILLING COMBINATIONS IN THE CCIS/CII DATABASE............................. 74

TABLE 4.8. BIVARIATE CORRELATION USING THE CCIS/CII SURVEY DATA........................... 76

TABLE 4.9. PRACTICAL SKILL COMBINATIONS (VILLALOBOS 1997)....................................... 78

TABLE 4.10. BIVARIATE CORRELATION BETWEEN PAIRS OF SKILLS USING CARLEY ET. AL

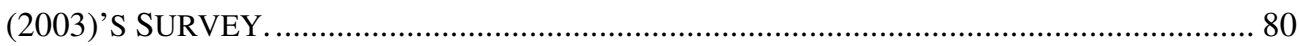

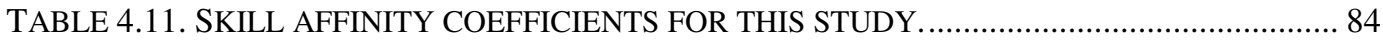

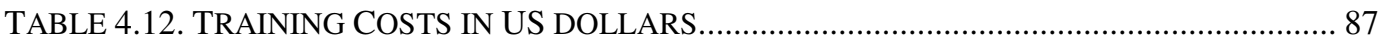

TABLE 4.13. MAXIMUM NUMBER OF WORKERS THAT CAN BE TRAINED IN AN ADDITIONAL

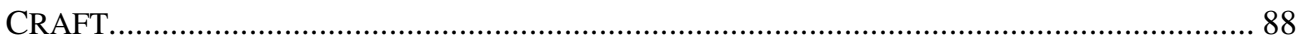

TABLE 4.14. MAXIMUM NUMBER OF WORKERS WITH ONE SKILL THAT CAN BE HIRED.... 91

TABLE 4.15. MAXIMUM NUMBER OF WORKERS WITH TWO SKILLS THAT CAN BE HIRED. 92

TABLE 4.16. HOURLY WAGES IN US DOLLARS 93

TABLE 4.17. HOURLY WAGES OF MULTISKILLED WORKERS IN US DOLLARS........................ 95

TABLE 5.1. CASE STUDY 1: HIRING AND TRAINING RECOMMENDATIONS.............................98

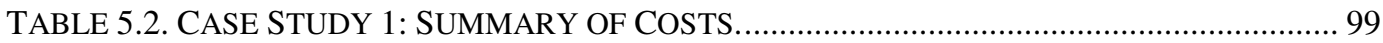

TABLE 5.3. CASE STUDY 2: HIRING RECOMMENDATIONS......................................................... 100

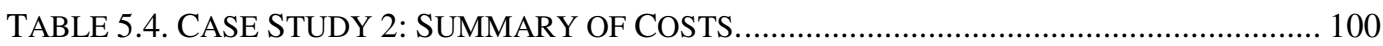

TABLE 5.5. CASE STUDY 3: HIRING AND TRAINING RECOMMENDATIONS........................... 101

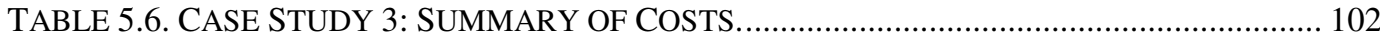

TABLE 5.7. CASE STUDY 4: HIRING AND TRAINING RECOMMENDATIONS............................ 103

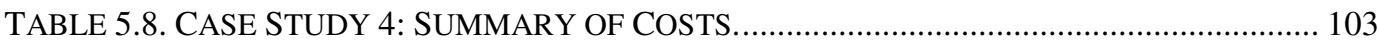




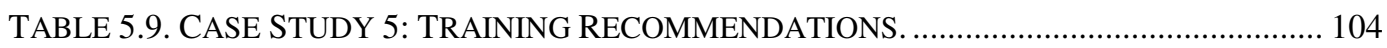

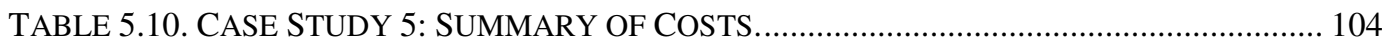

TABLE 5.11. COMPARISON OF RESULTS FROM FIVE CASE STUDIES. .................................... 105

TABLE 6.1. MAXIMUM NUMBER OF WORKERS THAT CAN BE TRAINED IN AN ADDITIONAL SKILL AND MAXIMUM NUMBER OF WORKERS THAT CAN BE HIRED......................... 119

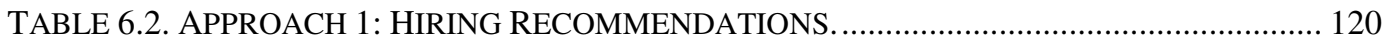

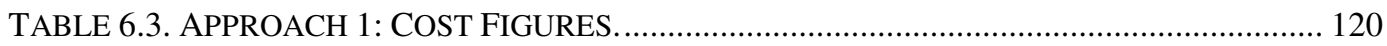

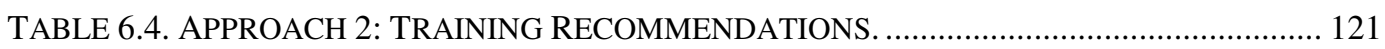

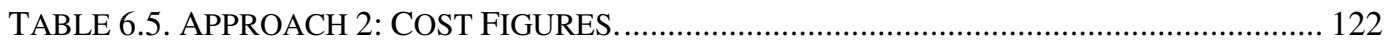

TABLE 6.6. OWIM SOLUTION: HIRING AND TRAINING RECOMMENDATIONS....................... 122

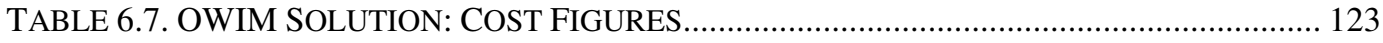

TABLE 6.8. SUMMARY OF SAVINGS IN OVERALL LABOR COSTS AND ADDITIONAL COST.126 


\section{List of Figures}

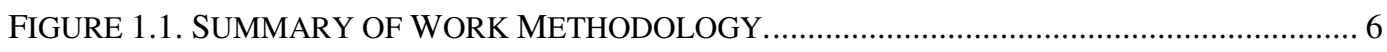

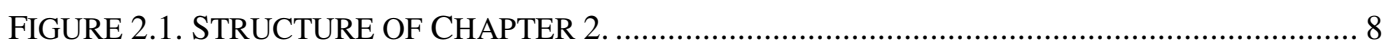

FIGURE 2.2. A COMPARISON OF AVERAGE HOURLY WAGE DATA WITH BLS VALUES AND AVERAGE HOURLY WAGES BY JOB TITLE............................................................... 14

FIGURE 2.3. LEVEL OF CAREER SATISFACTION BY JOB TITLE ............................................. 17

FIGURE 2.4. PERCENTAGE OF PROJECTED EMPLOYMENT CHANGE, BY SELECTED CONSTRUCTION OCCUPATION, 2000-2010 (CPWR 2002)............................................. 29

FIGURE 3.1. ILLUSTRATION OF THE WORK PRESENTED IN THIS DISSERTATION AS COMPARED

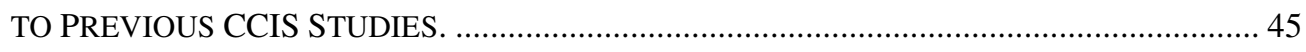

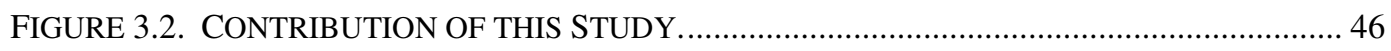

FIGURE 3.3. GRAPHICAL EXAMPLE OF A TWO-VARIABLE LP (WINSTON 1995).................... 49

FIGURE 3.4. FORMULATION OF THE OWIM-AN LP MODEL PROVIDING OPTIMAL INVESTMENT

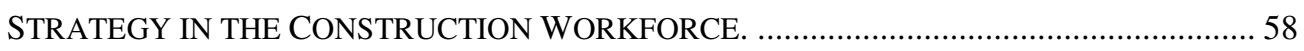

FIGURE 4.1. FREQUENCY DIAGRAM OF SKILL AFFINITY COEFFICIENTS............................... 85

FIGURE 5.1. SUMMARY OF TRAINING COSTS IN THE FIVE CASE STUDIES........................... 105

FIGURE 5.2. SUMMARY OF HIRING COSTS IN THE FIVE CASE STUDIES. ............................... 106

FIGURE 5.3. SUMMARY OF WAGES INCURRED IN THE FIVE CASE STUDIES......................... 106

FIGURE 5.4. SUMMARY OF TOTAL COSTS IN THE FIVE CASE STUDIES................................ 107

FIGURE 5.5. NUMBER OF WORKERS TO HIRE OR TRAIN VERSUS BASIC TRAINING COST PER

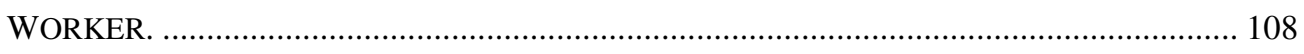

FIGURE 5.6. SENSITIVITY OF THE TOTAL COSTS TO THE BASIC TRAINING COST PER WORKER. 108

xiii 
FIGURE 5.7. SENSITIVITY OF THE TRAINING COSTS TO THE BASIC TRAINING COST PER WORKER. 109

FIGURE 5.8. SENSITIVITY OF THE HIRING COSTS TO THE BASIC TRAINING COST PER WORKER. 109

FIGURE 5.9. SENSITIVITY OF THE INCURRED WAGES TO THE BASIC TRAINING COST PER WORKER. 110

FIGURE 5.10. NUMBER OF WORKERS TO TRAIN OR HIRE VERSUS HIRING COST PER WORKER.

FIGURE 5.11. SENSITIVITY OF THE TOTAL COSTS TO THE HIRING COST PER WORKER..... 111 FIGURE 5.12. SENSITIVITY OF THE TRAINING COSTS TO THE HIRING COST PER WORKER.112 FIGURE 5.13. SENSITIVITY OF THE HIRING COSTS TO THE HIRING COST PER WORKER.... 112 FIGURE 5.14. SENSITIVITY OF THE INCURRED WAGES TO THE HIRING COST PER WORKER.113 FIGURE 5.15. NUMBER OF WORKERS TO HIRE OR TRAIN VERSUS HOURLY WAGES........... 114 FIGURE 5.16. SENSITIVITY OF THE TOTAL COSTS TO THE HOURLY WAGES........................ 114 FIGURE 5.17. SENSITIVITY OF THE INCURRED WAGES TO THE HOURLY WAGES................ 115 FIGURE 5.18. SENSITIVITY OF THE TRAINING COSTS TO THE HOURLY WAGES. ................. 115 FIGURE 5.19. SENSITIVITY OF THE HIRING COSTS TO THE HOURLY WAGES....................... 116 FIGURE 6.1. SUMMARY OF TRAINING AND HIRING COSTS USING APPROACH 1, APPROACH 2, AND THE OWIM. 123

FIGURE 6.2. SUMMARY OF WAGES INCURRED AND TOTAL COSTS USING APPROACH 1, APPROACH 2, AND THE OWIM. 123 


\section{Chapter 1: Introduction}

\subsection{BACKGROUND AND MOTIVATION}

Accelerating change in external environments of construction entities combined with the recurrent problem of skilled labor shortages necessitate more attention to strategic planning than ever before. Unfortunately, human resource management is an area receiving very little strategic planning effort (Maloney 1997). The list of subjects a construction organization should address while developing strategies for human resources includes: the organization's strategic vision, its view of human resources, whether it has a management or a worker driven orientation, whether it has a short-term or a long-term orientation, production technologies, workforce diversity, and the availability of a skilled workforce, which is a major problem faced by today's construction industry.

Emerging initiatives to address this problem include craft and supervisory training, multiskilling, and self-directed work teams as well as productivity enhancements utilizing technology, constructability, and prefabrication. Efforts to quantify or qualify the resulting benefits, however, have been unsatisfactory. Much of the workforce remains unskilled or under-skilled, therefore training must be considered as an option when staffing for a project.

Recent work at the University of Texas at Austin produced a new theoretical model to address the problem of the construction workforce shortage in a more comprehensive manner. Although the method, known as "Tier II," is new and futureoriented, it may have considerable impact on the construction workforce and industry (Castaneda 2002). Tier II is based on the utilization of fewer, more-educated and skilled workers who can perform craft work in addition to some lower-management tasks. The strategy emphasizes multiskilling and craftsmen level management skills, resulting in 
more productive workers who would receive a skills-based higher wage rate (Castaneda 2002).

A second strategy, complimentary to Tier II, was also developed to address the challenge of workforce shortages: Tier I (Brandenburg 2004). This strategy is based on the concept that productivity gains from optimal management of the workforce will relieve pressure on demand and will encourage workers to remain on a project and in the industry. These productivity gains will be achieved by applying intense field management, training, collaboration, and the use of technology in a systematic way to maximize the effectiveness of the front-line supervisors. Tier I proposes that the cohesive, structured implementation of industry accepted best practices will improve the management and utilization of the workforce. It is anticipated that this will lead to improved productivity, reduced absenteeism and turnover, and eventually to overall project success. This two-tier strategy calls for training workers in one or more skills, including management and other soft skills.

Despite addressing the problem of the construction workforce shortage in a comprehensive manner, the two-tier strategy does not provide a region or company specific suggestions on how to improve or allocate its pool of workers in order to optimally match work demand.

\subsection{GOALS OF THE STUDY}

The primary goal of this study is to provide an optimization-based framework for most efficiently matching supply and demand of construction labor through training, recruitment, and allocation. Given a project schedule or demand profile and the available pool of workers, the suggested model provides human resource managers a combined 
strategy for training the available workers and hiring additional workers. The objective of the model is to minimize labor costs while satisfying project labor demands.

The optimization-based model can be applied to a range of problems. A company in the process of planning for a specific project can use the model as the baseline for its labor strategies during the construction period. With some modifications, the model can be used by a firm in the process of planning for labor management across several projects to evaluate different labor strategies across the different projects, such as the number of workers to be shifted from one job-site to another, the number of workers to hire, the number of workers to train etc. The model can be expanded in the future to serve a regional planning group which is in the process of performing labor forecasting for the near future. Knowing the labor demand and supply projections, the model can provide the most cost effective strategy to overcome potential labor shortage issues.

\subsection{SCOPE OF WORK}

The proposed optimization-based framework consists of the formulation of matching supply and demand of construction labor as a mathematical problem, namely a linear program. The input data to the proposed model consists of a certain available labor pool, cost figures for training workers in different skills, the cost of hiring workers, hourly labor wages, and estimates of affinities between the different considered skills. The output of the proposed model includes the number of construction workers to be hired and the number of construction workers to be trained, in each craft, in order to meet a job-site demand pattern over a certain period of time in the most cost-effective fashion. The model is coded in an optimization software entitled General Algebraic Modeling System (GAMS) and solved by the CPLEX solver.

Several real-world cases are studied in order to benchmark the developed model against current industry practices. The sensitivity of the model output to variations in the 
input data is also studied. The model may ultimately be used to map Pareto optimal boundaries for investment decisions if enough simulations are conducted. Finally, the benefits and costs associated with the implementation of the model are presented.

\subsection{METHODOLOGY}

A background review and synthesis of the body of knowledge in the construction workforce arena is performed. The effort aims at describing the characteristics of today's US construction workforce based on a recent survey, discussing the main challenges faced by this workforce and some of the innovative solutions being attempted, and presenting major labor management elements, namely multiskilling. Consultations with industry experts which further reinforce the need for solutions are also described. This effort concludes with an illustration of the need for optimization techniques to provide optimal strategic investment in construction workforces.

A model is developed to provide an optimization-based framework for matching supply and demand most efficiently through training, recruitment, and allocation. Given labor demand information and the available pool of workers, the suggested model provides human resource managers a training strategy for the available workers as well as a strategy for hiring additional workers over the planning horizon. The optimization model is tested and validated on the CII Model Plant, a theoretical industrial project that has been used in several CII studies.

\subsection{DOCUMENT ORGANIZATION}

This dissertation has seven chapters. The current chapter presents the introduction to the document. Chapter Two provides a synthesis of the relevant body of knowledge in the construction workforce arena. The chapter concludes with an illustration of the need for optimization techniques to provide optimal strategic investment in construction 
workforces. Chapter Three presents the analysis framework through a discussion of the type of model that is used as well as the model formulation. Then, Chapter Four presents the project on which the model was applied, the assumptions that were made, and other input data to the proposed model. Chapter Five discusses the results of the optimization runs along with several sensitivity analyses. Chapter Six presents an assessment of the benefits and costs associated with the implementation of the formulated model. Finally, Chapter Seven summarizes the conclusions and recommendations of this study. The following figure presents a summary of the research methodology through the five remaining chapters of this document. 


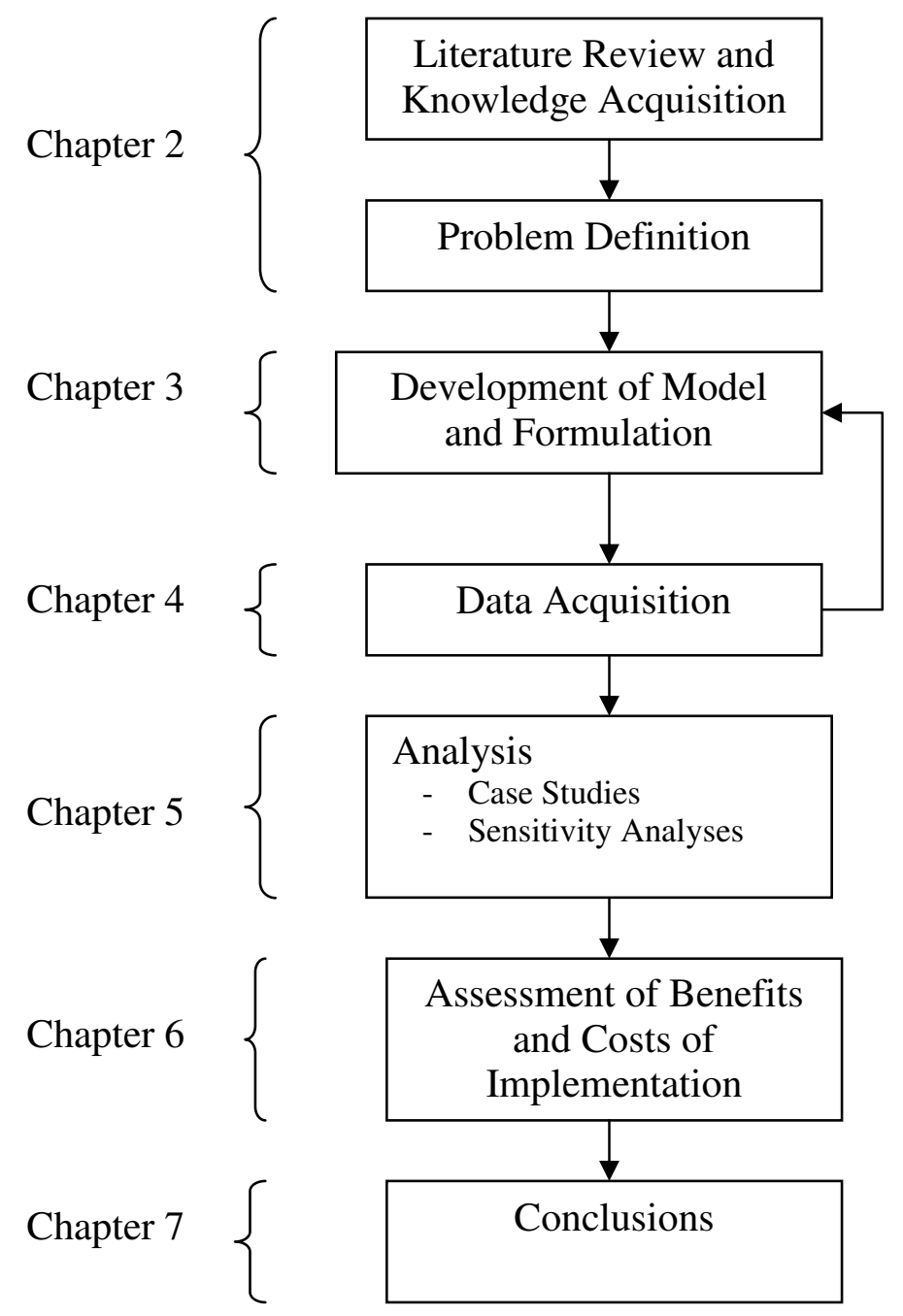

Figure 1.1. Summary of Work Methodology. 


\title{
Chapter 2: Review and Synthesis of the Body of Knowledge in the Construction Workforce Arena
}

\begin{abstract}
As shown in Figure 2.1, this chapter starts with an introduction to the US construction industry followed by a presentation of the current state of today's US construction workforce. This presentation, which is based on a recent survey, highlights the major characteristics of the construction workforce and then discusses the worker attributes that the industry values the most. This segment, section 2.2 , is followed by a discussion of a major challenge faced by today's construction industry, namely skilled labor shortages. The chapter then discusses previous strategic planning efforts related to the construction workforce to overcome this challenge, such as the two-tier strategy, and concludes by illustrating the need for optimization techniques; not only to alleviate the problem of skilled labor shortage but also to provide optimal strategic investment in the construction workforce. Examples of the applications of optimization techniques to construction and non-construction related problems are also presented.
\end{abstract}




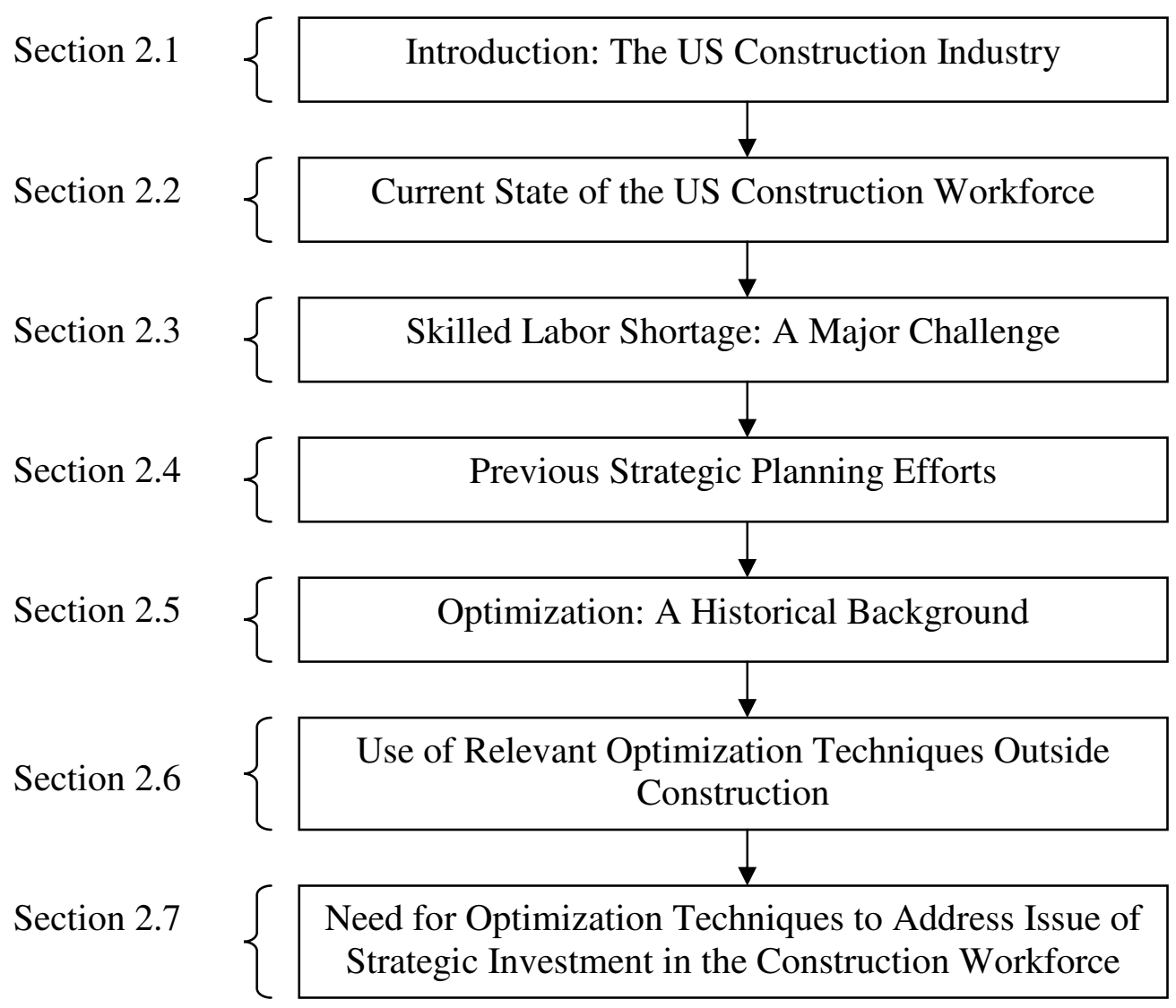

Figure 2.1. Structure of Chapter 2.

\subsection{INTRODUCTION: THE US CONSTRUCTION INDUSTRY}

The US construction industry accounts for $4.8 \%$ of the gross domestic product ( $\$ 372$ billions) and is therefore considered one of the largest industrial sectors (BEA 2004). Currently, the construction industry employs 5.2\% of all workers and accounts for 9.8\% of all establishments (BLS 2004). Current employment statistics show total annual average employment in the construction industry rising from 5,095,000 in 1994 to $6,826,000$ in 2001 . The most recent "construction chart book report" published by the Center to Protect Workers' Rights (CPWR) shows that the construction industry employed 9.4 million workers in 2001 including all positions as shown in Table 2.1. The 
total number of construction establishments increased by 30\% from 1992 to 1997 to reach 2.55 million. The total dollar value of these construction establishments increased from $\$ 581.6$ billion in 1992 to $\$ 945.7$ billion in 1997 (CPWR 2002).

Despite these robust figures, the construction industry is constantly confronting challenges. Among them are attracting, training, and retaining skilled workers. In an occupational survey that was given to junior and senior high school students, construction ranked $248^{\text {th }}$ out of 250 occupations, preceding only custodial care and migrant farm work (Reid 1997). According to Rowings and Federle (1996), these challenges are the result of changing demographic characteristics in the United States as well as the changes in the socio-economic and technological environments of the past few decades.

The construction workforce is a subset of the national labor pool and therefore shares its socio-economic conditions as well as its demographic attributes. The construction industry has lacked information on its workforce as compared to other industries such as the manufacturing and service sectors (McFillen and Maloney 1986). This type of information helps the construction industry develop an understanding of the nature of its labor pool in order to improve the utilization of the available workers and plan for future labor demand. 
Table 2.1. Occupational Classification and Distribution in Construction (CPWR 2002).

\begin{tabular}{|c|c|c|c|}
\hline Label & Code & Description & $\begin{array}{l}\text { Number in } \\
\text { Thousand } \\
\text { (Percent) }\end{array}$ \\
\hline Manager & 0 to 197 & General Manager, Supervisor \& Professional & $1,499(16.0)$ \\
\hline Carpenter & 567,569 & Carpenter \& Apprentice & $1,287(13.8)$ \\
\hline Laborer/Helper & $\begin{array}{c}865,866, \\
869,877, \\
883 \\
\end{array}$ & $\begin{array}{c}\text { Laborer, Helper, Mechanic/Repair, Freight, Stock } \\
\text { Handler, Material Handler/Bagger }\end{array}$ & $1,078(11.5)$ \\
\hline Foreman & 558 & Supervisors who can't be classified by occupation & $750(8.0)$ \\
\hline Electrical & $\begin{array}{l}555,575- \\
577\end{array}$ & $\begin{array}{l}\text { Electrician \& Electric Worker, Including Supervisor } \\
\text { and Apprentice }\end{array}$ & $643(6.9)$ \\
\hline Painter & $\begin{array}{l}556,579 \\
583,584 \\
\end{array}$ & $\begin{array}{c}\text { Painter, Paperhanger \& Plasterer, including supervisor } \\
\text { and apprentice support staff }\end{array}$ & $620(6.6)$ \\
\hline Adm. Support & 208 to 457 & Support Staff & $591(6.3)$ \\
\hline Plumber & $\begin{array}{l}557,585 \\
587\end{array}$ & Plumber \& Pipefitter, Steamfitter Apprentice & $431(4.6)$ \\
\hline Op. Engineer & $\begin{array}{l}594,843- \\
859 \\
\end{array}$ & Operating Engineer, including supervisor & $378(4.0)$ \\
\hline Heat $\mathrm{A} / \mathrm{C}$ mech & 534 & Heat and Air Conditioning Mechanic & $231(2.5)$ \\
\hline Bricklayer, mason & $\begin{array}{l}553,563- \\
564\end{array}$ & $\begin{array}{c}\text { Bricklayer, stone mason; including supervisor and } \\
\text { apprentice }\end{array}$ & $230(2.5)$ \\
\hline Drywall & 573 & Drywall Installer and Taper & $209(2.2)$ \\
\hline Roofer & 595 & Roofer & $196(2.1)$ \\
\hline Truck Driver & $\begin{array}{c}803-804, \\
814 \\
\end{array}$ & $\begin{array}{c}\text { Truck Driver/Motor Transport Occupation, including } \\
\text { motor vehicle supervisor }\end{array}$ & $182(2.0)$ \\
\hline Const. Nec. & 599 & Construction trades except supervisor & $172(1.8)$ \\
\hline Repair & $\begin{array}{l}503-533, \\
538-539, \\
547-549 \\
\end{array}$ & Repair and Mechanic & $169(1.8)$ \\
\hline Concrete & 588 & Concrete and Terrazzo Finisher & $90(1.0)$ \\
\hline Carpet Layer & 566 & Carpet Layer & $87(0.9)$ \\
\hline Welder & $783-784$ & Welder \& Cutter, Solderer \& Brazer & $84(0.9)$ \\
\hline Tile & 565 & Tile Setter & $82(0.9)$ \\
\hline Ironworker & 597 & Structural Metal Worker & $69(0.7)$ \\
\hline Sheet Metal & 596,653 & Sheet Metal Worker \& Sheet Metal Duct Installer & $58(0.6)$ \\
\hline Insulation & 593 & Insulation Worker & $40(0.4)$ \\
\hline Glazier & 589 & Glazier & $26(0.3)$ \\
\hline Elev. Constructor & 543 & Elevator Installation Construction & $17(0.2)$ \\
\hline Boilermaker & 643 & Boilermaker & $8(0.1)$ \\
\hline Other & & $\begin{array}{c}\text { Including Extraction, Driller, Millwright, Rail/Water } \\
\text { Trans., Machine, Plant/sys op. }\end{array}$ & $110(1.2)$ \\
\hline Total & & & $9,351(100.0)$ \\
\hline
\end{tabular}




\subsection{CURRENT STATE OF THE US CONSTRUCTION WORKFORCE}

This section presents the current state of today's US construction workforce. First, it presents the social and demographic attributes of a sample of 862 construction workers that were interviewed as part of an on-going research effort at the University of Texas at Austin. Second, it discusses the worker attributes the construction industry values the most, as reflected in both hourly wages and average annual incomes.

\subsubsection{Demographics}

This section presents the current state of the US construction workforce based on a recent survey conducted by the Center for Construction Industry Studies (CCIS) at the University of Texas at Austin. These findings are compared with national data provided by the Bureau of Labor Statistics (BLS) and the Center to Protect Workers' Rights (CPWR). The CCIS research effort aims at studying the challenges faced by today's US construction workforce and suggests innovative solutions. Data gathered from 19 site visits to industrial-type projects scattered around the nation are compared to national data as reported by the Bureau of Labor Statistics (BLS) and the Center to Protect Workers' Rights (CPWR). The process of data acquisition is explained in further detail in Castaneda (2002) and Brandenburg (2004). The questionnaires used as part of this study are presented in Appendix A.

Union workers are the majority at 4 of the 19 visited projects in the survey set. The total number of workers on unionized projects in the set is 215 , which is equivalent to approximately $25 \%$ of the overall group of interviewed workers. Data reported by the CPWR (2002) indicate that 19\% of construction employees are union-members. Current Population Survey (CPS) data indicate that $20 \%$ of all construction workers in 2000 were union members as compared to $36 \%$ in 1976. Until the early 1970's, construction in the 
US was performed primarily by unionized workers (Maloney and McFillen 1995). In 1950, approximately $85 \%$ of the construction contractors were affiliated with unions (ABC 2000). In fifty years, there has been a dramatic shift. According to the BLS, approximately 1.22 million construction workers were members of a union in 2000, while 1.27 million workers were represented by a union (this number includes the workers who report no union affiliation but whose jobs are covered by a union or an employee association contract). This amounts to respectively $18.3 \%$ and $19 \%$ of the total construction workforce (Srour et. al 2004). According to Allen (1994), the decline in union membership is due to the adoption of strategies by both contractors and owners to control labor costs and to changes in the interpretation of labor laws which gave contractors more flexibility in collective bargaining. Dieckmann and Peppler (1984) link the growth of open-shop to wage rate differentials, union work rules and union productivity disputes.

The average age of the surveyed workers in this study is 40, which is slightly higher than the national average of 38.7 for construction workers in CPWR's survey (2002). This can be attributed to the fact that this study aimed at surveying workers at the journeyman level and above only. These workers are typically older than apprentices and helpers. The average age of union workers in the survey is 42.5 years whereas the average age of non-union workers is 39.2 years. Union workers generally have more years of experience at the craftsman level than non-union workers in the survey $(17.7$ years on average as compared to 11.3 for non-union workers). Union workers received an average of 85.66 hours of craft training in the past three years whereas non-union workers received on average 58 hours of training during the same time period. The average number of crafts possessed by union workers is 1.6 which is similar to the number of crafts possessed by a non-union worker (1.5). 
Eighteen per cent of the surveyed workers consider Spanish as their first language and $12.8 \%$ have Mexican origins. These figures are consistent with the current national average of $17 \%$ Hispanic construction workers as compared to only $9.2 \%$ in 1994 (BLS 2004). The national average of Hispanics in the full US workforce is $10.9 \%$ (CPWR 2002). Despite being a minority in the overall national construction workforce, Hispanic workers are the majority in some states. They make up $69.4 \%, 55.9 \%$, and $51.4 \%$ of Texas', New Mexico's, and California's respective construction workforce (Goodrum 2004).

Only $1.7 \%$ of the surveyed workers are female, which is significantly lower than the figure reported by the CPWR (2002) of 9\%. This is possibly due to the fact that the CPWR figure includes administrative-staff jobs, which comprise $47 \%$ of female construction jobs, whereas this study aimed at surveying craft workers and not administrative-staff workers. The low percentage of females in construction suggests that the industry is failing to attract a segment of the workforce that potentially can alleviate labor shortage problems in high demand periods.

A positive and unexpected finding is that more than half of the surveyed workers know how to use computers. Fifty six per cent of union workers and $59 \%$ of non-union workers know how to use computers. The average time with the firm that the workers currently work is 4.6 years. The average hourly pay rate is $\$ 18.63$ which is slightly lower than the national average of $\$ 18.95$ as reported by the BLS (2004). In the survey set, union workers make on average $\$ 21.90$ whereas non-union workers make on average \$17.54. This result is consistent with Allen (1994)'s study who found an average wage differential between union and non-union workers of $29 \%$, which is significantly smaller than the wage differential in the 1970s (approximately 50\%). Foremen, general foremen, and superintendents make on average $\$ 3.26$ more than craftsmen and journeymen who in 
turn make $\$ 5.77$ more on average than apprentices and helpers (Figure 2.2). The data shown in Table 2.2 show only minor differences between average wage values per trade with national figures. Note that these figures do not include benefits such as health insurance.
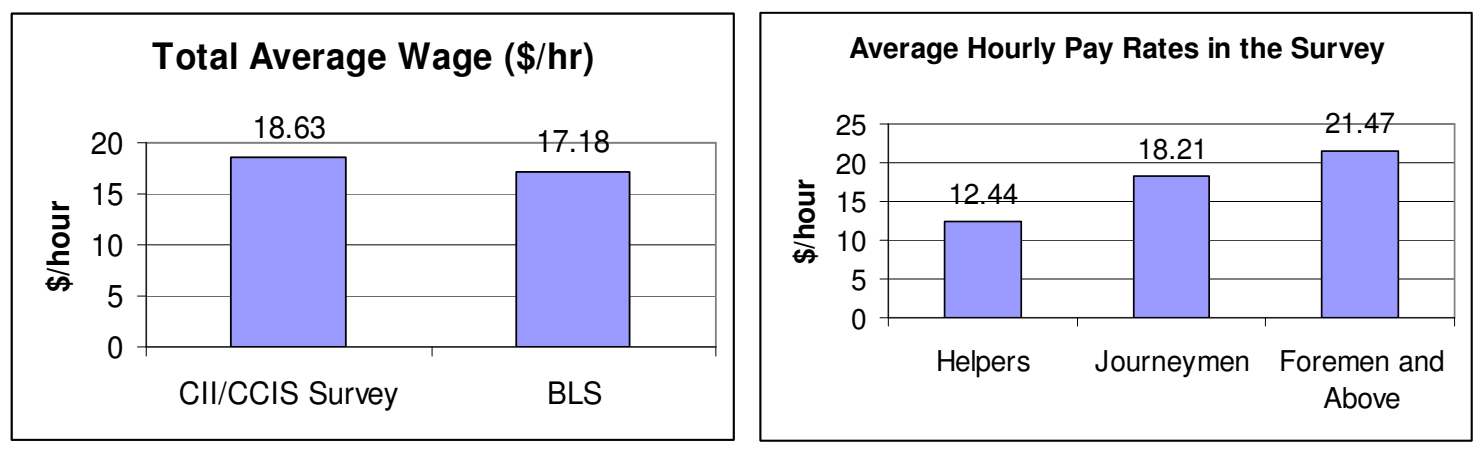

Figure 2.2. A Comparison of Average Hourly Wage Data with BLS Values and Average Hourly Wages by Job Title. 
Table 2.2. Average Hourly Wages in the Different Crafts (CII/CCIS Survey Versus BLS Data).

\begin{tabular}{|c|c|c|c|c|}
\hline & Number & Pay Rate $(\$ / h r)$ & BLS-Pay Rate $(\$ / h r)$ & Discrepancy \\
\hline boilermaker & 205 & 19.49 & 24.91 & $-21.8 \%$ \\
\hline carpenter & 118 & 17.68 & 19.73 & $-10.4 \%$ \\
\hline concrete finisher & 54 & 16.75 & 17.05 & $-1.8 \%$ \\
\hline crane operator & 47 & 19.00 & 20.89 & $-9.0 \%$ \\
\hline Equipment operator & 128 & 18.08 & 20.89 & $-13.5 \%$ \\
\hline electricians & 163 & 19.40 & 23.16 & $-16.2 \%$ \\
\hline instrument fitter & 60 & 18.65 & 20.29 & $-8.1 \%$ \\
\hline Glass/glazing & 6 & 19.8 & $\mathrm{~N} / \mathrm{A}$ & $\mathrm{N} / \mathrm{A}$ \\
\hline instrument technician & 24 & 19.79 & $\mathrm{~N} / \mathrm{A}$ & $\mathrm{N} / \mathrm{A}$ \\
\hline insulation & 43 & 18.46 & 13.79 & $33.9 \%$ \\
\hline laborer & 59 & 16.50 & 13.54 & $21.9 \%$ \\
\hline mason & 13 & 17.08 & 18.48 & $-7.6 \%$ \\
\hline welder & 280 & 19.30 & 15.48 & $24.7 \%$ \\
\hline millwright & 104 & 18.28 & 20.08 & $-9.0 \%$ \\
\hline operating engineer & 7 & 19.90 & 18.56 & $7.2 \%$ \\
\hline painter & 53 & 16.62 & 16.33 & $1.8 \%$ \\
\hline Pipe fitter & 222 & 18.71 & 20.29 & $-7.8 \%$ \\
\hline plumber & 46 & 18.89 & 20.29 & $-6.9 \%$ \\
\hline Roofer & 37 & 17.49 & $\mathrm{~N} / \mathrm{A}$ & $\mathrm{N} / \mathrm{A}$ \\
\hline Reinforcing rodman & 53 & 18.39 & 16.56 & $11.1 \%$ \\
\hline Rigger & 199 & 19.27 & 13.42 & $43.6 \%$ \\
\hline Structural ironworker & 182 & 18.60 & 21.32 & $-12.8 \%$ \\
\hline sheetmetal worker & 72 & 19.23 & 25.48 & $-24.5 \%$ \\
\hline
\end{tabular}

Sixty four percent of the surveyed workers are satisfied with their wage. The average number of weekly hours of work is 48.61 which is higher than the average found by Rowings and Federle (1996) of 47 hours per week based on a study of 4600 craft workers across the United States. Both figures are higher than the national average for construction workers of 41.8 hours as reported by the CPWR (2002) based on the Current Population Survey for the year 2000. Finally, the average number of weeks of work per year in the survey is 45.25 which is slightly higher than the average found by Rowings

\footnotetext{
${ }^{1}$ Number of interviewed workers per craft (CII/CCIS Survey)
} 
and Federle (1996) of 43 weeks. The average reported by the CPWR (2002) for construction workers in the year 2000 is 48.7 weeks. In the survey, union workers work on average 47 weeks per year whereas non-union workers work on average 44.66 weeks per year. Of course, volume of work in the industry is cyclical and these numbers may reflect temporal and regional relationships between supply and demand for worker hours.

Table 2.3 presents a summary of the major demographic attributes of the surveyed workers as part of the CCIS study.

Table 2.3. Demographic Statistics of Surveyed Workers.

- $\quad$ Male: $98.3 \%$ Female: $1.7 \%$

- $81.4 \%$ English first language

- $\quad$ Apprentice 5.8\% Craftsmen 70\%

- $\quad 84.7 \%$ US origins

- $\quad 18.63 \$ / \mathrm{hr}$ average pay rate

- 45.25 weeks per year

- $\quad$ Average time with firm: 4.6 years

- $58.1 \%$ know how to use computer
- $\quad$ Average age 40 years

- $\quad 17.9 \%$ Spanish first language

- $\quad$ Foreman and above $22.4 \%$

- $12.8 \%$ Mexican origins

- $\quad$ Average income $\$ 42,730$

- $\quad 48.61$ hours per week

- Union: $21 \%$ Non-union: $79 \%$

- $\quad 64.4 \%$ satisfied with pay

- Years of experience apprentice: 2.45 , craftsman: 10.8 , foreman: 2.54

The following figure suggests that most workers are either satisfied (levels 4 and 5 on a 1 to 5 scale of satisfaction) or at least have a neutral opinion about their career (level of satisfaction of 3). As expected, craftsmen/journeymen are less satisfied than foremen, general foremen, and superintendent. These results conform to previous studies such as Rowings and Federle (1996) who found that general foremen and foremen are twice as likely as journeymen and apprentices to report high levels of job satisfaction. 


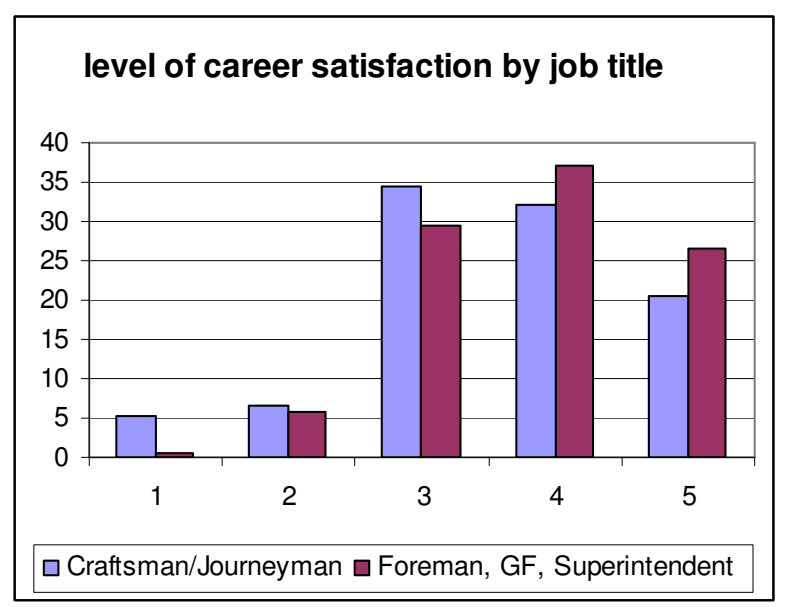

Figure 2.3. Level of Career Satisfaction by Job Title.

The education of a workforce is an indicator of its skill level. As presented in Brandenburg (2004), the percentage of surveyed workers who have completed a high school degree or higher is $82 \%$. This is slightly higher than the average national value for US citizens of $80 \%$ for the year 2000 (BLS 2004). The percentage of construction workers who had not completed high school dropped from $35.4 \%$ in the 1978 to $24.4 \%$ in 1989 (Allen 1994). These numbers track broader historical trends in the US. More people complete high school now that did in the past.

The percentage of surveyed workers who have earned a Bachelor's degree or higher is only $2.5 \%$ as compared to the national value for US citizens of $24.4 \%$. These results are similar to findings from a study performed by McFillen and Maloney (1986) who concluded that the surveyed construction workers have higher percentages than the general population at the elementary, junior high, and high school levels of education. However, the sample did not have as high a percentage of workers who have attended college as the general population. 


\subsubsection{What Does the Industry Value in its Workers?}

Keeping the broad characteristics of today's construction workforce in mind, the following question arises: What among the previously mentioned workers characteristics does the industry value the most? The answer to this question provides background information to the problem of skilled labor shortage (which is explained in further detail in section 2.3 of this document) by showing the worker attributes that contractors would look for while trying to make hiring decisions.

The answer to this kind of question is difficult to quantify. Previous attempts to answer such questions include a study by Wolters and Burleson (1996) who examined the recruitment and selection processes of skilled and common labor based on mail survey responses from non-union contractors. Sixty-five percent of the surveyed contractors did not have formal written policies governing recruitment and selection processes. Only seven percent of the surveyed firms included a specific estimate of recruitment and selection costs as part of their project bid proposals. The authors also found that only a few firms quantify the costs and benefits associated with selection and recruitment processes.

The hiring processes of construction workers differ between union contractors and non-union contractors (Allen 1994). Union contractors rely upon transferring journeymen and foremen to other jobs and selecting individuals with special skills that are at the hiring hall at this time. Contracts often call union contractors to perform their hiring through the hiring hall. Non-union contractors have no restrictions on their selection of recruiting methods. They rely on informal mechanisms to recruit enough applicants. These mechanisms include applications "at the gate" and contacts through friends or relatives. In a non-unionized environment, most hiring is done through 
informal methods in small firms and through sometimes innovative screening methods in large firms.

Despite discussing the recruitment and selection processes of skilled and common labor, the aforementioned studies do not present any quantitative measure of what the industry values in its workers. This dissertation, in contrast, uses wages and income as measures of value. These figures do not include fringe benefits, payroll taxes, wage premiums, or any type of worker compensation insurance which can by itself add up to $22 \%$ of wages according to Newman and Hancher (1991). Correlations between these measures of value and workers' attributes are then examined. The assumption is that if a correlation exists, it may reflect the extent to which an attribute contributes to a worker's value to his employer, or to the industry, if the sample is representative. An obvious weakness to this approach is accurately quantifying attributes. In this study, the attribute data is self-reported. It is hoped that over and under-estimates balance.

Another obvious weakness is that on most projects wages are often kept uniform within broad classes of workers because of labor agreements or for reasons of morale among workers, or because individual productivity is difficult to measure. On the other hand, wages vary by location, by craft, and sometimes by type of work within each craft (Paulson 1976). Levitt (1979) found considerable variation in skills and productivity of individual journeymen in both the union and the open-shop sectors. In a unionized environment, since employers are required to pay all journeymen the same minimum hourly rate, they respond by keeping the most productive workers and letting the least productive go. In theory, in an open-shop environment, contractors may vary wage levels based on the individual differences in worker characteristics. Wages can even differ across essentially identical workers (Postel-Vinay and Robin 2002). 
This dissertation does not attempt to explain what influence wages; instead it uses wages to measure what the construction industry values in its workers. Along with temporal and geographic variation in labor market conditions, the findings from this dissertation are expected to add weight to the idea that social connectedness is a major influence on wages and incomes.

Table 2.4 presents bivariate correlation values between hourly wages and workers' attributes. Positive correlation values generally suggest a possible positive relationship between two factors. For instance the correlation value of 0.29 between hourly wages and age indicate that older workers in general make more money.

Values higher than 0.2 generally indicate relatively significant correlation between factors. The results presented in Table 2 show relatively high correlation between hourly wages and age (AGE), years of experience at both journeymen level (YREXPJM) and foremen level (YREXPFM), and years of experience with the current craft $(\text { YREXPCR })^{2}$. This means that older workers and workers with more years of experience at either the journeyman or foreman level generally earn higher wages than others. On the other hand, the number of skills or crafts (NUMCR), computer knowledge (COMPKN), hours of work per week (HRSWEEK), time with the firm (TIMEFIRM), pay satisfaction (PAYSATIS), career satisfaction (CARSATIS), self-assessed performance (PERFORM), hours of craft training over the past three years (HRCRTRN) and years of experience at the apprentice/helper levels (YREXPAP) had less significant positive correlation with high wages. These results conform in general to Goodrum and Gangwar's (2004) study. They found no statistically significant relation between computer usage and hourly wages for non-supervisory construction workers after

\footnotetext{
2 all highly cross correlated among themselves
} 
controlling for the effects of experience, education, and age. This situation may change if computer use increases on sites.

Table 2.4. Bivariate Correlation Between Hourly Wages and Workers Characteristics.

\begin{tabular}{|c|c|c|c|c|c|c|c|c|c|c|c|c|c|}
\hline & $\underset{\mho}{\mathbb{Z}}$ & $\begin{array}{l}y \\
y \\
y \\
y \\
\end{array}$ & 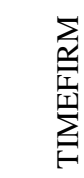 & 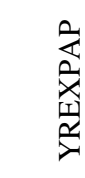 & 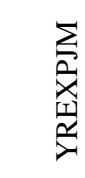 & 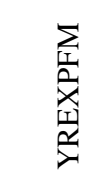 & $\frac{Z}{0}$ & 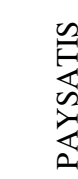 & 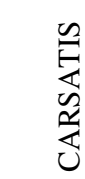 & 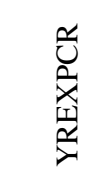 & $\begin{array}{l}\sum_{0} \\
0 \\
\frac{1}{2} \\
\frac{1}{2}\end{array}$ & $\sum_{z}^{0}$ & 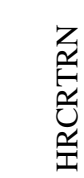 \\
\hline & 0.29 & -0.04 & 0.18 & 0.05 & 0.28 & 0.29 & 0.10 & 0.11 & 0.20 & 0.38 & 0.12 & 0.13 & 0.11 \\
\hline
\end{tabular}

The relationships between annual income and workers' characteristics were also studied (Table 2.5). The idea is to test whether any of the workers' attributes has an effect on annual income but not on hourly wage. The only factor that became significant when compared to annual income instead of hourly wage is the number of crafts a worker possesses. This suggests that the industry does not directly reward workers with many skills by increasing their wages, however these workers may stay on job sites longer or move quickly to new opportunities and therefore have higher annual incomes.

Table 2.5. Bivariate Correlation Between Annual Income and Workers Characteristics

\begin{tabular}{|c|c|c|c|c|c|c|c|c|c|c|c|c|c|}
\hline & $\frac{1}{2}$ & 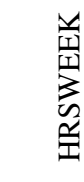 & 总 & 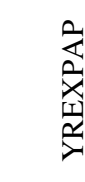 & \begin{tabular}{l}
$\sum_{2}$ \\
$\bar{x}$ \\
\multicolumn{1}{c}{} \\
$\frac{\lambda}{2}$
\end{tabular} & 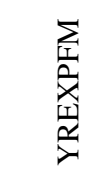 & $\frac{z}{0}$ & 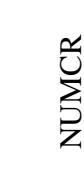 & 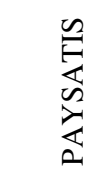 & 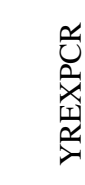 & 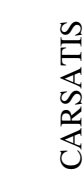 & 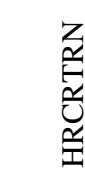 & 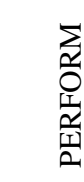 \\
\hline $\begin{array}{l}\text { Annual } \\
\text { Income }\end{array}$ & 0.14 & 0.03 & 0.10 & 0.07 & 0.19 & 0.25 & 0.08 & 0.20 & 0.01 & 0.25 & 0.16 & 0.05 & 0.19 \\
\hline
\end{tabular}


The relationships between workers' attributes and hourly wage were further studied following Carley et. al (2003) who developed a series of multiple regressions to examine the effect of workers' estimated number of trades on the annual number of weeks worked and hourly wage. Their study was based on surveys collected from 721 non-union construction workers in 1999. With respect to multiskilling, their analysis showed that the skills in a number of trades outside a person's primary trade appear to have only a minimal effect on the number of weeks that a person is employed per year. The analysis also showed that the number of trades positively affects hourly wages up to a certain point. Beyond this optimum number of trades, the effect becomes negative.

As in the Carley et. al (2003) study approach, a series of regression models were tried in addition to the correlation analyses in order to gain insight. Statistically insignificant variables were removed. Only variables with a t-value of greater than or equal to 1.6 were kept (Table 2.6). The only variable that was removed was selfassessment of performance. This implies that everything else kept constant, the selfassessed performance does not have a significant positive correlation with hourly wage.

Overall, the $\mathrm{R}^{2}$ value of 0.183 indicates that the proposed model explains $18.3 \%$ of the variation in the collected data. The unexplained variation in wages could be due to external factors such as the state of the economy in the area, the availability of a less expensive foreign labor source, and owners' control of labor wages. These factors, which are not easily quantifiable, can have a significant effect on wage rates at construction sites. Eight variables were found statistically significant (years of experience at the apprentice/helper level, years of experience at the journeyman level, years of experience at the foreman level, computer knowledge, number of crafts, time with the firm, age, and craft training in the past three years). 
A surprising but encouraging result is the importance of computer knowledge which seems to contradict the correlation analysis finding (Table 2.3) of no significant positive correlation between computer literacy and hourly wages. A z-test was performed to resolve the apparent contradicting results. The following null-hypothesis was tested: "workers who know how to use a computer generally earn higher hourly wages." The results of the z-test, which was performed at the $95 \%$ confidence level, confirm the aforementioned null hypothesis. According to the regression analysis, workers who know how to use a computer make on average $\$ 1$ more than workers who do not possess computer knowledge. This might be a sign of the increasing importance of computer literacy in the construction industry or perhaps it might indicate that workers who take the initiative make more and also learn to use computers in their personal lives. It may also show that workers who are already smart, literate, and self-motivated will learn how to use computers more readily.

A less surprising result is the fact that an extra year of experience at the apprentice/helper level implies an increase of 8 cents in the hourly wage whereas an extra year of experience at the journeyman level increases hourly wage by 7 cents and an extra year of experience at the foreman level increases hourly wage by 16 cents. These results fall into the same range of Carley et. al's (2003) results which show that each additional year of construction experience increased hourly wage by 13 cents whereas each additional year of education increased hourly wage by 19 cents.

The coefficient on the number of hours of craft training in the past three years indicates that 100 craft training hours result in an increase of approximately 8 cents per hourly wage. Older workers generally make slightly higher hourly wages than younger workers (only 4 cents per hour per additional year). Also, workers who have been with their current firm for a longer time make slightly higher hourly wages than other workers 
(only 4 cents per hour per additional year). Finally, the coefficient on the (NUMCR) variable indicates that the industry rewards its workers with only 17 cents per hour per additional possessed craft.

Table 2.6. Regression of Hourly Wages Against Key Worker Attributes.

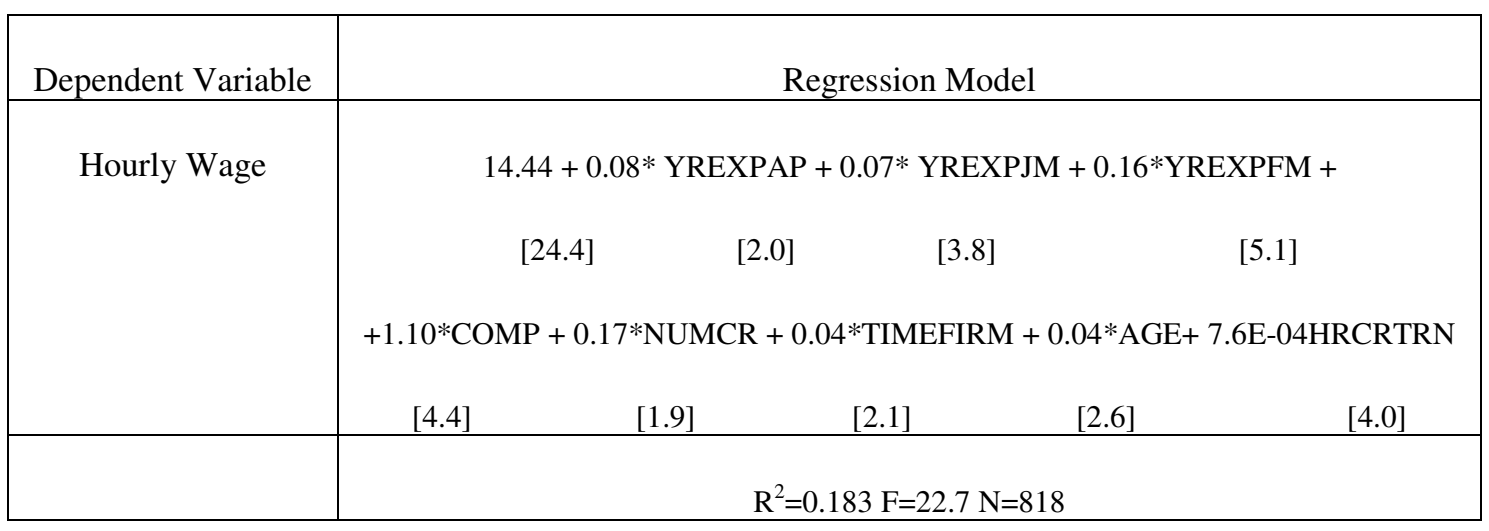

t-values shown in bracket

Again, the relationships between annual income and workers' characteristics were studied using regression analysis. The model shown in Table 2.7 includes statistically significant variables only. These are years of experience at the apprentice/helper level, journeyman level, and foremen level, computer knowledge, number of crafts, and selfassessment of work performance. Overall the model has an $\mathrm{R}^{2}$ value of 0.14 .

The positive sign on the performance coefficient indicates that workers reporting higher performance tend to earn a higher yearly income, which is an encouraging result. Again, the number of crafts a worker possesses was found to have a higher statistically significant impact on annual income than on hourly wage (t-value of 4.4 as compared to 1.9 in the hourly wage model). This emphasizes the aforementioned observation that the industry or circumstances reward the workers who possess more skills by increasing their annual working period rather than hourly income. Finally, as expected the results show that an extra year of experience at the foreman level has a higher impact on yearly 
income than has an extra year of experience at either the apprentice/helper level or at the craftsman level.

Table 2.7. Regression of Annual Income Against Key Worker Attributes.

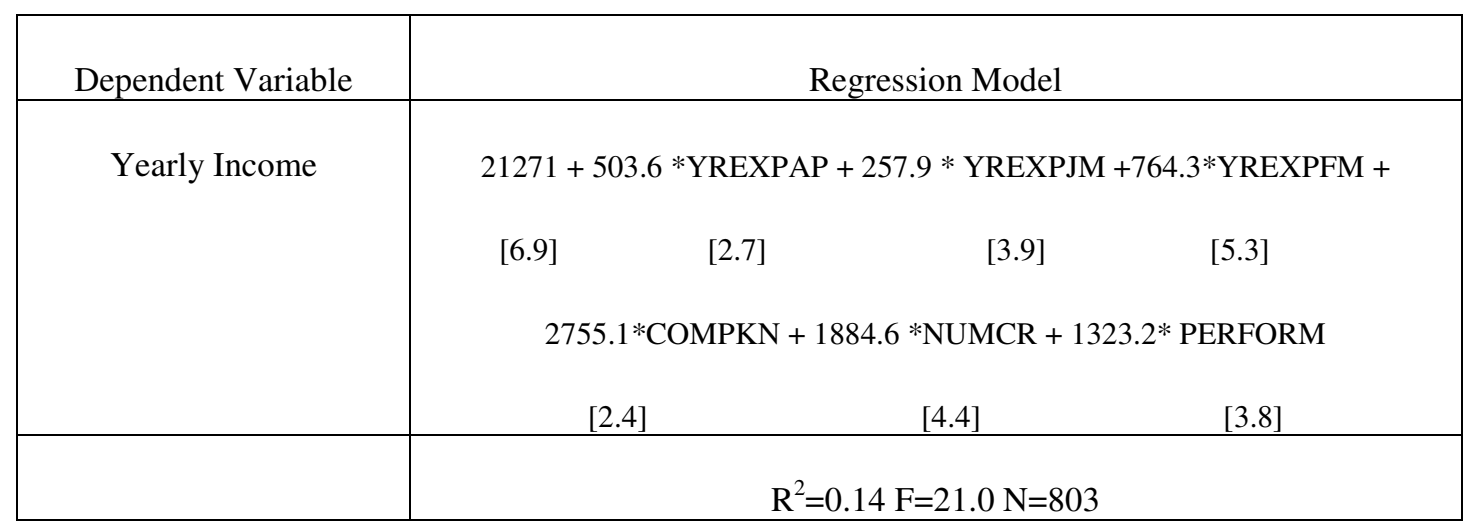

t-values shown in bracket

This section presented the major characteristics of today's construction workforce as well as the worker attributes the industry values the most. These attributes include years of experience at any level, computer knowledge, and the number of possessed crafts. This type of information helps understand what contractors look for while trying to make decisions on whom to hire. Unfortunately, these skills/attributes are not always present in the available labor pool. The following section elaborates on the source and impact of skilled labor shortages.

\subsection{Skilled labor Shortage: A Major Challenge}

Veneri (1999) provides the following definition for labor shortage: "Shortages occur in a market economy when the demand for workers for a particular occupation is greater than the supply of workers who are qualified, available, and willing to do that job." Despite the simplicity of this definition, the perception of labor shortage can differ between the employer and the market. Employers are used to hiring (with a specific level 
of effort) workers with a specific level of training or experience when labor is abundant. However, when the labor market becomes restricted, employers might not be able to hire the same level of workers; and therefore, they have one of at least three options: settle for workers with less levels of training or experience, offer higher wages and try to attract other candidates, or recruit more widely and harder. From the employer's perspective, there is a shortage of workers. In contrast, from the job market perspective, there is no shortage since the job was filled by a worker (Veneri 1999).

An alternative definition of labor shortage is provided by Franke and Sobel (1970) who described shortage as "a situation existing over an extended period of time in which employers were unable to hire at going wages or salaries sufficient numbers of qualified persons to fill positions for which there were budgeted funds and for which personnel were required to meet existing demands for services."

Based on both definitions, the construction industry is facing skilled labor shortages in all trades over all regions of the United States of America. A report issued by the Construction Users Round Table (CURT, 2001) attributes the problem to several factors including poor retention, poor training, and relatively low wages. Tucker et. al (1999) attribute the problem to other factors such as the generally poor image of the industry, a working environment that is considered undesirable, the transient nature of the work, and the resulting unclear career paths in construction. Kiplinger (2002) predicts the trend to stay due to the retirement of $40 \%$ of the current workforce.

The problem of skilled labor shortages in the US construction industry was predicted more than two decades ago. A report written by the Business Round Table (BRT) in 1983 described skilled labor shortages as one of the main challenges the US Construction industry would be facing in the last decade of the past century (BRT 1983). The BRT predicted shortages of construction labor in both the open-shop environment 
and the union environment due to contractors' lack of interest in training and owners' ignorance. The State Department of Highways and Public Transportation (SDHPT) in Texas, for example, faced a large increase in construction projects without a planned increase in the workforce (SDHPT 1989).

A more recent study by the BRT (BRT 1997) validated this prediction. A survey of 200 owner companies showed that $60 \%$ of the participants reported shortages on their projects, with $90 \%$ of the Chemical and Petrochemical firms reporting shortages. Of those who reported shortages, $75 \%$ indicated that the trend has worsened over the previous five years and $25 \%$ reported shortages resulting in cost overruns and schedule delays. The same report concludes that projections indicate that the construction industry should recruit 200,000-250,000 new craft workers per year to meet future demands. As for the main reasons behind this shortage, the report blames contractors for being reluctant to train workers. Furthermore, for non-union workers, contractors do not have an effective means for passing the costs of training to owners.

A second subsequent survey of construction owners and contractors confirmed the problem of skilled labor shortages. The Construction Industry Institute (CII) surveyed 1,200 construction workers from its member companies in 1998 (CII 2000) and found that $70 \%$ of the surveyed companies reported nation-wide shortages of skilled labor. Most surveyed firms claimed that the situation has worsened over the previous two years. The report identified the following reasons behind these shortages: poor industry image, lack of participatory management, job site conditions, and lack of effective career development programs.

Finally, a study performed in 2001 by the Construction User Round Table (CURT 2001) showed that owner companies considered the shortage of skilled labor as the most critical problem today's construction industry is facing. Of the responding companies, 
$82 \%$ experienced shortages of skilled workers on their projects. Within the same sample, $78 \%$ indicated that the trend has worsened over the past few years. Finally, $73 \%$ described the impact on projects as "moderate to significant." The study found that all types $^{3}$ of construction projects are affected by shortages; however, the most affected crafts were electricians, pipe fitters, and welders.

Recent statistics published by the BLS (2004) indicate that by 2010, there will be a need to replace $1,469,000$ construction trade worker jobs. Based on recent BLSreleased data, the Center to Protect Workers' Rights (CPWR 2002) claims that the construction industry is projected to be the largest and fastest source of employment growth among goods-producing industries. About 630,000 new jobs will be created in construction. As shown in Figure 2.4, employment of sheetmetal workers is expected to have the fastest growth among other trades, adding 43,400 new jobs. Another fastgrowing occupation is electricians, which will experience demand for 84,800 jobs. Finally, the demand for construction laborers is expected to increase by 106,480 by 2010 . Given this projected growth in the need for skilled construction workers and the poor image of the industry, construction employers might face problems finding new entrants to fill these positions.

\footnotetext{
${ }^{3}$ All sizes, all areas and in every craft
} 


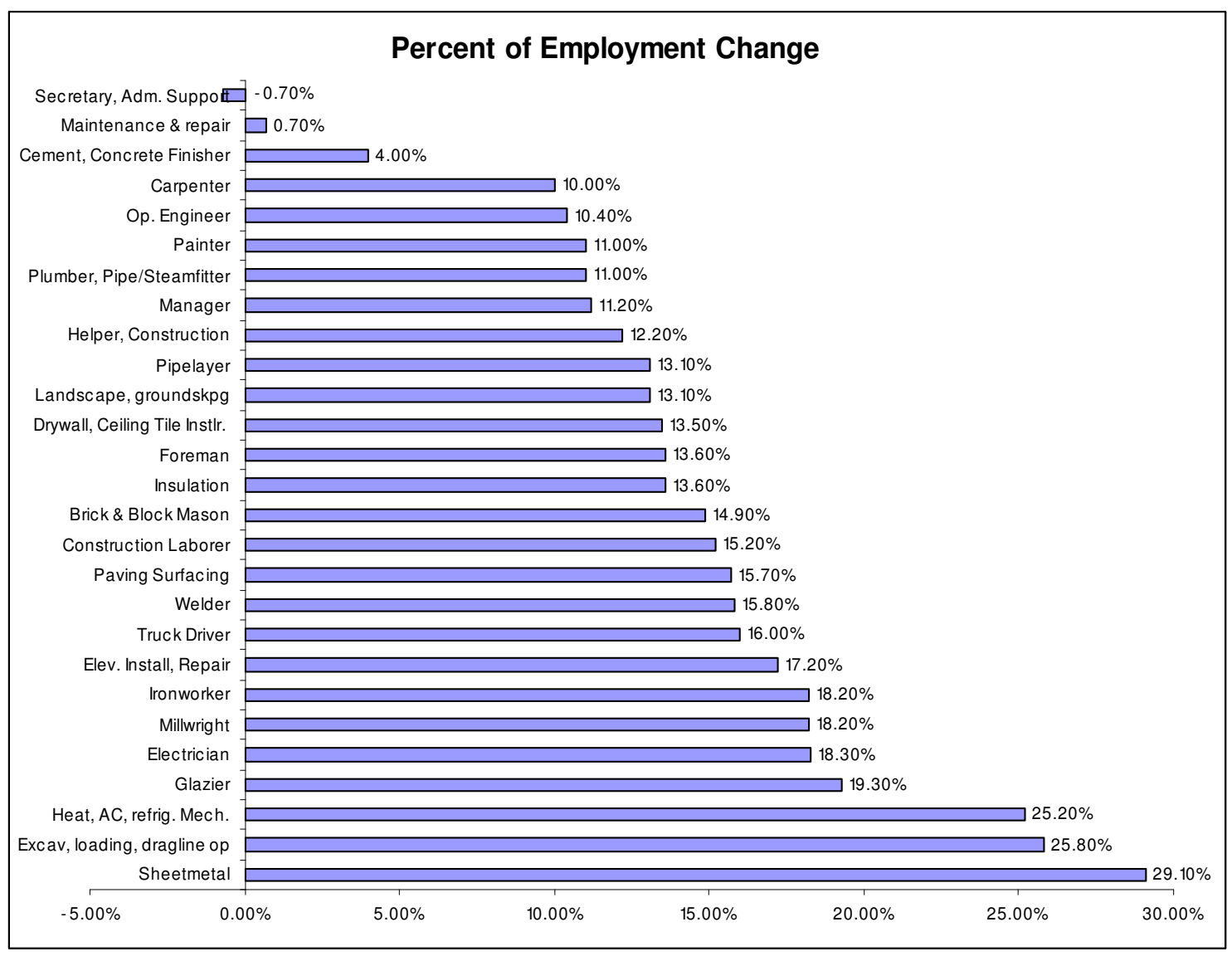

Figure 2.4. Percentage of Projected Employment Change, by Selected Construction Occupation, 2000-2010 (CPWR 2002).

The skilled labor shortage extends beyond the US. The Construction Industry in the United Kingdom (UK) for example is facing skilled labor shortages (Mackenzie et. al 2000). According to the authors of this study, the UK construction industry must draw from all labor sources irrespective of construction-related experience, age, gender, ethnic or social background. A study of infrastructure in South Africa revealed a shortage of individuals to build and maintain infrastructure in underdeveloped areas (Philips et. al 1995). A study of railways in Japan linked the reduction in maintenance of the existing lines to the problem of labor shortages (Tarumi 1994). 
The recent annual outlook by the Construction Workforce Development Forecasting Committee (CWDFC) of the Construction Owners Association of Alberta (COAA) reported shortages in some construction trades in Alberta, Canada, as shown in the two tables below. The COAA develops outlooks for the supply and demand for construction workers in the Province of Alberta for a period of five years. The values in Table 2.8 represent the excess supply of construction workers as compared to the demands (in percent). A positive value suggests a surplus of workers whereas a negative value suggests a shortage of workers equal to the indicated percentage. Six trades faced shortages in 2002. These are: boilermakers, electricians, carpenters, bricklayers, insulators, and plumbers/pipe fitters.

Table 2.8. Excess Supply of Construction Workers in Alberta in Percent (CWDFC 2002).

\begin{tabular}{|c|c|c|}
\hline & 2001 & 2002 \\
\hline Sheet Metal Workers & 0.9 & 1.7 \\
\hline Welders & 1.5 & 2.5 \\
\hline Boilermakers & 0 & -0.4 \\
\hline Millwrights & -1.1 & 0.1 \\
\hline Electricians & 0.2 & -0.6 \\
\hline Carpenters & 0.1 & -0.9 \\
\hline Bricklayers & 1 & -0.7 \\
\hline Insulators & 0.3 & -0.9 \\
\hline Plumbers-Pipe Fitters & 0 & -0.5 \\
\hline Ironworkers & -0.1 & 0.4 \\
\hline Operating Engineers & -0.2 & 0.6 \\
\hline Laborers & 5.4 & 5.9 \\
\hline
\end{tabular}

The numbers of available workers in the considered trades in 2002 are presented in Table 2.9. 
Table 2.9. Number of Available Workers in Alberta in 2002 (CWDFC 2002).

\begin{tabular}{|c|c|}
\hline Sheet Metal Workers & 3,500 \\
\hline Welders & 16,400 \\
\hline Boilermakers & 1,300 \\
\hline Millwrights & 7,600 \\
\hline Electricians & 7,200 \\
\hline Carpenters & 16,700 \\
\hline Bricklayers & 900 \\
\hline Insulators & 2,000 \\
\hline Plumbers-Pipe Fitters & 9,200 \\
\hline Ironworkers & 2,700 \\
\hline Operating Engineers & 14,900 \\
\hline Laborers & 15,000 \\
\hline
\end{tabular}

According to the CURT, all construction projects stakeholders (owners, contractors, labor organization, and local user councils) should work to alleviate the problem of skilled labor shortages (CURT 2001). The owners have the following duties:

- Take the lead to support the development of emerging solutions

- Make contractors commitment to craft training a factor in their qualifying for taking the job.

- Understand funding mechanisms for craft training and incorporate training requirements into contractors

- Support continued updating and improvement of apprenticeship training

- Endorse the National Center for Construction Education and Research (NCCER)'s efforts to develop craft training criteria and industry Image Improvements Initiatives.

Contractors, on the other hand, should:

- Invest in training curriculum development

- Support NCCER like efforts

- Develop methods to assess effectiveness of craft training 
- Create programs to improve retention

- Reorganize labor agreements with unions that hinder workforce mobility or limit the ratio of apprenticeship to journeyman.

Other solutions include revision of organized labor laws and legislation to require training and/or skill standards (Srour et. al 2003).

The following section sheds the light at other major strategic planning efforts that were suggested to ease the problem of skilled labor shortages in the construction industry, namely the two-tier strategy which is the product of a collaboration between industry leaders and the Center for Construction Industry Studies (CCIS).

\subsection{Previous Strategic Planning Efforts}

Several solutions have been recommended to alleviate the problem of skilled labor shortages in construction. These include increased wages and other incentives such as guaranteed overtime, implementation of training incentives, employing foreign labor or even outsourcing construction work to foreign sources, and reduction of demand through automation and technology (Pappas 2004). However, such measures are difficult to sustain unless backed by a long-term strategy to support them.

Human resources is one of the areas receiving the least strategic effort (Maloney 1997). The continuous change in external environments of construction entities necessitates a special attention to strategic planning in different areas, namely human resource management. The list of issues a construction organization should address while developing strategies for human resources includes: the organization's strategic vision, its view of human resources, whether it has a management or a worker driven orientation, whether it has a short-term or a long-term orientation, production technologies, workforce diversity, and the availability of a skilled workforce. Maloney's 
study provides general guidelines for developing strategic human resource planning and therefore avoid problems such as the skilled labor shortage, however it does not provide specific implementation plans or empirical justification.

The Construction Industry Institute (CII) and others have funded research on the problem of skilled workforce shortage in the construction industry and generated potential solutions. The industry uses a number of initiatives including craft and supervisory training, multiskilling, and self-directed work teams as well as productivity enhancements utilizing technology, constructability, and prefabrication. Efforts to quantify or qualify the resulting benefits, however, have been unsatisfactory. A recent collaboration between the CII and the Center for Construction Industry Studies at the University of Texas at Austin produced a theoretical model for a revolutionary new way to address the issue in a more comprehensive manner. Although the method, called "Tier II," is new and future-oriented, it may have a considerable impact on the construction workforce and industry. Tier II is based on three propositions (Chang 2002):

- The industry needs a systematic approach that incorporates all known best practices in a coordinated way

- This systematic approach is expected to result in a more skilled craft worker, higher productivity, and reduced costs. This higher productivity would allow contractors to pay Tier II workers a higher hourly wage resulting in an increased retention of the workforce.

- The use of universally accepted metrics would drive behavioral changes in the industry by placing strategies to promote Tier II craft workers.

Chang (2002) presents a detailed description of the Tier II strategy, the concept behind it, and the metrics that can be used to assess its level of implementation. 
Castaneda (2002) and Pappas (2004) discussed preliminary Tier II results from 19 visited construction job sites in the US.

Even though Tier II is a revolutionary strategy that is expected to have a significant impact on the construction industry, there might be situations where the use of Tier II workers is not practical or appropriate (Brandenburg 2004). For instance, it might not be feasible to develop Tier II workers in situations such as work in remote areas, severe shortages of workers, short-term projects, or in locations where training facilities are not available. Some contractors simply do not have the necessary infrastructure for the development of Tier II workers. A second complimentary strategy to Tier II was developed to address the workforce shortage under such conditions: Tier I (Brandenburg 2004). It is based on the concept that productivity gains from optimal management of the workforce will relieve pressure on demand and will encourage workers to remain on a project and in the industry. These productivity gains will be achieved by applying training, collaboration, and the use of technology in a systematic way to maximize the effectiveness of the front-line supervisors. Tier I proposes that the cohesive, structured implementation of industry accepted best practices will improve the management and utilization of the workforce. It is anticipated that this will lead to improved productivity, reduced absenteeism and turnover, and eventually to overall project success.

The two-tier strategy reflects a concept that developed in the 1990's. Marshall (1992) claimed that there are two ways to compete in the modern global economy: reduce income or increase productivity. He recommended the implementation of highperformance organizations, which is similar to the Tier II concept. Maloney (1997) suggested two prototype strategies: one for an organization with a progressive set of human resources and one for an organization with a more traditional human resource management approach. The first strategy calls for self-managing work teams, a 
knowledge-based pay, a performance-based pay, a broad education, continuous in-house training, and a formal career path and development programs. The second strategy calls for skill-based training, a strict hierarchical organization, and market rate-based pay (Maloney 1997).

The proposed two-tier strategy calls for training workers possibly in more than one skill, including management and other soft skills. Pappas (2004) studied the current status of the construction industry based on the Tier II metrics and identified the requirements that are needed to achieve an advanced level of Tier II implementation.

This dissertation, on the other hand, focuses on the implementation of one of the main elements of the Tier II strategy, namely how to improve workers' skill sets. The main objective is to provide a framework for making the best use of the available workforce and its skill set using an optimization-based approach.

The following sections present a brief overview of the history of optimization and its applications in different fields such as engineering, management, and economics.

\subsection{OPTIMIZATION: A HISTORICAL BACKGROUND}

The goal of optimization is to provide the best decision for a given set of possibilities without having to enumerate all of them. Optimization techniques use the mathematical structure of the problem to find the most efficient solution. The size of solvable problems has followed the growth in computer capability (Pike 1986).

Scientists have always studied questions of optimization such as finding extreme points, i.e. maxima and minima. In 300 B.C., Euclid tackled the problem of finding the shortest distance from a point to a line. In 100 B.C., Heron of Alexandria worked on the optimization problem of light traveling between two points by the shortest path (Pike 1986). Gibbs in 1875 formulated the law that states that a system is in equilibrium when 
the free energy is at its minimum value (Wilde and Beightler 1967). In 1917, Hancock wrote the first modern book on optimization, entitled "Theory of Maxima and Minima" (Pike 1986). Hancock, in this book, claims that the development of mathematical theory for optimization followed closely the development of calculus (Hancock 1960).

The interest in optimization grew exponentially with the events of World War II (Mital 1979). During this period, George Dantzig studied the mathematical structure of military logistics problems and developed an efficient method for solving linear programming problems, entitled the Simplex Method (Winston 1995). Both linear programming and the Simplex Method are explained in further detail in Chapter 3 of this document.

Research in optimization grew further with the advance of the space age in 1950s and 1960s. As pointed out by Pike (1986), the method of dynamic programming and the maximum principle were developed to provide the optimal trajectory for missiles. These optimization methods have recently been extended to almost all fields of study.

\subsection{USE OF RELEVANT OPTIMIZATION TECHNIQUES OUTSIDE CONSTRUCTION}

The use of optimization techniques is not limited to the construction industry. Optimization is a concept that has been extensively used in different fields such as communication, transportation, health care, manufacturing, finance, and others.

Shift scheduling is a classical problem in a variety of service organizations such as airlines, police departments, hotels, banks, hospitals, and telephone companies. The problem typically involves meeting a certain demand pattern which often changes over the course of an operating day or week. The analysis of the model usually provides the assignment of employees to various shifts that are specified by shift type, length, start-

time, and the number and length of breaks (Aykin, 1996). Early attempts to tackle this 
problem include Edie (1954) and Dantzig (1954), who provided a set-covering formulation.

Beaumont (1997) used mixed integer techniques to address the problem of scheduling staff to meet a certain demand pattern which varies significantly with the time of day and moderately with the day of the week. The identity of the organization providing the data was kept confidential however the work of the staff is similar to police traveling between incidents, taxis serving the public, or repair workers traveling between faulty elevators (Beaumont 1997). The objective of the model was to minimize the total cost incurred which includes payment to the employees, cost of traveling between jobs, and the cost of waiting incurred by the clients.

Thompson (1995) developed an integer programming model which provides optimal shift schedules for a hotel staff. His model was based on the implicit shift modeling work of Moondra (1976) and the implicit meal-break modeling work of Bechtold and Jacobs (1990). The model provides the scheduling of overtime and the scheduling of rest breaks.

There is a renewed emphasis on employee development in the United States, especially in the manufacturing arena. The adoption of newer forms of manufacturing organizations often calls for additional training and/cross training of employees. As described by Stewart et. al. (1994): "decisions of whom to train and how much training should be done are often made in a qualitative fashion by human resource or personnel managers." Stewart et. al. (1994) developed a series of models to provide optimal solutions to such problems with the following objectives:

- Minimizing total costs of training

- Maximizing the flexibility of the considered workforce

- Minimizing the total time required for training 
- Optimizing the trade-off between minimizing the total cost of training and maximizing the flexibility of the workforce.

The list of constraints in each of these models includes the available production hours, schedule requirements, and budget limitations.

Campbell (1999) proposed a model for allocating cross-trained workers at the beginning of a shift in a multi-department service business. Worker capabilities were modeled by parameters ranging from zero to one, with fractional values representing the workers that are not fully qualified. The problem was modeled using a non-linear programming technique which is a variant of the generalized assignment problem. The results of the model runs indicate that cross-utilization of workers can have significant benefits. The results also indicate that additional cross-training beyond a certain point adds little value and is therefore not worthwhile.

This dissertation uses mathematical modeling techniques (i.e. optimization) to provide a strategy to work within the constraints of the construction workforce shortage problem. The developed model provides an optimal investment strategy for construction companies in their workforce. This is accomplished through additional hiring and crosstraining which was studied by Stewart et. al (1994). Also, the model addresses the issue of workforce allocation in order to meet job site demands, which was studied by Campbell (1999), Beaumont (1997), and Thompson (1995).

\subsection{NEED FOR OPTIMIZATION TECHNIQUES TO ADDRESS THE ISSUE OF STRATEGIC INVESTMENT IN THE CONSTRUCTION WORKFORCE}

The need for mathematical programming techniques to optimize strategic investment in the construction workforce has been noted in several studies (Burleson et. al. 1998, Gann and Senker 1998, and Gomar et. al 2002). Burleson et al. (1998), who 
studied 4 multiskilling strategies (dual-skill, four-craft, four-craft-helper, theoretical maximum) on a hypothetical petro-chemical $\$ 70 \mathrm{k}$ processing facility, recommended developing an automated analysis process to determine optimal multiskilling strategies.

This need for optimization techniques to evaluate various investment strategies in the construction workforce was also noted by several industry practitioners in interviews and personal discussions with the author of this dissertation.

Gomar et. al (2002) acknowledged this need and developed a model capable of optimizing the labor allocation and assignment process of a partially multiskilled workforce and a single skilled workforce. His model provides the number of workers within the different crafts to hire over time. The objective function of the model consists of any combination of the following items:

- minimizing the total number of workers used in a project

- minimizing hires and fires

- minimizing switching of workers from crew to crew and from activity to activity

- maximizing employment duration of workers on the construction job

The model was applied to the CII model plant. A sample of 10 days was taken from the project schedule. The model ensured demand is satisfied using a workforce supply of 20 workers, mostly multiskilled.

The authors conducted tests by changing the percentage of multiskilling in the considered workforce from $0 \%$ to $60 \%$. The results showed only marginal benefits of multiskilling beyond $15 \%$. The authors also studied the relationship between the number of skills a worker can possess and the extended duration on a job site. The results showed marginal benefits for workers after they possess 4 skills.

The authors recognized the need for having models that can solve problems with more than 20 workers over a period of time longer than 20 days. They also recommended 
running tests with different skill combinations that represent natural affinities in order to determine the most effective combinations.

Several other studies mentioned the need for a multiskilled workforce to optimize the use of construction labor. Gann and Senker (1998) claim that versatile multi-skilled employees are needed increasingly, especially in repair and maintenance work. Maintenance employees need to be multi-skilled to enable them to deal with mechanical, electrical and electronic control equipment. The authors recommended a new common foundation training program for all new entrants to the construction workforce, intended to provide orientation on modern construction practices, technologies and work environments. The entrants then choose one of three tracks: core foundation skills training, a multi-skills track, and a specialist skills track.

Optimization has been extensively used in other fields in construction, namely in project schedule and cost analyses. Mattila and Abraham (1998) developed an integer linear program to level the resources of a highway construction project. They defined resource leveling as: "the process of positioning the activities on the network such that the use of project resources is minimal on a day-to-day basis." The objective of their model is to minimize the sum of the absolute value of the deviation of resources used on any day from an average daily resource use.

Hegazy and Wassef (2001) developed a model for scheduling and cost optimization of repetitive projects. The model objective is to minimize total construction cost which includes direct cost, indirect cost, interruption cost, and incentives and liquidated damages.

The authors used a non-traditional optimization technique, genetic algorithms (GAs), to search complex solution spaces for the global optimum. GAs work by emulating the natural evolution in living organisms through a process of crossover and 
mutation among a group of random parent solutions and cycles of generating and testing offspring solutions until the optimum solution is found.

In Hegazy and Wassef's model (2001), an Excel-based spreadsheet formulation was used for integrating Critical Path Method/Line-Of-Balance calculations and cost optimization in four steps:

- $\mathrm{CPM}$ calculation for a single repetitive unit

- Crew synchronization calculations to meet project deadline

- Detailed schedule calculations

- Cost optimization

An excel add-on called Evolver, designed for Genetic Algorithms-based techniques, was used for optimization. The user entered data in Microsoft Project which is linked to the Excel Add-on where the optimization is performed. Once the optimization is completed, the scheduled times of activities can then be automatically returned to Microsoft Project.

Even though it presents a methodology to integrate schedule and cost optimization into one system, Hegazy and Wassef's study does not attempt to address the issue of worker allocation to specific job tasks or the issue of strategic investment in the construction workforce.

Tam et. al (2001) used Genetic Algorithms to optimize labor deployment. Their proposed model is designed to minimize the total labor costs by assigning construction workers of different skills to complete a defined amount of work in a defined time frame. Three scenarios were studied:

- The available labor resource exceeding the numbers of work required, in order to obtain the lower possible cost.

- Some types of tradesman are inadequate 
- Increased supply of work of a particular trade

The main finding of Tam et al.'s study is that genetic algorithms can maximize the use of an existing workforce. Even though it provides a model to optimize labor deployment, Tam et. al's study does not provide guidelines on how to invest in the existing workforce. In other words, it does not provide suggestions on how to improve the skill sets of the available workers in order to meet job site demands during periods of skilled labor shortages.

The model developed in this dissertation addresses the recommendations made in the aforementioned studies. First, it recognizes the need for a multiskilled workforce to optimize the use of construction labor which was mentioned by Gann and Senker (1998). Second, it provides an automated process to determine optimal multiskilling strategies as recommended by Burleson et. al (1998). Third, it addresses the problems of strategic investment in the construction workforce and worker allocation as applied to a larger problem than the one used in Gomar et. al (2002). Finally, the model, which is explained in further detail in the following chapter, takes into consideration affinities between construction skills while recommending cross-training of workers. In summary, given a project schedule and the available workers pool, the suggested model provides human resource managers a training strategy for the available workers as well as a strategy for hiring additional workers to minimize overall labor costs. The model attempts to provide firms the highest possible return on investment in their labor pool. 


\section{Chapter 3: Analysis Framework}

This chapter presents the methodology followed in order to achieve the goals that were discussed in Chapter 1.

\subsection{INTRODUCTION: MAIN OBJECTIVE OF THE STUDY}

Chapter 2 of this document discussed previous studies aimed at addressing a major problem faced by the US construction industry, namely the problem of skilled labor shortage. Special focus was given to the Tier II strategy, a systematic approach incorporating all known best practices in workforce management in a coordinated way. The Tier II strategy calls for more skilled craft workers, higher productivity, and reduced

costs. This study, however, focuses on the implementation of one of the main elements of the Tier II strategy, namely how to improve workers' skill sets. The main objective is to provide a framework for making the best use of the available workforce and its skills set using an optimization-based approach.

Gomar et. al (2002), as discussed in Chapter 2, optimized the labor allocation and assignment process of a partially multiskilled workforce and a single skilled work force, without addressing the issue of investment in the construction workforce. Furthermore, Gomar et.al (2002) recognized the need for having models that can solve problems with more than 20 workers over a period of time longer than 20 days, and also recommended running tests with different skill combinations that represent natural affinities in order to determine the most effective combinations. This study addresses this final recommendation.

The primary goal of this study is to provide an optimization-based framework for matching supply and demand of construction labor most efficiently through training, recruitment, and allocation. Given a project schedule or demand model and the available 
pool of workers, the suggested model provides human resource managers a combined strategy for training the available workers and hiring additional workers. Using an optimization-based process does not only provide an automated system for human resources managers to allocate workers but also recommends the most cost-effective investment strategy in the workforce in order to meet job-site demands.

Figure 3.1 illustrates how this study fits with the previous work performed at the Center for Construction Industry Studies (CCIS) addressing skilled labor shortage. The Tier I and Tier II studies provided high-level strategies for construction workforce management. Gomar et. al (2002) addressed the issues of assignment and allocation of a company's labor pool at a small scale. This dissertation presents a model which is not only capable of determining the assignment and allocation of a company's labor pool to meet job-site demands for a complete project schedule, but also provides a framework for determining the optimal investment strategy in a subset of the company's labor pool through cross-training in additional skills and/or hiring. The model also helps understanding the trade-offs amongst different investment options: cross-training versus hiring additional workers, hiring single-skilled workers versus hiring multiskilled workers, etc. 


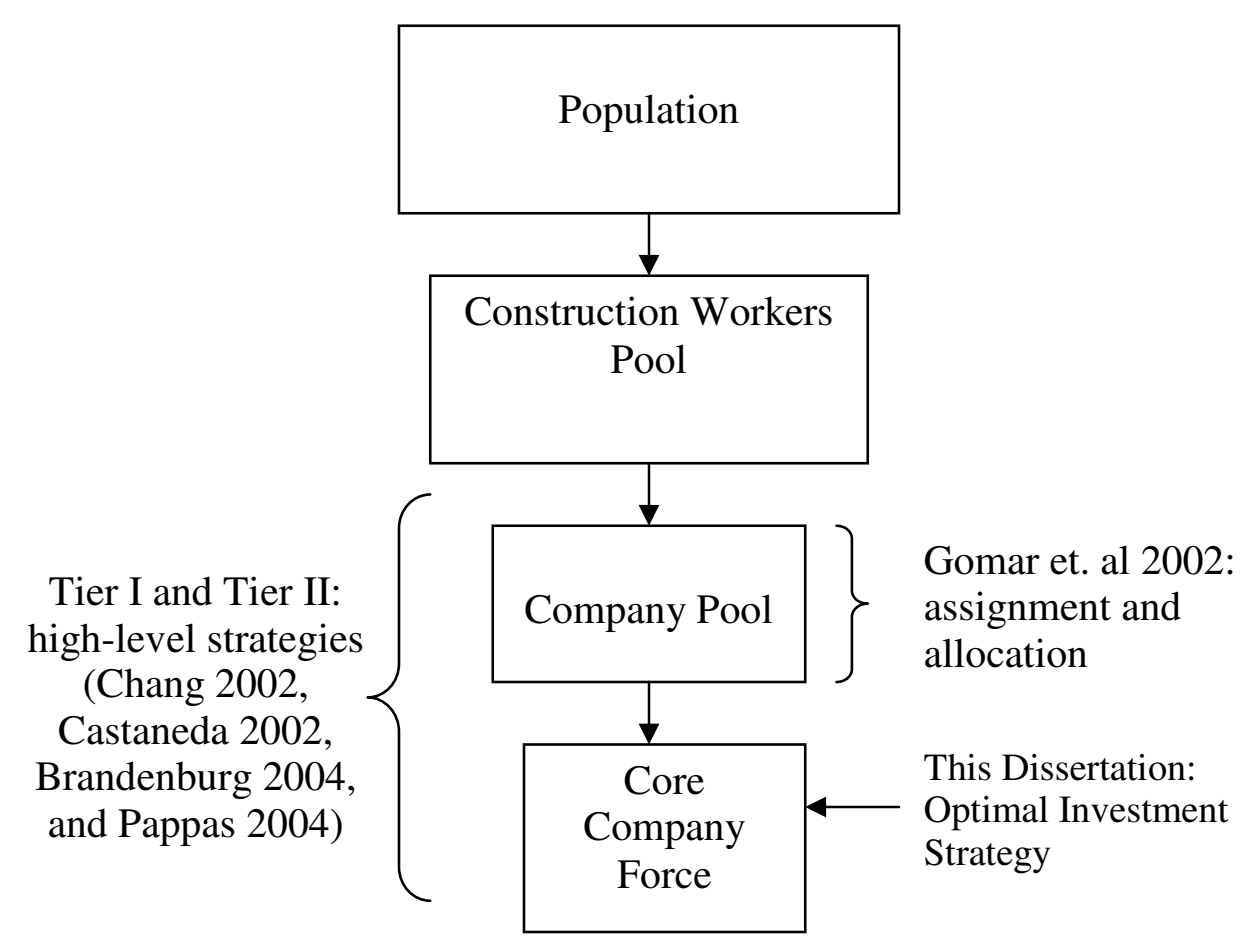

Figure 3.1. Illustration of the Work Presented in this Dissertation as Compared to Previous CCIS Studies.

Figure 3.2 further illustrates the contribution of this research effort. This study presents a methodology for making the best use of the available labor pool in order to meet job site demands. It does not, however, attempt to study external factors affecting the availability of labor (e.g. new entrance, retirement, leaving the industry etc). In order to meet job site demands, the optimization model might call for training some workers in more than one skill and/or hiring additional workers. The output of the model includes the number of workers (if any) to be trained in more than one skill and the specific skills workers should be trained in. The model also specifies the number of workers to hire in the different needed crafts. By considering the training of workers in more than one skill, this model recognizes the potential value of multiskilling that is recognized by the 
industry and is well documented in the literature (Villalobos 1997, Burleson et. al 1998, Haas et. al 2001, and Gomar et. al 2002). Workers trained in more than one task are more likely to stay longer on site or with their company, and their annual income will more likely exceed the average.

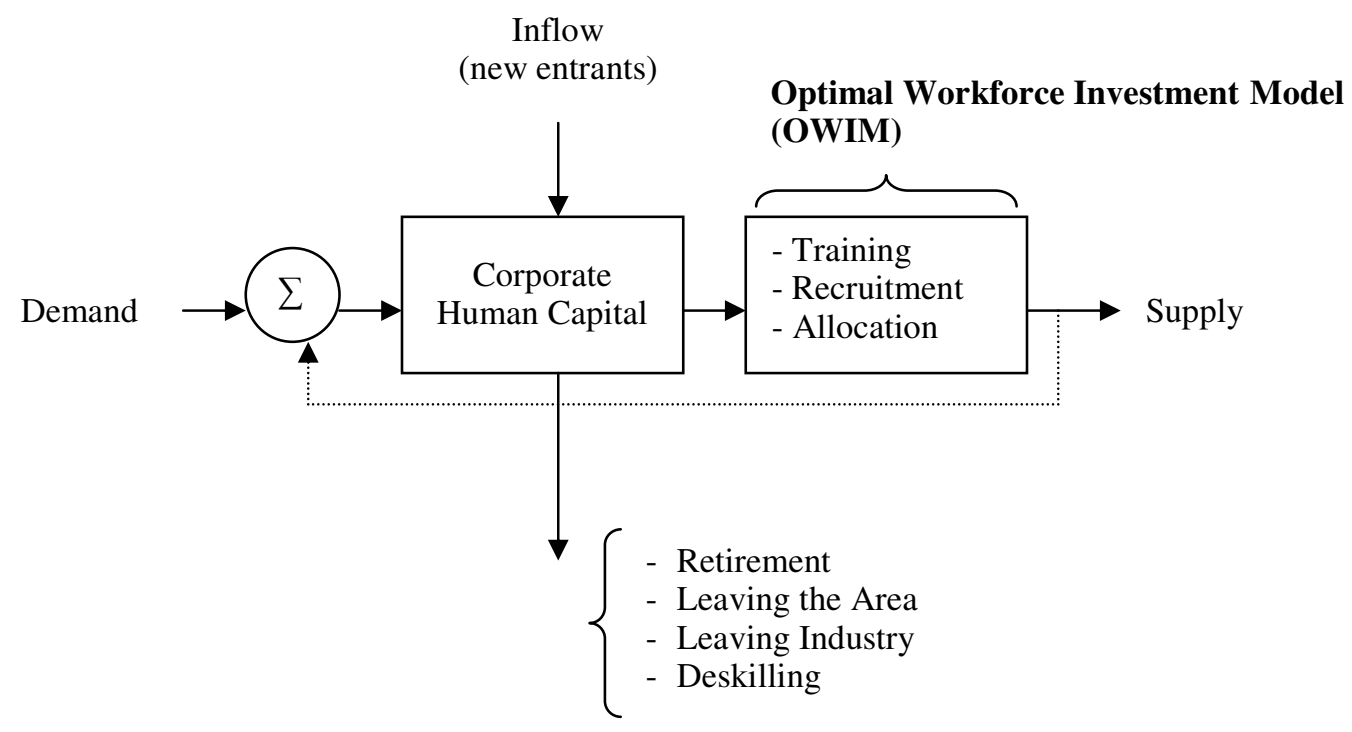

Figure 3.2. Contribution of this Study.

\subsection{MODEL FORMULATION}

This section contains six sub-sections each devoted to describing specific model components. The first subsection discusses the type of model and the solution algorithm used in this study. The second subsection discusses the main assumptions made during the model formulation process. The third subsection presents the decision variables. The fourth subsection presents the model objective function. The fifth subsection presents the 
model constraints. Finally, the sixth subsection presents a summary of the model formulation.

\subsubsection{Type of Model and Solution Algorithm}

The Optimal Workforce Investment Model (OWIM) is formulated as a linear programming (LP) model. The term "programming" of linear programming does not refer to computer programming but to scheduling. LP is the most widely applied optimization method (Pike 1986). As described in Chapter 2, this technique has been applied to several fields. LP was developed in 1947 by George Dantzig who recognized a generalization in the mathematics of scheduling and planning problems (Pike 1986). The development of LP has followed the advance in digital computing. Today's algorithms and computers have the ability to solve models with thousands of independent variables and constraints.

As explained in Winston (1995), a LP model is a type of optimization problem in which the goal is to maximize or minimize a linear function, composed of decision variables, and known as the "objective function." The value of the decision variables must satisfy a set of constraints that are each represented as either a linear equation or linear inequality. There is a sign restriction on each decision variable. What follows is an example of an LP written in the standard form (Bertsimas and Tsitsiklis 1997): 


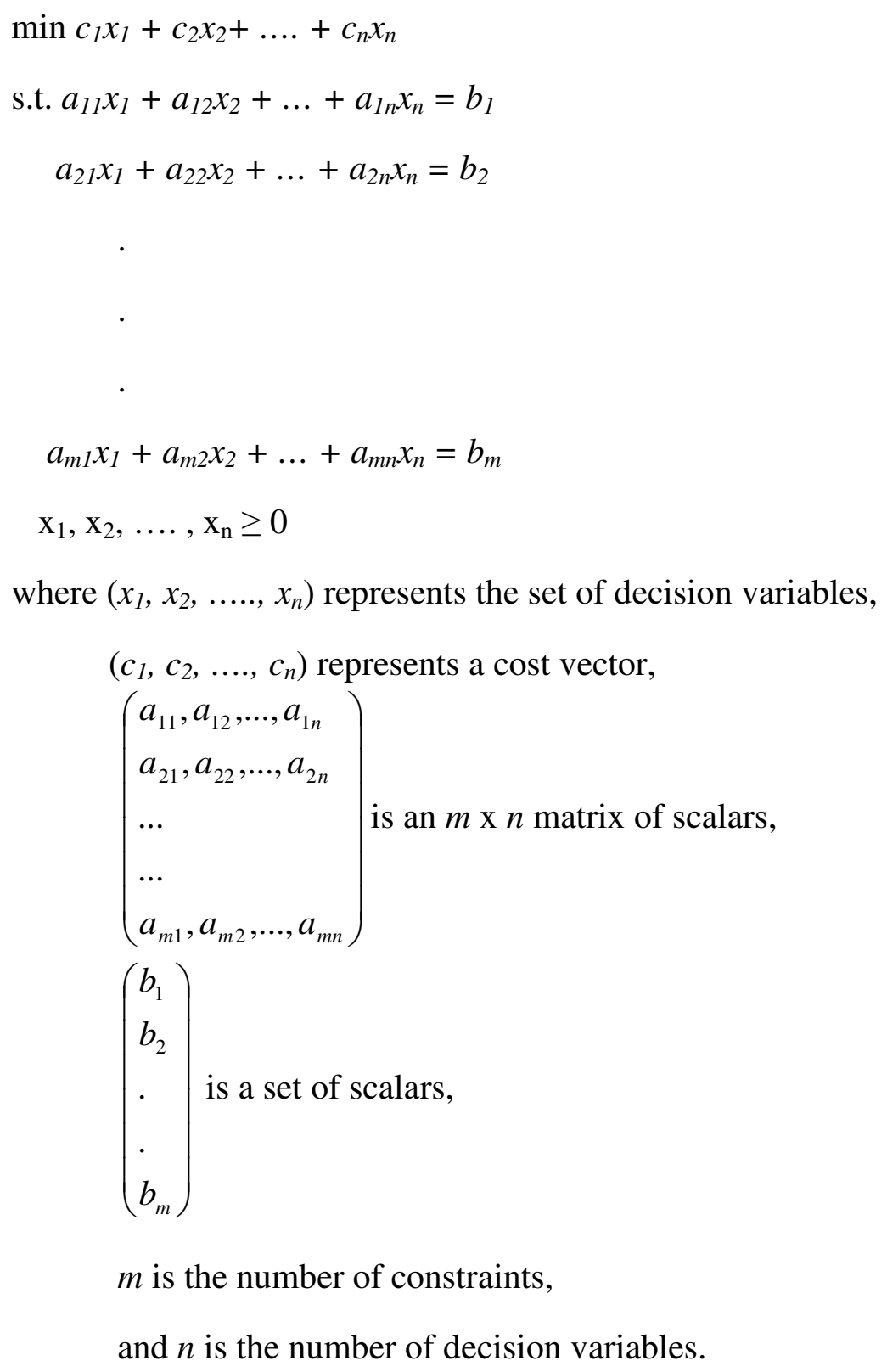

As shown in Figure 3.3, the feasible region of an LP model is the set of all points, or values of decision variables, satisfying all of the constraints including sign restrictions. It is delineated by all constraints and sign restrictions. An optimal solution of an LP model is a point in the feasible region with the largest objective function value for a 
maximization case or the smallest objective value for a minimization case. In the former case, for example, the objective function "slides" inside the feasible region until it hits the last point which represents the optimal point.

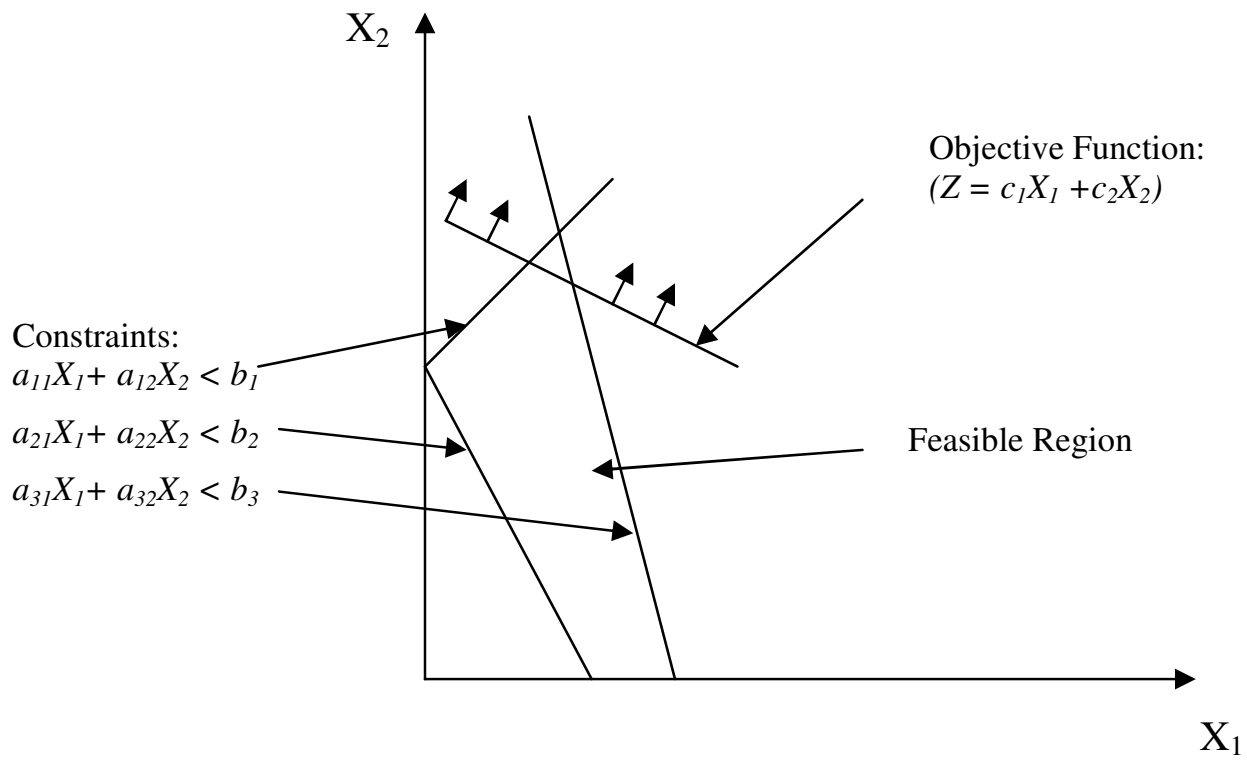

Figure 3.3. Graphical Example of a Two-Variable LP (Winston 1995).

Dantzig (1954) developed an efficient method to solve LP models. As described in Pike (1986), the technique which is called the Simplex Method is an algorithm that steps from one basic feasible solution ${ }^{4}$ to another basic feasible solution in a way that the objective function always increases (in a maximization problem) or decreases (in a minimization problem).

The Simplex Method can be used manually to determine the optimal solutions for any LP problem. This process can, however, become tedious for real-world problems which sometimes involve hundreds, even thousands, of decision variables and

\footnotetext{
${ }^{4}$ A basic feasible solution is an intersection of the constraint equations or a vertex of the feasible region)
} 
constraints. Thus, the technique has been implemented into several computer software programs which have the ability of solving such problems in fractions of seconds.

The following sections provide a detailed description of the formulated model: main assumptions, decision variables, objective function, constraints, and full formulation.

\subsubsection{Main Assumptions}

The formulation of the OWIM offers the workers who are currently employed a chance to get basic training in only one additional skill. This restriction is based on previous studies which indicated limited benefits for cross-training workers in more than one additional skill (Gomar 1999, Campbell 1999, and Burleson et. al 1998). One of the conclusions of Gomar's study is that the benefits of an extended duration of employment are marginal after workers possess skills in two or three crafts. The results of Gomar's model runs indicate average employment duration of $40 \%$ of the overall project time for single-skilled workers, as compared to $80 \%$ for workers who possess 2 skills, and $95 \%$ for workers who possess 3 skills. Burleson (1997) and Haas et. al (2001) reported many challenges that would be faced while trying to cross-train construction workers in additional skills. These include:

- Workers resistance

- Union resistance

- Traditional hierarchical management structure

- Training issues: who will perform it, where, and when?

- Wage differentiation scale

- Deterioration of unused skills 
- Information overload: marginally skilled workers unable to perform higher level technical skills because of the lack of education and/or training

The OWIM also assumes that training is performed a priori, i.e. during the project planning phase. The model is intended to be a guiding tool for human resources management for a specific project during the pre-project planning phase. During this phase, decisions are made concerning labor planning strategies such as the number of workers to hire, the number of workers to train, the training mechanisms, etc.

Training can be performed within a reasonable time prior to the beginning of the project. Programs which provide this type of training already exist. For example, Compass Educational Holdings $(\mathrm{CEH})$ concentrates four-year apprenticeship programs into an intensive nine-month training period (Pappas 2004). Training is provided in two stages. The first stage consists of an intensive four-week program (eight hours per day) of training in the areas of safety, basic construction skills, and the Contren ${ }^{\circledR}$ Level One curriculum $^{5}$ for a construction craft (NCCER 2003). The second stage consists of an eight-month externship in which the workers work for a local contractor during the week and attend classes on Saturdays. The programs which are available in electrical, carpentry, plumbing, pipefitting and HVAC cost $\$ 10,000$ to $\$ 13,000$ per individual.

Another alternative for training workers in additional crafts a few months prior to the beginning of the project is provided by the Construction Industry Network for Essential Training in Alberta, Canada (CINESTA), a group of six organizations which offer trade-focused skills training programs (Pappas 2004). One of the organizations, the Mennonite Central Committee Employment Development, provides a 21-week Trades Entry Program at no cost for participants. The first 10 weeks consist of classroom

\footnotetext{
${ }^{5}$ In 1979, in conjunction with the Merit Shop Foundation and NCCER, the Associated Builders and Contractors developed a construction technical training curriculum entitled the Wheels of Learning, which has been continually upgraded and is now known as the Contren ${ }^{\circledR}$ Learning Series (Contren ${ }^{\circledR} 2004$ ).
} 
instructions in core skills such as Math, Science, English language, team-building, and conflict resolution. The second part of the program consists of hands-on technical and safety training and work experience (COAA 2004).

\subsubsection{Decision Variables}

The users of a model, in this case human resource managers, are ultimately interested in knowing "what to do." In addition to the value of the objective function, the output of an optimization model includes the values of each decision variable at optimality. The OWIM includes the following decision variables:

- $\quad x_{i j}$ : the number of workers who possess only skill $i$ but will be trained in skill $j$ prior to the project's initiation

- $y_{i}$ : the number of workers with only skill $i$ to be hired

- $\quad z_{i j}$ : the number of workers possessing skills $i$ and $j$ to be hired

- $l_{i j t}$ : the number of workers possessing skills $i$ and $j$ ( $i$ not equal to $j$ ) working in their primary skill $i$ during time period $t$

- $m_{i j t}$ : the number of workers possessing skills $i$ and $j$ working in their secondary skill $j$ during time period $t$

- $n_{i t}$ : the number of workers with skill $i$ working during time period $t$

The last three decision variables in this list are typically used by site management. They represent the worker assignments, i.e. the job they are responsible for on a particular day or time period. The first three decision variables in the list, which consist of the number of workers to hire and the number of workers to train, represent decisions HR departments make either at a project level or at a corporate level. They also reflect

\footnotetext{
${ }^{6}$ This study assumes that workers possessing skills $i$ and $j$ can perform work equally in either of their two skills. The notation of "primary" and "secondary" is useful only for the formulation of the model. This definition of the $l$ and $m$ variables ensures that a worker can work in only one craft during time period $t$, i.e. it avoids the problem of allocating a worker to two jobs during one time period.
} 
the amount of investment a firm is willing to make in its labor group. Several contractors are reluctant to invest in their labor pool through training in additional skills. Some shift the responsibility of training to projects owners; others prefer not to train their workers given some workers' willingness to leave their employer and join another for a slightly higher wage. Nonetheless, training workers in additional skills is sometimes essential, especially during periods of skilled labor shortages in specific crafts. Burleson (1997) listed some of the advantages of training construction workers in additional skills:

- Decreased labor and project costs

- Reduction in the required labor force

- Increased employment duration

- Increased labor earnings

- Labor motivation

- Productivity improvements: having more challenged and interested workers results in reductions in idle time

While selecting the workers to be trained in additional skills, a priority should be given to the "core" workforce, i.e. workers who with stay with their company through a number of projects as opposed to the "transient" workforce comprised of workers who are hired specifically for one project and who may or may not continue with the company after that project (Pappas 2004).

As explained in Villalobos (1997), training can be performed either through an on-the-job mechanism or through a formal approach or a combination of both. During a certain project stage, the worker with the most expertise in a certain craft can assume the role of the mentor and the remaining members of the crew can assume the roles of apprentices or helpers. As pointed out by Maloney and McFillen (1995), the training of apprentices by individual craftsman has been the norm for centuries, prior to the 
development of union apprenticeship programs and non-union training programs. Formal training, conversely, is usually performed after hours or on weekends. Training can take the form of structured modules.

A survey of 700 construction workers at 10 project sites indicated that the preferred method for acquiring skills is on-the-job training (Carley et. al 2003). Thirty six percent of the respondents prefer on-the-job training, 27\% prefer company provided training, $21 \%$ prefer union provided training and $8 \%$ prefer community college provided training.

\subsubsection{Objective Function}

As previously discussed, the objective function of any linear optimization model is a linear function composed of decision variables. The goal of the optimization model is to maximize or minimize this function. The OWIM attempts to minimize the construction labor-related costs incurred in the planning and execution phases of the project, while matching the labor demand profile over the course of the project. The objective function of the OWIM is a summation of the following four terms:

- the cost that will be incurred to train in skill $j$ the workers who already possess skill $i: \sum_{i} \sum_{j} \frac{\text { traincost }_{i j} \times x_{i j}}{a_{i j}}$ where traincost $_{i j}$ is the cost in US dollars to train in skill $j$ a worker who possesses skill $i . a_{i j}$, which will be explained in further detail in the next chapter, is a skill affinity penalty between skills $i$ and $j$ with values ranging between 0 and 1 that are related to an absolute, real cost scale,

- the cost that will be incurred to hire workers with skill $i$ : $\sum_{i} y_{i} \times$ hirecost $_{i}$ where hirecost $t_{i}$ is the hiring cost in U.S. dollars of a worker with skill $i$, 
- the cost that will be incurred to hire workers with skills $i$ and $j$ : $\sum_{i} \sum_{j} z_{i j} \times$ host $_{i j}$ where cost $_{i j}$ is the hiring cost in U.S. dollars of a

worker who possess skills $i$ and $j$,

- the incurred wages on site:

a. by workers who possess only skill $i: \sum_{i} \sum_{t} n_{i t} \times$ wage $_{i} \times$ hrsperweek where wage $_{i}$ is the hourly wage in U.S. dollars of a worker with skill $i$ and hrsperweek is the number of weekly hours of work, and $t$ is a time period index

b. by workers who possess both skills $i$ and $j$ working with skill $i$ during time period $t: \sum_{i} \sum_{j} \sum_{t} l_{i j t} \times w_{i j} \times$ hrsperweek where $w_{i j}$ is the hourly wage in US dollars of a worker with skills $i$ and $j$

c. by workers who possess both skills $i$ and $j$ working with skill $j$ during time period $t: \sum_{i} \sum_{j} \sum_{t} m_{i j t} \times w_{i j} \times$ hrsperweek

Thus, the formulation of the objective function is as follows:

$$
\begin{aligned}
& \min \left(\sum_{i} \sum_{j} \frac{\text { traincost }_{i j}}{\alpha_{i j}} \times x_{i j}+\sum_{i} y_{i} \times \text { hirecost }_{i}+\sum_{i} \sum_{j} z_{i j} \times \text { hcost }_{i j}\right. \\
& +\sum_{i} \sum_{t} n_{i t} \times \text { wage }_{i} \times \text { hrsperweek }+\sum_{i} \sum_{j} \sum_{t} l_{i j t} \times w_{i j} x \text { hrsperweek } \\
& \left.+\sum_{i} \sum_{j} \sum_{t} m_{i j t} \times w_{i j} \times \text { hrsperweek }\right)
\end{aligned}
$$

The values of hiring costs and labor wages that are used in this study are explained in further details in the next chapter. 


\subsubsection{Constraints}

The limiting constraints of the OWIM are as follows:

- Meeting the demand $d_{i t}$ for skill $i$ during time period $t$ using multiskilled workers (possessing skills $i$ and $j$ ) and single-skilled workers (possessing skill $i): \sum_{j} l_{i j t}+\sum_{j} m_{i j t}+n_{i t} \geq d_{i t}$

$d_{i t}$ can be obtained from Primavera Project Planner (P3) or any other scheduling software. It consists of the daily demand loading as calculated by P3 based on the project schedule, loading of all project activities with the resource requirements, and leveling the schedule using these resources. This equation may be interpreted as follows: the number of workers working with skill $i$ during the time period $t$ must be greater than or equal to the demand for workers with skill $i$ during the same time period.

- Training capacity of skill $j: \sum_{i} x_{i j} \leq$ traincap $_{j}$. The reason for having this set of constraints is that there might be conditions in which there is a limitation on the number of workers that can be trained during a short time period. For example, if training is to be performed on-the-job, there might not be enough workers that can serve as mentors for the trainees. If training is performed in a formal fashion, there might not be enough training centers or facilities.

- Hiring capacity

- $y_{i} \leq$ hirecap $_{i}$ : the number of workers to hire with skill $i$ is limited by a certain number of available workers hirecap . $_{\text {. }}$

- $z_{i j} \leq h$ cap $_{i j}$ : the number of workers to hire with skills $i$ and $j$ is limited by a certain number of available workers $h c a p_{i j}$. 
This set of constraints is particularly important in cases where the project is in a remote area with limited labor resources. It is also important during periods of labor shortages due to economic conditions or other factors. Of course, these constraints are essentially arbitrary estimates. For example, hiring regions can be expanded. In such a case, however, one could represent the consequences of such a decision with an increased (average) hiring cost number.

- Availability constraints:

$\circ n_{i t} \leq s_{i}+y_{i}-\sum_{j} x_{i j}$ : a set of constraints which makes sure that the model does not use more workers with skill $i$ during time period $t$ than the available pool, where $s_{i}$ represents the number of workers with skill $i$ who are already employed by the company.

○ $l_{i j t}+m_{i j t} \leq x_{i j}+z_{i j}+p_{i j}$ : a set of constraints which makes sure that the model does not use more workers with skills $i$ and $j$ during time period $t$ than the available pool, and where $p_{i j}$ represents the number of workers with skills $i$ and $j$ who are already employed by the company.

\subsubsection{Full Formulation}

The full formulation of the OWIM, the LP problem developed in this study to ascertain optimal investment in the construction workforce, is presented in Figure 3.4. The resulting model is an appropriate level of abstraction of the situation in the realworld. With understanding, its constraints and penalty functions can be modified to represent varied assumptions. 


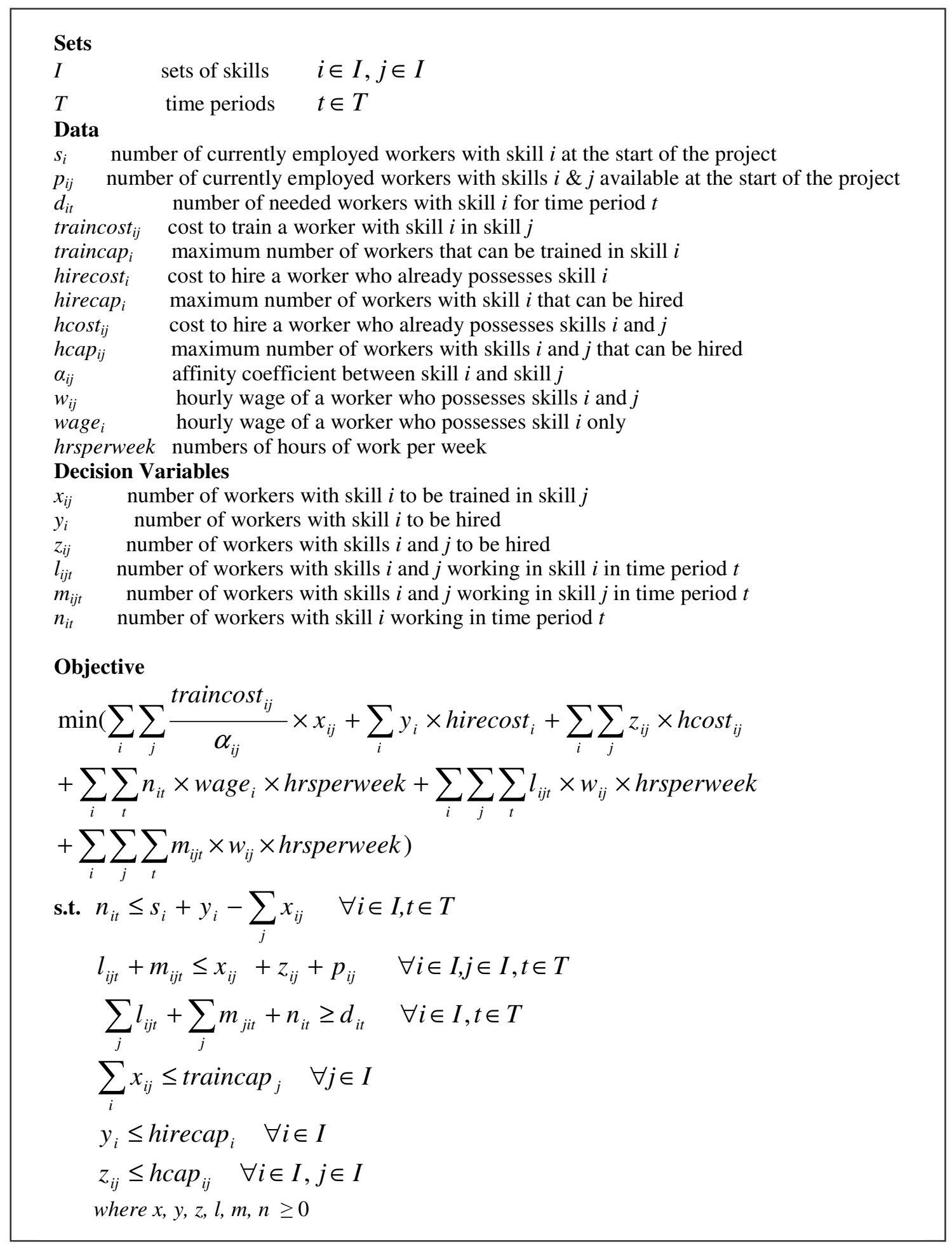

Figure 3.4. Formulation of the OWIM-an LP Model Providing Optimal Investment Strategy in the Construction Workforce. 


\subsection{SOFTWARE SELECTION}

Microsoft Excel offers an optimization tool called "LP Solver," which has the ability to solve moderate sized LP problems. The user-friendly spreadsheet format of Excel makes it easy to input problem data; however, as noticed in Gomar (1999), this tool is not robust. Data input can become tedious in the case of a large multivariate problem. Also, it is necessary to re-enter all input data when there is a slight change to be made to the problem. Similarly to Gomar (1999), this study uses the General Algebraic Modeling System (GAMS) for the development and testing of the OWIM.

GAMS can handle linear, non-linear, mixed integer and other optimization problems (Brooke et. al 1998). It is designed to model large and complex problems. Optimization problems are expressed independently of the data. This separation of logic and data is useful in large and complex problems which may require some revisions before arriving to the final version of the formulated problem. In such cases, revisions will be made only in the data part of the formulated problem. Another advantage of the separation of logic and data is that it allows the user to increase the size of the formulated problem without causing an increase in the complexity in the representation. Hence, the process of multiple runs and sensitivity analyses becomes easier. GAMS is also helpful in the debugging process. It identifies the location of syntax and formulation errors and provides a description of the type of errors. Finally, unlike some other optimization software, GAMS is available with a Windows-based version.

A final note in this section is that GAMS does not solve optimization problems; rather, the software calls one of several solvers that are built-in (CPLEX, ZOOM, etc). The used solver provides an optimal solution to the formulated problem in a separate output file. This study utilizes CPLEX, a widely used solver in LP optimization, to solve the formulated model. 


\subsection{MODEL TESTING}

After formulating the strategic investment problem as a mathematical program and selecting the solver, this model was tested on a small scale problem. The model was applied on a problem consisting of a 4-week project with only four crafts. The input data to the model consisted of hypothetical values.

The solutions obtained from the model runs were examined. Training costs, hiring costs, and wages incurred onsite were computed manually and compared with the values provided by the model. The model-derived worker assignments were checked against the labor demand profile to make sure that the demand values were satisfied. The number of workers who were assigned to perform the work in each craft was checked against the number of available workers at each time period. Finally, the sensitivity of the solution provided by the model was checked. For example, increasing training costs to significantly larger values than hiring costs resulted in a solution with no cross-training, i.e. a solution recommending hiring workers provided that they are available.

The remaining four chapters of this document describe the application of the OWIM on a real-world size project, namely the CII Model Plant. Chapter 4 discusses the input data to the model with all the assumptions that were made. Chapter 5 presents the analyses that were performed on the obtained model runs. Chapter 6 provides an assessment of the benefits and costs associated with the implementation of the OWIM. Finally, Chapter 7 highlights the major conclusions of this study along with recommendations for future work. 


\section{Chapter 4: Application of the OWIM on the CII Model Plant}

This chapter presents the details of the project to which the OWIM was applied, the assumptions that were made, and other input data to the proposed model. Information on training and hiring costs was gathered from different sources including academic literature and industry data. While the former is easily available, the latter is less accessible since it represents proprietary information and possibly a competitive advantage. Most of the data used in this study as input to the optimization model were obtained from Burleson et. al (1998) and Pappas (2004) who collected information from meetings and personal interviews with experienced industry professionals.

\subsection{APPLICATION SCENARIO}

With some minor modifications, the OWIM - presented in Chapter 3 - can be applied at the project level, at the company level, or at a regional or national level. The model can also be applied to any type of construction project: commercial, residential, and industrial. While this model may be applied to the smallest of projects, the benefits of determining optimal investment increase along with the size of the project. Thus, it is recommended that the OWIM be applied to relatively large projects. This dissertation studies the application of this model at the project level, using an industrial-type project. The CII Model Plant, a hypothetical project used in several CII studies (CII 1986, Burleson et.al 1998, Gomar et. al 2002, Pappas 2004 and others), is used as a case study in this dissertation. The model plant, explained in further details in section 4.2 of this chapter, was selected because of the ready availability of schedule and labor data.

The OWIM is applied on all crafts required by the CII Model Plant, both key and non-key crafts. Key crafts were defined by Pappas (2004) as "those crafts having the greatest impact on the cost and schedule performance of the project." These key crafts are 
electricians, instrumentation workers, millwrights, pipe fitters, structural steel erectors, and welders. Burleson et. al (1998) developed a baseline schedule of manpower craft requirements and costs for the CII Model Plant Project using information supplied by three leading firms in the construction industry. Table 4.1 lists labor requirements for the Model Plant. The six key crafts, identified by Pappas (2004) and presented in Bold-face font, combined represent approximately half of the total direct labor work hours. The reason for applying the model on all needed crafts and not limiting it to key crafts is that practical skill combinations often involve one key craft and one non-key craft such as structural steel erectors and ironworkers and sometimes two non-key crafts such as carpenters and painters.

Table 4.1: CII Model Plant Workforce (Burleson et. al 1998).

\begin{tabular}{|c|c|c|c|}
\hline Trade Classification & Peak trade usage & $\frac{\text { Average Use }}{\text { Total Hires }}$ \\
\hline Carpenter & 54 & 23 & 81 \\
\hline Concrete Finisher & 10 & 7 & 19 \\
\hline Crane Operator & 16 & 14 & 16 \\
\hline Electrician & $\mathbf{3 0}$ & $\mathbf{1 8}$ & $\mathbf{4 4}$ \\
\hline Equipment Operator & 35 & 13 & 40 \\
\hline General Laborer & 39 & 12 & 57 \\
\hline Instrumentation Worker & $\mathbf{1 0}$ & $\mathbf{4}$ & $\mathbf{1 3}$ \\
\hline Insulator & 27 & 15 & 35 \\
\hline Iron Worker & 34 & 14 & $\mathbf{4 4}$ \\
\hline Millwright & $\mathbf{3 5}$ & $\mathbf{1 6}$ & 25 \\
\hline Painter & 25 & 24 & $\mathbf{1 2 9}$ \\
\hline Pipe Fitter & $\mathbf{6 0}$ & $\mathbf{3 5}$ & 18 \\
\hline Rigger & 13 & 6 & $\mathbf{2 1}$ \\
\hline Structural Steel Erector & $\mathbf{1 5}$ & $\mathbf{1 0}$ & 14 \\
\hline Surveyor & 11 & 6 & 20 \\
\hline Truck Driver & 14 & 6 & $\mathbf{7 1}$ \\
\hline Welder & $\mathbf{6 0}$ & $\mathbf{2 7}$ & \\
\hline Project Peak & 306 & & \\
\hline
\end{tabular}


The OWIM calls for cross-training some of the workers in additional skills. This does not mean that workers will possess mastery level skills in multiple trade areas; however, they can effectively contribute to the work output of trade disciplines other than their primary trade. This might not be feasible in a union environment where workers are generally limited to the skills or crafts in their locals. It is important to note here that the non-union sector has more craft divisions than the union sector (Pappas 2004). Tables 4.2 and 4.3 below illustrate this fact. The first table shows 15 construction affiliated unions. The second table, on the other hand, shows 26 different craft divisions as recognized by a large non-unionized labor organization, the National Center for Construction Education and Research (NCCER). Hence, some unions have been training workers in skills that would be considered out of their trades in a non-union environment. For example, in 1989, the International Brotherhood of Boilermakers (IBB) added welding certification to its joint apprenticeship program (IBB 2004). Currently, more than 11,000 boilermakers hold welding certifications (IBB 2004). Union pipe fitter and structural ironworker apprenticeships programs include welding as well (Pappas 2004). Instrumentation training is performed in pipe fitter and electrician apprenticeship programs. These observations indicate that it is equally possible to apply the OWIM on a unionized workforce as a non-unionized workforce.

The staffing on the Model Plant was developed for a non-union environment. Furthermore, the majority of data used in this dissertation was obtained from studies of Houston area non-union industrial contractors (Pappas 2004, Burleson et. al 1998, and Villalobos 1997). Therefore the available workforce in this study is assumed to be nonunionized. 


\section{Table 4.2. Construction Unions and Trades Represented.}

\begin{tabular}{|c|c|}
\hline Union & Trade(s) Represented \\
\hline $\begin{array}{c}\text { International Brotherhood of Boilermakers, Iron Ship Builders, Blacksmiths, Forgers } \\
\text { and Helpers (1880) }\end{array}$ & Boilermakers \\
\hline International Union of Bricklayers and Allied Craftworkers (1865) & $\begin{array}{c}\text { Bricklayers, Stonemasons, Concrete Finishers, Terrazzo } \\
\text { Workers }\end{array}$ \\
\hline International Union of Operating Engineers (1896) & $\begin{array}{c}\text { Construction Equipment Operators, Mobile Equipment } \\
\text { Operators }\end{array}$ \\
\hline International Brotherhood of Electrical Workers (1891) & Electricians \\
\hline International Union of Elevator Constructors (1901) & Elevator Installers and Repairers \\
\hline International Association of Heat and Frost Insulators and Asbestos Workers (1910) & Insulation Workers \\
\hline Laborers' International Union of North America (1903) & Laborer \\
\hline International Brotherhood of Painters and Allied Trades (1887) & $\begin{array}{c}\text { Painters, Paperhangers, Interior Finishers, Glaziers, } \\
\text { Carpet, Floor, and Tile Installers and Finishers }\end{array}$ \\
\hline $\begin{array}{l}\text { Operative Plasterers' and Cement Masons' International Association of the United } \\
\text { States and Canada (1864) }\end{array}$ & Plasterers, Cement, Masons, Stucco Masons \\
\hline $\begin{array}{l}\text { United Association of Journeymen and Apprentices of the Plumbing and Pipefitting } \\
\text { Industry of the United States and Canada (1889) }\end{array}$ & Plumbers, Pipefitters, Steamfitters \\
\hline United Union of Roofers, Waterproofs and Allied Workers (1903) & Roofers \\
\hline Sheet Metal Workers' International Association (1888) & Sheet Metal Workers, Duct Installers, HVAC \\
\hline $\begin{array}{l}\text { International Association of Bridge, Structural, Ornamental, and Reinforcing Iron } \\
\qquad \text { Workers (1896) }\end{array}$ & Structural and Reinforcing Metal Workers \\
\hline International Brotherhood of Teamsters & Truck Drivers \\
\hline United Brotherhood of Carpenters and Joiners of America & Carpenters, Scaffolding, Drywall Installers and Finishers \\
\hline
\end{tabular}


Table 4.3. Crafts Areas as Specified by the National Center for Construction Education and Research.

\section{Crafts}

- Boilermaking

- Carpentry

- Concrete Finishing

- Construction Craft Laborer

- $\quad$ Electrical

- Electronic Systems Technician

- $\quad$ Glazing

- Heavy Equipment Operators

- Heavy Highway Construction

- Heating, Ventilating, and Air Conditioning

- Instrumentation

- Insulating

- Ironworking
- Masonry

- Metal Building Assembly

- Millwright

- Mobile Crane Operations

- Painting

- $\quad$ Pipefitting

- Pipelayer

- Plumbing

- Roofing

- Scaffolding

- $\quad$ Sheet Metal

- $\quad$ Sprinkler Fitting

- Welding 


\subsection{DESCRIPTION OF PROJECT}

The CII model plant was developed by CII member companies in 1985 to provide standardized physical productivity measurements. The model plant has been used for other studies including two benchmark productivity analyses, an analysis of multifunctional equipment, and an economic analysis of multi-skilled workforce.

The project consists of a petro-chemical processing facility to be built in Baytown, Texas. It is composed of nine separate areas (a refractionation unit, a tank farm, a compressor unit, two turbine generators, underground piping, pipe-bridge, and a complete civil site package). The compiled documentation of the project is as follows:

- Approximately 2300 drawings and corresponding specifications,

- A detailed material, work-hour, and cost estimate for approximately $\$ 65$ million of the total $\$ 85$ million dollar project value,

- A seventy eight week project schedule,

- A standardized code of accounts, and

- A series of simplifying assumptions which addressed many variables such as project location, soil conditions, labor supply, and related factors.

The project was estimated to cost $\$ 85$ million (Burleson et. al 1998). Estimates of material takeoffs were performed for $\$ 65$ million, which is equivalent to $76 \%$ of the project. The current value of the Model Plant is $\$ 140$ million and the estimated portion is \$106 million (Pappas 2004).

The project schedule extends over seventy seven weeks based on a working schedule of four 10-hour days per week. Overall, the schedule called for 510,000 direct labor work hours (CII 1986). A more recent study of the CII Model Plant estimated the need for 484,280 direct labor work hours to complete the project using a multi-skilled workforce (Burleson et. al 1998). 


\subsection{LABOR DEMAND REQUIREMENTS}

With the help of project managers of petrochemical processing facilities and several scheduling experts, Burleson et. al (1998) developed a schedule for the Model Plant. The activities that were created in Primavera Project Planner (P3) were assigned values for production quantities and total activity worker hours that were obtained from the project estimate. Activity durations and logical connection (start-to-start, end-to-start, lag times etc) were then assumed. The total worker hours allocated to each activity were divided by assumed productivity figures to determine the activity durations.

The resource loading of the schedule was performed with the help of three companies with extensive background in petro-chemical construction. Trade specific resource curves were created for seventeen crafts by each of the three participating companies. The three sets of data were similar enough to select a single average dataset for use in this study.

For the purpose of this study, the complete labor demand profile of 77 weeks was selected for the illustration of the optimization model. Table 4.4 summarizes the demand data that was input to the formulated optimization model. 
Table 4.4. Labor demand over the analysis period (key crafts are highlighted).

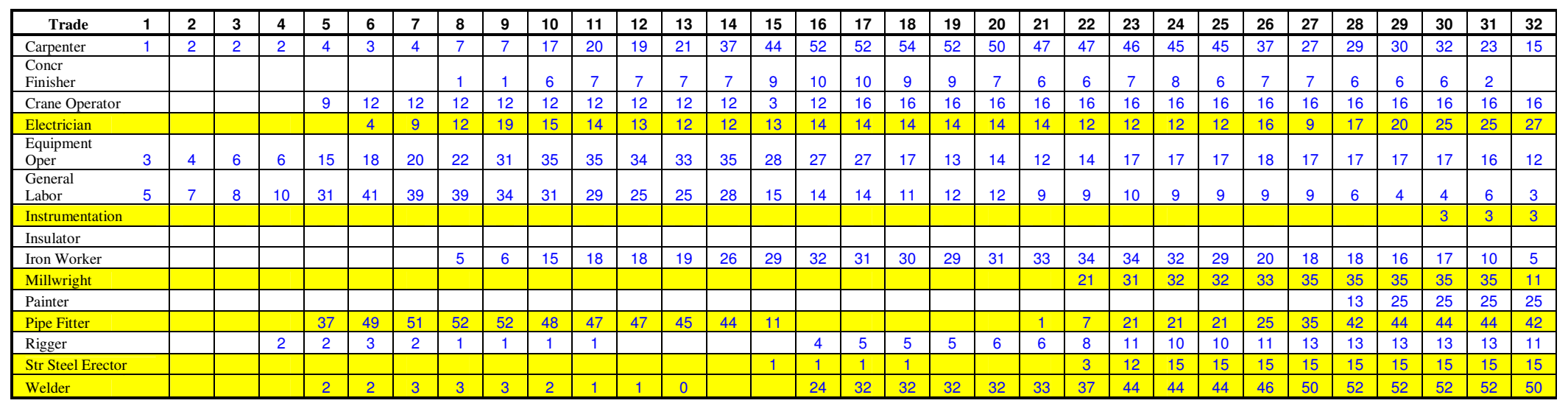

\section{Table 4.4 (continued)}

\begin{tabular}{|c|c|c|c|c|c|c|c|c|c|c|c|c|c|c|c|c|c|c|c|c|c|c|c|c|c|c|c|c|c|c|c|}
\hline Trade & 33 & 34 & 35 & 36 & 37 & 38 & 39 & 40 & 41 & 42 & 43 & 44 & 45 & 46 & 47 & 48 & 49 & 50 & 51 & 52 & 53 & 54 & 55 & 56 & 57 & 58 & 59 & 60 & 61 & 62 & 63 \\
\hline Carpenter & 9 & 11 & 25 & 25 & 25 & 24 & 21 & 15 & 14 & 13 & 14 & 14 & 19 & 23 & 24 & 24 & 24 & 24 & 24 & 23 & 22 & 22 & 22 & 22 & 22 & 22 & 22 & 22 & 22 & 22 & 22 \\
\hline Concr Finisher & & & & & & & & & & 6 & 8 & 8 & 2 & & & & & & & & & & & & & & & & & & \\
\hline Crane Operator & 16 & 16 & 16 & 16 & 16 & 16 & 16 & 16 & 16 & 4 & & & & & & & & & & & & & & & & & & & & & \\
\hline Electrician & 28 & 28 & 22 & 17 & 20 & 24 & 20 & 19 & 19 & 19 & 19 & 19 & 19 & 27 & 30 & 30 & 30 & 30 & 30 & 30 & 30 & 30 & 19 & 16 & 16 & 16 & 16 & 16 & 16 & 16 & 16 \\
\hline $\begin{array}{l}\text { Equipment } \\
\text { Oper }\end{array}$ & 10 & 11 & 12 & 10 & 11 & 11 & 10 & 10 & 9 & 10 & 10 & 10 & 10 & 12 & 12 & 12 & 11 & 11 & 9 & 6 & 6 & 6 & 6 & 6 & 6 & 6 & 6 & 6 & 6 & 6 & 6 \\
\hline General Labor & 2 & 4 & 8 & 8 & 9 & 10 & 10 & 6 & 5 & 7 & 8 & 8 & 9 & 11 & 11 & 12 & 11 & 11 & 11 & 10 & 10 & 10 & 10 & 10 & 10 & 10 & 10 & 10 & 9 & 10 & 10 \\
\hline Instrumentation & 3 & 3 & 3 & 3 & 5 & 5 & 9 & 10 & 10 & 6 & 5 & 5 & 5 & 5 & 5 & 5 & 5 & 5 & 5 & 5 & 5 & 5 & 5 & 5 & 5 & 5 & 5 & 4 & 1 & & \\
\hline Insulator & & & & & & & & & & & & & 2 & 2 & 2 & 2 & 1 & 1 & 4 & 4 & 4 & 4 & 4 & 4 & 12 & 15 & 15 & 15 & 14 & 23 & 27 \\
\hline Iron Worker & 4 & 4 & 5 & 5 & 5 & 5 & 5 & 5 & 4 & 3 & 3 & 3 & 3 & 3 & 3 & 3 & 3 & 3 & 2 & & & & & & & & & & & & \\
\hline Millwright & 3 & 3 & 3 & 3 & 3 & 3 & 3 & 3 & 3 & 10 & 12 & 12 & 12 & 12 & 5 & 2 & & & & & & & & & & & & & & & \\
\hline Painter & 25 & 25 & 25 & 25 & 28 & 26 & 25 & 25 & 25 & 25 & 25 & 25 & 25 & 13 & & & & & & & & & & & & & & & & & \\
\hline Pipe Fitter & 42 & 46 & 59 & 60 & 60 & 53 & 51 & 46 & 32 & 32 & 34 & 34 & 42 & 45 & 45 & 45 & 45 & 52 & 31 & 27 & 26 & 26 & 26 & 26 & 26 & 26 & 26 & 26 & 26 & 26 & 26 \\
\hline Rigger & 10 & 10 & 10 & 8 & 8 & 9 & 9 & 9 & 9 & 5 & 4 & 4 & 6 & 6 & 6 & 6 & 5 & 5 & 3 & 3 & 3 & 3 & 3 & 3 & 3 & 3 & 3 & 3 & 3 & 3 & 3 \\
\hline $\begin{array}{l}\text { Str Steel } \\
\text { Erector }\end{array}$ & 15 & 14 & 8 & & & & & & & 4 & 5 & 5 & 1 & & & & & & & & & & & & & & & & & & \\
\hline Welder & 50 & 52 & 60 & 60 & 60 & 59 & 58 & 56 & 48 & 24 & 17 & 17 & 22 & 23 & 23 & 23 & 23 & 22 & 17 & 16 & 15 & 15 & 15 & 15 & 15 & 15 & 15 & 15 & 15 & 15 & 15 \\
\hline
\end{tabular}


Table 4.4 (continued)

\begin{tabular}{|l|c|c|c|c|c|c|c|c|c|c|c|c|c|c|}
\hline \multicolumn{1}{|c|}{1} & 64 & 65 & 66 & $\mathbf{6 7}$ & $\mathbf{6 8}$ & $\mathbf{6 9}$ & $\mathbf{7 0}$ & $\mathbf{7 1}$ & $\mathbf{7 2}$ & $\mathbf{7 3}$ & $\mathbf{7 4}$ & $\mathbf{7 5}$ & $\mathbf{7 6}$ & $\mathbf{7 7}$ \\
\hline Carpenter & 22 & 22 & 22 & 22 & 22 & 18 & 8 & 1 & & & & & & \\
\hline Concr Finisher & & & & & & & & & & & & & & \\
\hline Crane Operator & & & & & & & & & & & & & & \\
\hline Electrician & 16 & 16 & 16 & 16 & 16 & 8 & 5 & 4 & & & & & & \\
\hline $\begin{array}{l}\text { Equipment } \\
\text { Oper }\end{array}$ & 6 & 6 & 6 & 6 & 6 & 5 & 3 & 1 & & & & & & \\
\hline General Labor & 10 & 10 & 10 & 10 & 10 & 9 & 8 & 7 & 12 & 12 & 10 & 2 & 1 & 1 \\
\hline Instrumentation & & 2 & 3 & 3 & 3 & 3 & 3 & 3 & 1 & & & & & \\
\hline Insulator & 27 & 27 & 27 & 27 & 27 & 27 & 27 & 27 & 27 & 27 & 27 & 19 & 4 & \\
\hline Iron Worker & & & & & & & & & & & & & & \\
\hline Millwright & & & & & & & & & & & & & & \\
\hline Painter & & & & & & & & & & & & & & \\
\hline Pipe Fitter & 26 & 28 & 28 & 28 & 28 & 28 & 17 & 5 & 1 & & & & & \\
\hline Rigger & 3 & 3 & 3 & 3 & 3 & 3 & 3 & 1 & & & & & & \\
\hline $\begin{array}{l}\text { Str Steel } \\
\text { Erector }\end{array}$ & & & & & & & & & & & & & & \\
\hline Surveyor & & & & & & & & & & & & & & \\
\hline Truck Driver & & & & & & & & & & & & & & \\
\hline Welder & 15 & 15 & 15 & 15 & 15 & 15 & 8 & 2 & & & & & & \\
\hline
\end{tabular}

Total number of workers needed: 461

Peak demand of 306 workers occurs at week 30 


\subsection{AVAILABLE WORKFORCE}

Previous research indicates the existence of two workforces within the US construction industry (Brandenburg 2004 and Pappas 2004). These are referred to as a "core workforce" and a "transient workforce" respectively. The former is comprised of workers who stay with their firm through a number of projects, whereas the latter is comprised of workers who are hired for one project only. This dissertation encourages implementing the results of the formulated LP model, namely cross-training, on the core workforce. In other words, while making the decision of whom to cross-train, it is recommended to give priority to the core workers.

The remainder of this section describes the assumed labor that is available for the $^{2}$ Model Plant project. Table 4.5 presents hypothetical figures of the available singleskilled workers. The values were assumed to be in the vicinity of the peak labor demand for each craft, some slightly higher (by 5\%) and some slightly lower (by 10\%). Table 4.6 presents hypothetical figures of the available multi-skilled workers. It is important to note here that different hypothetical figures were tried in order to study the impact of labor availability on the model results. This effort is presented in further details in Chapter 5.

\footnotetext{
${ }^{7}$ Already employed
} 
Table 4.5. Number of Single-Skilled Workers Available at the Beginning of the Project.

\begin{tabular}{|c|c|}
\hline & $\mathrm{N}$ \\
\hline Carpenter & 35 \\
\hline Concrete Finisher & 7 \\
\hline Crane Operator & 9 \\
\hline Electrician & 30 \\
\hline Equipment Operator & 24 \\
\hline General Laborer & 45 \\
\hline Instrumentation Worker & 5 \\
\hline Insulator & 30 \\
\hline Iron Worker & 22 \\
\hline Millwright & 36 \\
\hline Painter & 17 \\
\hline Pipe Fitter & 66 \\
\hline Rigger & 5 \\
\hline Structural Steel Erector & 14 \\
\hline Welder & 40 \\
\hline Total & 385 \\
\hline
\end{tabular}


Table 4.6. Number of Available Workers with Two Skills at the Beginning of the Project.

\begin{tabular}{|c|c|c|c|c|c|c|c|c|c|c|c|c|c|c|c|}
\hline $\begin{array}{l}\text { Secondary Skill } \\
\text { Primary Skill }\end{array}$ & 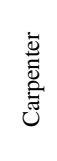 & $\begin{array}{l}\text { 童 } \\
\frac{0}{2} \\
\frac{0}{0} \\
0 \\
0\end{array}$ & 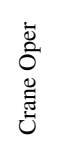 & 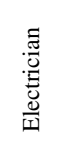 & 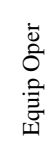 & 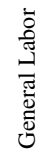 & 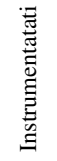 & 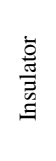 & 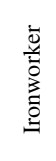 & 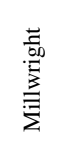 & 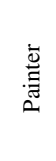 & $\begin{array}{l}\overrightarrow{\mathrm{D}} \\
\stackrel{0}{0} \\
\stackrel{0}{0}\end{array}$ & $\begin{array}{l}\text { 总 } \\
\stackrel{.00}{\approx}\end{array}$ & 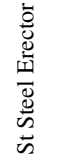 & $\frac{\frac{\pi}{0}}{\frac{\pi}{3}}$ \\
\hline Carpenter & & 2 & & & & & & & & & 1 & & & & 1 \\
\hline Concrete Finisher & & & & & & & & & & & 1 & & & & \\
\hline Crane Operator & & & & & 2 & & & & 1 & & & & & & \\
\hline Electrician & & & & & & & 2 & & & & & & & & \\
\hline Equipment Oper & & & & & & & & & & & & & & & \\
\hline General Laborer & & & & & & & & & & & & & & & \\
\hline Instrumentation & & & & 1 & & & & & & & & & & & \\
\hline Insulator & & & & & & & & & & & & & & & \\
\hline Iron Worker & & & & & & & & & & & & & & & \\
\hline Millwright & & & & & & & & & & & & & & & \\
\hline Painter & 1 & 1 & & & & & & & & & & & & & \\
\hline Pipe Fitter & & & & & & & & & 1 & 1 & & & 1 & & 1 \\
\hline Rigger & & & & & & & & & 1 & 2 & & & & & \\
\hline Str Steel Erector & & & & & & & & & 1 & & & & 1 & & 1 \\
\hline Welder & & & & & & & & & & & & 2 & & & \\
\hline
\end{tabular}

Total number of available multiskilled workers $=25$

Total number of available workers ( ingle-skilled and multiskilled) $=385+25=410$ 


\subsection{LOgICAL COMbinations OF SKILlS}

As explained in Chapter 3, in order to meet job site demands, the optimization model might call for training some workers in more than one skill. The output of the model includes the number of workers to be trained in more than one skill and the specific skills workers should be trained in. As explained by Pappas (2004): "some combinations of skills or crafts are naturally more desirable or useful than others." Pappas argues that contractors should identify the desirable combinations of skills that ensure most value not only to the company but also to the workers themselves. What follows is a description of four different sources of labor skill affinities that were considered in this study.

\subsubsection{CII/CCIS Survey}

Pappas (2004) studied the observed multiskilling combinations using the CCIS/CII database of 19 construction projects, which was previously discussed in Chapter 2 of this document. Table 4.7 summarizes his finding concerning multiskilling. 
Table 4.7. Multiskilling Combinations in the CCIS/CII Database.

\begin{tabular}{|c|c|c|c|c|c|c|}
\hline & Electrician & Instrument & Millwright & Pipe Fitter & $\begin{array}{l}\text { Structural } \\
\text { Ironworker }\end{array}$ & Welder \\
\hline $\begin{array}{c}\text { Number of } \\
\text { Observations }\end{array}$ & 142 & 17 & 47 & 121 & 80 & 98 \\
\hline $\begin{array}{c}\text { Percent } \\
\text { multiskilled }\end{array}$ & $25 \%$ & $53 \%$ & $70 \%$ & $60 \%$ & $88 \%$ & $58 \%$ \\
\hline Skill \#1 & $\begin{array}{c}\text { Instrumentation } \\
(13 \%) \\
\end{array}$ & $\begin{array}{c}\text { Electrician } \\
(29 \%) \\
\end{array}$ & $\begin{array}{c}\text { Structural IW } \\
(36 \%) \\
\end{array}$ & $\begin{array}{c}\text { Boilermaker } \\
(32 \%)\end{array}$ & Rigger $(65 \%)$ & $\begin{array}{c}\text { Boilermaker } \\
(30 \%)\end{array}$ \\
\hline Skill \#2 & Welders $(10 \%)$ & Pipefitter $(18 \%)$ & Rigger $(30 \%)$ & Rigger $(21 \%)$ & Welder $(51 \%)$ & $\begin{array}{c}\text { Structural } \\
\text { Ironworkers } \\
\text { (27\%) }\end{array}$ \\
\hline Skill \#3 & Carpenter $(6 \%)$ & $\begin{array}{c}\text { Equipment } \\
\text { Operator }(6 \%)\end{array}$ & Welder (28\%) & Welder $(21 \%)$ & $\begin{array}{c}\text { Boilermaker } \\
(24 \%) \\
\end{array}$ & Pipefitter $(24 \%)$ \\
\hline Skill \#4 & $\begin{array}{c}\text { Equipment } \\
\text { Operator }(5 \%)\end{array}$ & Rigger $(6 \%)$ & $\begin{array}{c}\text { Equipment } \\
\text { Operator }(21 \%)\end{array}$ & $\begin{array}{l}\text { Instrumentation } \\
\qquad(15 \%) \\
\end{array}$ & $\begin{array}{c}\text { Equipment } \\
\text { Operator }(20 \%)\end{array}$ & Rigger (17\%) \\
\hline Skill \#5 & & Welder $(6 \%)$ & $\begin{array}{l}\text { Pipe fitter } \\
\text { (19\%) }\end{array}$ & $\begin{array}{c}\text { Structural } \\
\text { Ironworkers } \\
(12 \%)\end{array}$ & $\begin{array}{c}\text { Millwright } \\
(19 \%)\end{array}$ & $\begin{array}{c}\text { Millwright } \\
(15 \%)\end{array}$ \\
\hline
\end{tabular}


As expected, electricians are the least multiskilled workers. Only $25 \%$ of the interviewed electricians possess additional skills. Conversations with electricians during the interview process indicated that they consider their craft as more important than any other craft, and therefore they are reluctant to get trained in additional skills. On the other hand, most of the interviewed ironworkers $(88 \%)$ indicated that they possess at least an additional skill, namely rigging (65\%) and welding (51\%). The most observed combinations are: instrumentation-electricians, millwright-iron work, millwright-rigging, pipefitting-boilermaking, ironwork-rigging, ironwork-welding, and weldingboilermaking.

Based on the same CCIS/CII survey, a bivariate correlation analysis was performed across all considered crafts (Table 4.8). Again, the idea is to test which pairs of skills are most likely to be combined. Positive correlation ${ }^{8}$ values generally indicate an "affinity" between the two considered skills, whereas negative values indicate that the two skills are not likely to be combined in practice.

\footnotetext{
8 Positive correlation values are highlighted in table 4.8 .
} 
Table 4.8. Bivariate Correlation Using the CCIS/CII Survey Data.

\begin{tabular}{|c|c|c|c|c|c|c|c|c|c|c|c|c|c|c|c|}
\hline & 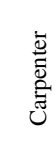 & 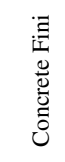 & $\begin{array}{l}\bar{\Xi} \\
\tilde{\Xi} \\
\tilde{\Xi} \\
\tilde{\Xi}\end{array}$ & 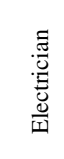 & 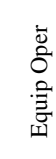 & 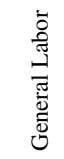 & 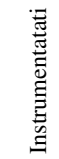 & 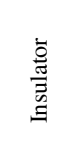 & 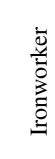 & 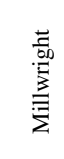 & 㐫 & 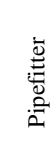 & $\begin{array}{l}\dot{\vec{D}} \\
.00 \\
\vec{a}\end{array}$ & 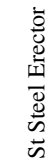 & $\frac{\bar{d}}{\frac{\pi}{0}}$ \\
\hline Carpenter & $\mathrm{n} / \mathrm{a}$ & 0.50 & 0.06 & -0.04 & 0.17 & 0.31 & 0.04 & 0.07 & 0.30 & 0.07 & 0.28 & -0.02 & 0.02 & 0.01 & -0.10 \\
\hline Concrete Finisher & 0.50 & $n / a$ & -0.02 & -0.07 & 0.10 & 0.30 & -0.01 & 0.09 & 0.40 & -0.03 & 0.25 & -0.08 & -0.02 & -0.05 & -0.12 \\
\hline Crane Operator & 0.06 & -0.02 & $\mathrm{n} / \mathbf{a}$ & -0.11 & 0.36 & 0.05 & 0.01 & -0.01 & 0.04 & 0.12 & 0.02 & 0.06 & 0.32 & 0.26 & 0.09 \\
\hline Electrician & -0.04 & -0.07 & -0.11 & $\mathrm{n} / \mathbf{a}$ & -0.09 & -0.01 & 0.15 & -0.09 & -0.12 & -0.11 & -0.02 & -0.24 & -0.21 & -0.22 & -0.24 \\
\hline Equipment Oper & 0.17 & 0.10 & 0.36 & -0.09 & $\mathrm{n} / \mathrm{a}$ & 0.16 & 0.02 & 0.03 & 0.03 & 0.18 & 0.11 & 0.03 & 0.31 & 0.21 & 0.08 \\
\hline General Laborer & 0.31 & 0.30 & 0.05 & -0.01 & 0.16 & $\mathrm{n} / \mathbf{a}$ & 0.01 & 0.06 & 0.26 & 0.03 & 0.26 & 0.02 & 0.05 & -0.01 & -0.07 \\
\hline Instrumentation & 0.04 & -0.01 & 0.01 & 0.15 & 0.02 & 0.01 & $n / a$ & 0.00 & -0.06 & 0.03 & 0.02 & 0.11 & 0.01 & -0.04 & -0.05 \\
\hline Insulator & 0.07 & 0.09 & -0.01 & -0.09 & 0.03 & 0.06 & 0.00 & $\mathrm{n} / \mathrm{a}$ & 0.00 & 0.02 & 0.13 & -0.03 & -0.05 & -0.07 & -0.08 \\
\hline Iron Worker & 0.30 & 0.40 & 0.04 & -0.12 & 0.03 & 0.26 & -0.06 & 0.00 & $\mathrm{n} / \mathbf{a}$ & -0.04 & 0.15 & -0.12 & 0.08 & 0.14 & -0.05 \\
\hline Millwright & 0.07 & -0.03 & 0.12 & -0.11 & 0.18 & 0.03 & 0.03 & 0.02 & -0.04 & $\mathrm{n} / \mathrm{a}$ & 0.09 & 0.04 & 0.19 & 0.23 & 0.11 \\
\hline Painter & 0.28 & 0.25 & 0.02 & -0.02 & 0.11 & 0.26 & 0.02 & 0.13 & 0.15 & 0.09 & n/a & -0.01 & 0.05 & 0.00 & -0.03 \\
\hline Pipe Fitter & -0.02 & -0.08 & 0.06 & -0.24 & 0.03 & 0.02 & 0.11 & -0.03 & -0.12 & 0.04 & -0.01 & $\mathrm{n} / \mathrm{a}$ & 0.10 & 0.04 & 0.08 \\
\hline Rigger & 0.02 & -0.02 & 0.32 & -0.21 & 0.31 & 0.05 & 0.01 & -0.05 & 0.08 & 0.19 & 0.05 & 0.10 & $\mathrm{n} / \mathrm{a}$ & 0.51 & 0.27 \\
\hline Str Steel Erector & 0.01 & -0.05 & 0.26 & -0.22 & 0.21 & -0.01 & -0.04 & -0.07 & 0.14 & 0.23 & 0.00 & 0.04 & 0.51 & $\mathrm{n} / \mathrm{a}$ & 0.27 \\
\hline Welder & -0.10 & -0.12 & 0.09 & -0.24 & 0.08 & -0.07 & -0.05 & -0.08 & -0.05 & 0.11 & -0.03 & 0.08 & 0.27 & 0.27 & $n / a$ \\
\hline
\end{tabular}


The obtained results are similar to Pappas' findings. The most common skill combinations are: instrumentation-electricians, millwright-ironwork, and weldingironwork. Electricians are the least likely to possess other skills. This is indicated by the negative bivariate correlation values between electricians and all other crafts except instrumentation.

\subsubsection{Villalobos (1997)}

Villalobos (1997) presented a matrix of practical skill combinations that was developed by thirty nine individuals from five CII member companies. Twenty-six different trades were considered. The matrix shows the number of times (in percent) that two trades have been grouped together regardless of the type of project and regardless of whether the blending was successful or not. Table 4.9 presents the values obtained by Villalobos. The author does not provide an explanation for the asymmetrical nature of the table. For example, the Rigger-Equipment Operator combination was observed $28 \%$ of the times whereas the Equipment Operator-Rigger combination was observed $51 \%$ of the times. 
Table 4.9. Practical Skill Combinations (Villalobos 1997).

\begin{tabular}{|c|c|c|c|c|c|c|c|c|c|c|c|c|c|c|c|c|c|c|c|c|c|c|}
\hline & 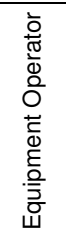 & 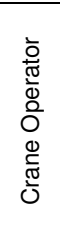 & 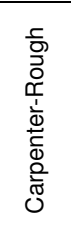 & 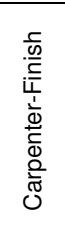 & 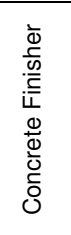 & 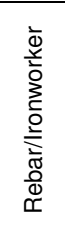 & 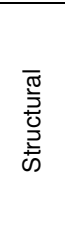 & 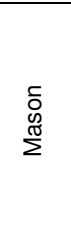 & 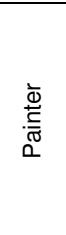 & 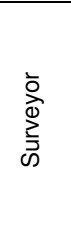 & 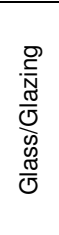 & $\begin{array}{l}\bar{\varpi} \\
\bar{\alpha} \\
\alpha \\
\alpha\end{array}$ & 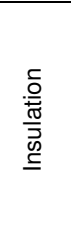 & 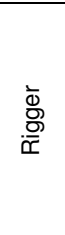 & 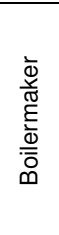 & 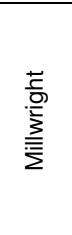 & $\frac{\stackrel{\bar{\Phi}}{\frac{E}{0}}}{\stackrel{\varrho}{\alpha}}$ & $\frac{\overline{\frac{d}{0}}}{\frac{0}{0}}$ & 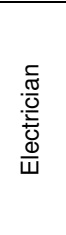 & 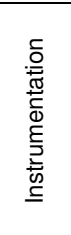 & 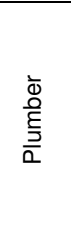 & 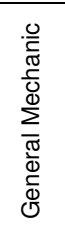 \\
\hline $\begin{array}{l}\text { Equipment } \\
\text { Operator }\end{array}$ & $51 \%$ & $9 \%$ & $5 \%$ & $0 \%$ & $3 \%$ & $3 \%$ & $3 \%$ & $0 \%$ & $3 \%$ & $0 \%$ & $0 \%$ & $0 \%$ & $0 \%$ & $51 \%$ & $0 \%$ & $5 \%$ & $0 \%$ & $5 \%$ & $0 \%$ & $0 \%$ & $0 \%$ & $54 \%$ \\
\hline Crane Operator & $79 \%$ & $46 \%$ & $0 \%$ & $3 \%$ & $3 \%$ & $0 \%$ & $8 \%$ & $0 \%$ & $3 \%$ & $0 \%$ & $0 \%$ & $0 \%$ & $0 \%$ & $59 \%$ & $0 \%$ & $8 \%$ & $0 \%$ & $10 \%$ & $0 \%$ & $0 \%$ & $0 \%$ & $54 \%$ \\
\hline Carpenter-Rough & $3 \%$ & $3 \%$ & $56 \%$ & $67 \%$ & $56 \%$ & $54 \%$ & $26 \%$ & $33 \%$ & $23 \%$ & $5 \%$ & $5 \%$ & $26 \%$ & $15 \%$ & $13 \%$ & $0 \%$ & $15 \%$ & $0 \%$ & $15 \%$ & $0 \%$ & $0 \%$ & $0 \%$ & $0 \%$ \\
\hline Carper & $3 \%$ & $0 \%$ & $67 \%$ & $7 \%$ & $51 \%$ & $31 \%$ & $15 \%$ & $8 \%$ & $18 \%$ & $3 \%$ & $15 \%$ & $15 \%$ & $18 \%$ & $3 \%$ & $0 \%$ & $13 \%$ & $0 \%$ & $8 \%$ & $0 \%$ & $5 \%$ & $0 \%$ & $0 \%$ \\
\hline Rebar//ronworker & $0 \%$ & $0 \%$ & $38 \%$ & $15 \%$ & $21 \%$ & $51 \%$ & $62 \%$ & $8 \%$ & $\frac{18 \%}{5 \%}$ & $3 \%$ & $0 \%$ & $3 \%$ & $3 \%$ & $\begin{array}{r}5 \% \\
54 \%\end{array}$ & $5 \%$ & $\begin{array}{r}0 \% \\
13 \%\end{array}$ & $0 \%$ & $\begin{array}{r}3 \% \\
33 \%\end{array}$ & $0 \%$ & $0 \%$ & $0 \%$ & $0 \%$ \\
\hline Structural & $5 \%$ & $5 \%$ & $13 \%$ & $0 \%$ & $8 \%$ & $72 \%$ & $44 \%$ & $0 \%$ & $3 \%$ & $0 \%$ & $0 \%$ & $0 \%$ & $0 \%$ & $62 \%$ & $8 \%$ & $8 \%$ & $3 \%$ & $49 \%$ & $0 \%$ & $0 \%$ & $0 \%$ & $3 \%$ \\
\hline Masol & $0 \%$ & $0 \%$ & $46 \%$ & $13 \%$ & $54 \%$ & $18 \%$ & $3 \%$ & $46 \%$ & $10 \%$ & $0 \%$ & $3 \%$ & $3 \%$ & $3 \%$ & $0 \%$ & $0 \%$ & $3 \%$ & $0 \%$ & $0 \%$ & $0 \%$ & $0 \%$ & $0 \%$ & $0 \%$ \\
\hline Painter & $0 \%$ & $0 \%$ & $33 \%$ & $8 \%$ & $5 \%$ & $5 \%$ & $0 \%$ & $5 \%$ & $44 \%$ & $0 \%$ & $18 \%$ & $3 \%$ & $8 \%$ & $0 \%$ & $0 \%$ & $0 \%$ & 09 & $0 \%$ & $0 \%$ & $0^{\circ}$ & $0 \%$ & $0 \%$ \\
\hline Surveyor & $3 \%$ & $0 \%$ & $8 \%$ & $3 \%$ & $3 \%$ & $3 \%$ & $5 \%$ & $0 \%$ & $5 \%$ & $44 \%$ & $0 \%$ & $0 \%$ & $0 \%$ & $3 \%$ & $0^{\circ}$ & $3 \%$ & 0 & $0 \%$ & $0 \%$ & 0 & $0 \%$ & $0 \%$ \\
\hline Glass/Glazing & $0 \%$ & $0 \%$ & $3 \%$ & $5 \%$ & $0 \%$ & $0 \%$ & $0 \%$ & $0 \%$ & $21 \%$ & $3 \%$ & $44 \%$ & $3 \%$ & $13 \%$ & $0 \%$ & $0 \%$ & $0 \%$ & $0 \%$ & $0 \%$ & $0 \%$ & $0 \%$ & $0 \%$ & $0 \%$ \\
\hline Roofer & $0 \%$ & $0 \%$ & $31 \%$ & $3 \%$ & $3 \%$ & $0 \%$ & $3 \%$ & $0 \%$ & $8 \%$ & $0 \%$ & $5 \%$ & $46 \%$ & $28 \%$ & $3 \%$ & $0 \%$ & $0 \%$ & $0 \%$ & $0 \%$ & $0 \%$ & $0 \%$ & $0 \%$ & $0 \%$ \\
\hline Insulatic & $0 \%$ & & $21 \%$ & $8 \%$ & $3 \%$ & $0 \%$ & $0 \%$ & $3 \%$ & $15 \%$ & $0 \%$ & $5 \%$ & $26 \%$ & $38 \%$ & $3 \%$ & $0 \%$ & $3 \%$ & 39 & $0 \%$ & $0 \%$ & 0 & $0 \%$ & $0 \%$ \\
\hline Rigger & $28 \%$ & $26 \%$ & $15 \%$ & $3 \%$ & $5 \%$ & $38 \%$ & $67 \%$ & $0 \%$ & $5 \%$ & $3 \%$ & $0 \%$ & $0 \%$ & $3 \%$ & $44 \%$ & $31 \%$ & $31 \%$ & $15 \%$ & $31 \%$ & $3 \%$ & $3 \%$ & $0 \%$ & $13 \%$ \\
\hline Boilermake & $0 \%$ & $0 \%$ & $0 \%$ & $0 \%$ & $0 \%$ & $5 \%$ & $31 \%$ & $3 \%$ & $5 \%$ & $3 \%$ & $3 \%$ & $3 \%$ & $3 \%$ & $38 \%$ & $41 \%$ & $36 \%$ & $41 \%$ & $49 \%$ & $0 \%$ & $3 \%$ & $5 \%$ & $5 \%$ \\
\hline Millwright & & 0 & $18 \%$ & $10 \%$ & $0 \%$ & 8 & $18 \%$ & 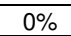 & $5 \%$ & $8 \%$ & $0 \%$ & 3 & $3 \%$ & $33 \%$ & $33 \%$ & $46 \%$ & 31 & $38 \%$ & $13 \%$ & $13 \%$ & $10 \%$ & $26 \%$ \\
\hline Pipefitter & $5 \%$ & $3 \%$ & $5 \%$ & $0 \%$ & $0 \%$ & $5 \%$ & $13 \%$ & $0 \%$ & $5 \%$ & $3 \%$ & $0 \%$ & $0 \%$ & $0 \%$ & $31 \%$ & $28 \%$ & $31 \%$ & $54 \%$ & $62 \%$ & $0 \%$ & $23 \%$ & $41 \%$ & $3 \%$ \\
\hline Welder & $8 \%$ & $5 \%$ & $8 \%$ & $3 \%$ & $0 \%$ & $18 \%$ & $23 \%$ & $0 \%$ & $3 \%$ & $0 \%$ & $0 \%$ & $0 \%$ & $0 \%$ & $31 \%$ & $38 \%$ & $31 \%$ & $58 \%$ & $41 \%$ & $3 \%$ & $5 \%$ & $8 \%$ & $8 \%$ \\
\hline Elect & 5 & & $10 \%$ & 3 & $0 \%$ & $0 \%$ & $0^{\circ}$ & $0^{\circ}$ & $3 \%$ & $3 \%$ & $0 \%$ & $0 \%$ & $0 \%$ & $18 \%$ & $10 \%$ & $13 \%$ & $5^{\circ}$ & $15 \%$ & $8 \%$ & $64 \%$ & $5 \%$ & $5 \%$ \\
\hline Instrur & $5 \%$ & $0 \%$ & $3 \%$ & $0 \%$ & $0 \%$ & 0 & $0 \%$ & $0 \%$ & $3 \%$ & $5 \%$ & $0 \%$ & $0 \%$ & $0 \%$ & $3 \%$ & $5 \%$ & $15 \%$ & $18 \%$ & $18 \%$ & $59 \%$ & $38 \%$ & $8 \%$ & $5 \%$ \\
\hline Plumbe & $\%$ & $\%$ & $8 \%$ & $0 \%$ & $0 \%$ & $0 \%$ & $3 \%$ & $0 \%$ & $8 \%$ & $3 \%$ & $0 \%$ & $0 \%$ & $3 \%$ & $5 \%$ & $5 \%$ & $8 \%$ & $51 \%$ & $8 \%$ & $3 \%$ & $13 \%$ & $38 \%$ & $0 \%$ \\
\hline & $\%$ & & $0 \%$ & 0 & $0 \%$ & 0 & $0 \%$ & 0 & 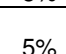 & 0 & $0 \%$ & $0 \%$ & $\%$ & $13 \%$ & $5 \%$ & $26 \%$ & 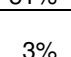 & $\%$ & $0 \%$ & $3 \%$ & $0 \%$ & $41 \%$ \\
\hline
\end{tabular}


Again, electrician with instrumentation skills is a common combination as well as structural and rebar, crane and equipment operators, and welding and pipefitting. Millwright-welding, ironwork-welding, plumbing-pipefitting, painter-carpenter, masonrebar-carpenter-concrete finisher, rebar-rigger, roofer-carpenter, boilermaker-millwrightpipefitter-welder, and rigger-boilermaker are also common. Electricians are unlikely to possess additional skills, except with instrumentation.

\subsubsection{Carley et. al (2003)}

Carley et. al (2003) studied experiences with multiskilling among craft workers on industrial construction projects through mail-out surveys. The survey which was filled and returned by 1,034 respondents in 1998 included a question on the different trades in which the respondents have worked outside their primary trades.

Similarly to the statistical analysis that was performed on the CCIS/CII survey, a bivariate correlation analysis was performed across all considered crafts (Table 4.10) using Carley's data. Again, the idea is to test which pairs of skills are most likely to be combined. 
Table 4.10. Bivariate Correlation Between Pairs of Skills Using Carley et. al (2003)'s Survey.

\begin{tabular}{|c|c|c|c|c|c|c|c|c|c|c|c|c|c|c|c|c|c|c|c|c|}
\hline & 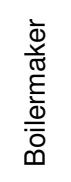 & 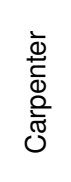 & 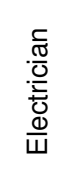 & 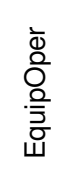 & 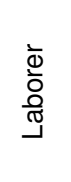 & $\begin{array}{l}\frac{N}{0} \\
\frac{N}{N} \\
\text { D } \\
\frac{\mathbb{O}}{N}\end{array}$ & 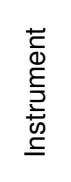 & 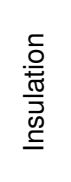 & 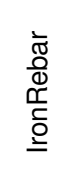 & 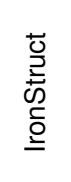 & 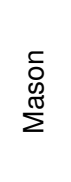 & 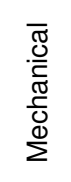 & 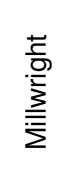 & $\begin{array}{l}\text { O } \\
\stackrel{్}{ \pm} \\
\text { Oे }\end{array}$ & 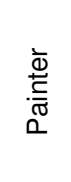 & 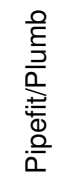 & $\begin{array}{l}\frac{\bar{\Phi}}{\grave{N}} \\
\frac{\pi}{\alpha}\end{array}$ & 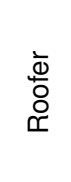 & $\begin{array}{l}\overline{\widetilde{J}} \\
\stackrel{\mathbb{D}}{E} \\
\underline{ \pm} \\
\frac{\Phi}{\omega}\end{array}$ & $\begin{array}{l}\frac{\overline{0}}{\frac{0}{0}} \\
\frac{0}{3}\end{array}$ \\
\hline Boile & $a$ & 21 & 24 & 34 & 24 & 0.36 & 0.30 & 31 & .34 & 43 & 26 & 0.31 & 31 & 33 & 0.25 & .47 & 27 & 0.22 & .38 & .35 \\
\hline Carpenter & 0.21 & $\mathrm{a}$ & .34 & 0.37 & 0.38 & 0.28 & 0.30 & 0.33 & 0.39 & .33 & 0.37 & 0.34 & 0.24 & 0.27 & 0.39 & .23 & .35 & 0.43 & 0.32 & 0.26 \\
\hline Electrician & 0.24 & 0.34 & $\mathrm{n} / \mathrm{a}$ & 0.32 & 0.30 & 0.43 & 0.45 & 0.35 & 0.30 & 0.25 & 0.37 & 0.42 & 0.30 & 0.39 & 0.36 & 0.32 & 0.38 & 0.41 & 0.33 & 0.29 \\
\hline EquipOper & 34 & .37 & 0.32 & $\mathrm{n} / \mathrm{a}$ & 0.35 & 0.34 & 0.34 & 0.35 & 0.38 & 0.41 & 0.34 & 0.42 & 0.33 & 0.40 & 0.36 & 0.37 & 0.33 & 0.37 & 0.37 & 0.42 \\
\hline Laborer & 24 & 38 & 0.30 & 0.35 & $n / a$ & 0.33 & 0.30 & 0.37 & 0.47 & 0.30 & 0.44 & 0.39 & 0.30 & 0.33 & 0.47 & 0.27 & 0.36 & 0.46 & .32 & 0.25 \\
\hline Gla & 36 & 28 & 43 & 0.34 & 0.33 & $n / a$ & 0.49 & 0.54 & 0.43 & 0.37 & 0.55 & 0.46 & 0.42 & 0.69 & 0.42 & .34 & 0.59 & 0.47 & .58 & 0.34 \\
\hline Inst & 0.30 & 0.30 & 0.45 & 0.34 & 0.30 & 0.49 & $\mathrm{n} / \mathrm{a}$ & 0.41 & 0.31 & 0.30 & 0.40 & 0.47 & 0.39 & 0.49 & 0.34 & 0.35 & 0.40 & 0.35 & 0.43 & 0.29 \\
\hline Insulation & 0.31 & 0.33 & 0.35 & 0.35 & 0.37 & 0.54 & 0.41 & $\mathrm{n} / \mathrm{a}$ & 0.42 & 0.33 & 0.43 & 0.39 & 0.32 & 0.50 & 0.46 & 0.33 & 0.51 & 0.47 & 0.56 & 0.26 \\
\hline IronRebar & 0.34 & 0.39 & 0.30 & 0.38 & 0.47 & 0.43 & 0.31 & 0.42 & $\mathrm{n} / \mathrm{a}$ & 0.49 & 0.48 & 0.34 & 0.35 & 0.40 & 0.46 & 0.26 & 0.47 & 0.48 & 0.43 & 0.33 \\
\hline Iron & 43 & 33 & 0.25 & 0.41 & 0.30 & 0.37 & 0.30 & 0.33 & 0.49 & $\mathrm{n} / \mathrm{a}$ & 0.38 & 0.37 & 0.33 & 0.36 & 0.29 & 0.36 & 0.36 & 0.29 & 0.38 & 0.45 \\
\hline Mas & 0.26 & 37 & 0.37 & 0.34 & 0.44 & 0.55 & 0.40 & 0.43 & 0.48 & 0.38 & $\mathrm{n} / \mathrm{a}$ & 0.46 & 0.36 & 0.50 & 0.45 & 0.30 & 0.57 & 0.52 & 0.47 & 0.37 \\
\hline $\mathrm{Mecl}$ & 0.31 & 0.34 & 0.42 & 0.42 & 0.39 & 0.46 & 0.47 & 0.39 & 0.34 & 0.37 & 0.46 & $\mathrm{n} / \mathrm{a}$ & 0.45 & 0.45 & 0.41 & 0.39 & 0.42 & 0.41 & .48 & 0.37 \\
\hline Millwright & 0.31 & 0.24 & 0.30 & 0.33 & 0.30 & 0.42 & 0.39 & 0.32 & 0.35 & 0.33 & 0.36 & 0.45 & $n / a$ & 0.42 & 0.28 & 0.30 & 0.31 & 0.31 & 0.44 & 0.34 \\
\hline OperatingEng & 0.33 & 0.27 & 0.39 & 0.40 & 0.33 & 0.69 & 0.49 & 0.50 & 0.40 & 0.36 & 0.50 & 0.45 & 0.42 & $\mathrm{n} / \mathrm{a}$ & 0.40 & 0.30 & 0.55 & 0.40 & 0.54 & 0.38 \\
\hline Painter & 0.25 & 0.39 & 0.36 & 0.36 & 0.47 & 0.42 & 0.34 & 0.46 & 0.46 & 0.29 & 0.45 & 0.41 & 0.28 & 0.40 & $n / a$ & 0.28 & 0.47 & 0.56 & 0.41 & 0.28 \\
\hline Pipefit/P & 0.47 & 0.23 & 0.32 & 0.37 & 0.27 & 0.34 & 0.35 & 0.33 & 0.26 & 0.36 & 0.30 & 0.39 & 0.30 & 0.30 & 0.28 & $n / a$ & 0.30 & 0.30 & 0.39 & 0.35 \\
\hline Plaster & 0.27 & 0.35 & 0.38 & 0.33 & 0.36 & 0.59 & 0.40 & 0.51 & 0.47 & 0.36 & 0.57 & 0.42 & 0.31 & 0.55 & 0.47 & 0.30 & $n / a$ & 0.47 & 0.52 & 0.34 \\
\hline Roofer & 0.22 & 0.43 & 0.41 & 0.37 & 0.46 & 0.47 & 0.35 & 0.47 & 0.48 & 0.29 & 0.52 & 0.41 & 0.31 & 0.40 & 0.56 & 0.30 & 0.47 & $\mathrm{n} / \mathrm{a}$ & 0.49 & 0.34 \\
\hline Sheetmetal & 0.38 & 0.32 & 0.33 & 0.37 & 0.32 & 0.58 & 0.43 & 0.56 & 0.43 & 0.38 & 0.47 & 0.48 & 0.44 & 0.54 & 0.41 & 0.39 & 0.52 & 0.49 & $n / a$ & 0.39 \\
\hline Welder & 0.35 & 0.26 & 0.29 & 0.42 & 0.25 & 0.34 & 0.29 & 0.26 & 0.33 & 0.45 & 0.37 & 0.37 & 0.34 & 0.38 & 0.28 & 0.35 & 0.34 & 0.34 & 0.39 & $\mathrm{n} / \mathrm{a}$ \\
\hline
\end{tabular}


The list of pairs of trades with high correlation coefficients includes: Glass/Glazing-Instrumentation (0.69), Glass/Glazing-Plasterer (0.59), Mason-Plasterer (0.57), Insulation-Sheet metal (0.56), Glass/Glazing-Mason (0.55), Glass/GlazingInsulation (0.54), and Mason-Roofer (0.52). It is important to note here that all of the obtained values lie within a narrow range of 0.21 to 0.69 .

\subsubsection{Navy}

The US Navy has a multiskilling strategy for its construction workers. As shown by Hyatt et. al (2004), the Naval Construction Force (Navy Seabees) implements multiskilling by combining crafts into seven military ratings:

- "Equipment Operator (EO) - Operation of construction equipment, transportation, blasting/rock crushing, well drilling, and paving,

- Construction Mechanic (CM) - Construction and automotive equipment maintenance, repair, overhaul, and management,

- Builder (BU) - Carpentry, masonry, reinforced concrete, roofing, and interior finish work,

- Steelworker (SW) - Welding, structural steel erection, sheet metal and ductwork fabrication,

- Construction Electrician (CE) - General electrical, telephone systems, and power generation and distribution,

- Utilitiesman (UT) - Plumbing, air conditioning systems, water production and distribution, sanitary and waste disposal, and

- Engineering Aid (EA) - Engineering technician, drafting and surveying, and soils and material testing." 


\subsubsection{Other Industry Practices}

A case study of high-performance teams presented by Chapman and Gerson (1999) reported the implementation of the following combinations of crafts by a major contractor:

- Electrical/Instrumentation Workers,

- Ironworkers/Rebar or Riggers,

- Millwrights/Instrumentation Workers, and

- Millwrights/Pipe fitters.

Chapman and Gerson recommended the use of a pay scale as an incentive for the workers to agree to cross-training. The authors also recommended the use of work-team selection processes to select the workers that are most suited for cross-training.

The following craft combinations were reported by another major contractor:

- Electrician/Instrument Fitter,

- Ironworker/Rigger/Operator,

- Carpenter/Cement Finisher/Rod-buster,

- Hydraulic/Dirt/Truck driver,

- Scaffold Builder/Carpenter/Rodbuster,

- Painter/Insulator/Metal man,

- Pipefitter/Boilermaker,

- Welder/Pipefitter, and

- Maintenance Technician.

\subsubsection{Summary: Values for this Study}

Based on the aforementioned data on skill combinations, a coefficient of affinity was assigned to each pair of crafts. The CII/CCIS survey was selected since it provides the most recent quantified measure of skill affinities between the different pairs of skills that are considered in this study. The bivariate correlation values, which were presented 
in Table 4.9, were changed to coefficients between 0 and 1, with higher values indicating crafts that are likely to be combined in practice. For example, ironwork and welding are more likely to be combined than instrumentation and pipefitting. Values less than -0.2 were changed to 0.25 , values between -0.2 and 0 were changed to 0.5 , values between 0 and 0.2 were changed to 0.75 and values higher than 0.2 where changed to 1 . In other words, the cost of training a worker in an additional craft is multiplied by a factor of 4 (i.e. 1/0.25), 2 (i.e. 1/0.5), 1.33 (i.e. 1/0.75) or 1 depending on the level of affinity between the worker's primary craft and the additional craft that he/she will be trained in. Table 4.11 summarizes the skill affinity coefficients that are used in this study. These cutoff values were selected in order to widen the range of distribution of the correlation values. Eighty-three out of the 105 original bivariate correlation values lied within the ($0.2,0.2)$ range. Figure 4.1 presents the distribution of the changed values that are used as affinity indicators in this study. 
Table 4.11. Skill affinity coefficients for this study.

\begin{tabular}{|c|c|c|c|c|c|c|c|c|c|c|c|c|c|c|c|}
\hline & 芯 & 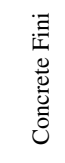 & 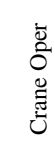 & 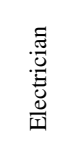 & $\begin{array}{l}\overrightarrow{0} \\
\tilde{0} \\
\stackrel{a}{\Xi} \\
\vec{\Xi}\end{array}$ & 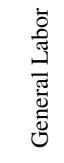 & 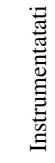 & 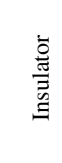 & 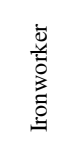 & 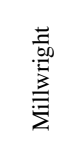 & 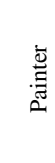 & 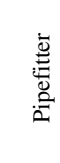 & $\begin{array}{l}\dot{\bar{\Delta}} \\
\stackrel{0}{.00} \\
\vec{\alpha}\end{array}$ & 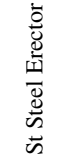 & $\frac{\overline{0}}{\frac{0}{0}}$ \\
\hline Carpenter & $\mathrm{n} / \mathrm{a}$ & 1 & 0.75 & 0.5 & 0.75 & 1 & 0.75 & 0.75 & 1 & 0.75 & 1 & 0.5 & 0.75 & 0.75 & 0.5 \\
\hline Concrete Finisher & 1 & $\mathrm{n} / \mathrm{a}$ & 0.5 & 0.5 & 0.75 & 1 & 0.5 & 0.75 & 1 & 0.5 & 1 & 0.5 & 0.5 & 0.5 & 0.5 \\
\hline Crane Operator & 0.75 & 0.5 & $\mathrm{n} / \mathrm{a}$ & 0.5 & 1 & 0.75 & 0.75 & 0.5 & 0.75 & 0.75 & 0.75 & 0.75 & 1 & 1 & 0.75 \\
\hline Electrician & 0.5 & 0.5 & 0.5 & $\mathrm{n} / \mathrm{a}$ & 0.5 & 0.5 & 0.75 & 0.5 & 0.5 & 0.5 & 0.5 & 0.25 & 0.25 & 0.25 & 0.25 \\
\hline Equipment Oper & 0.75 & 0.75 & 1 & 0.5 & $\mathrm{n} / \mathrm{a}$ & 0.75 & 0.75 & 0.75 & 0.75 & 0.75 & 0.75 & 0.75 & 1 & 1 & 0.75 \\
\hline General Laborer & 1 & 1 & 0.75 & 0.5 & 0.75 & $\mathrm{n} / \mathrm{a}$ & 0.75 & 0.75 & 1 & 0.75 & 1 & 0.75 & 0.75 & 0.5 & 0.5 \\
\hline Instrumentation & 0.75 & 0.5 & 0.75 & 0.75 & 0.75 & 0.75 & $\mathrm{n} / \mathrm{a}$ & 0.5 & 0.5 & 0.75 & 0.75 & 0.75 & 0.75 & 0.5 & 0.5 \\
\hline Insulator & 0.75 & 0.75 & 0.5 & 0.5 & 0.75 & 0.75 & 0.5 & $\mathrm{n} / \mathrm{a}$ & 0.5 & 0.75 & 0.75 & 0.5 & 0.5 & 0.5 & 0.5 \\
\hline Iron Worker & 1 & 1 & 0.75 & 0.5 & 0.75 & 1 & 0.5 & 0.5 & $\mathrm{n} / \mathrm{a}$ & 0.5 & 0.75 & 0.5 & 0.75 & 0.75 & 0.5 \\
\hline Millwright & 0.75 & 0.5 & 0.75 & 0.5 & 0.75 & 0.75 & 0.75 & 0.75 & 0.5 & $\mathrm{n} / \mathrm{a}$ & 0.75 & 0.75 & 0.75 & 1 & 0.75 \\
\hline Painter & 1 & 1 & 0.75 & 0.5 & 0.75 & 1 & 0.75 & 0.75 & 0.75 & 0.75 & $\mathrm{n} / \mathrm{a}$ & 0.5 & 0.75 & 0.5 & 0.5 \\
\hline Pipe Fitter & 0.5 & 0.5 & 0.75 & 0.25 & 0.75 & 0.75 & 0.75 & 0.5 & 0.5 & 0.75 & 0.5 & $\mathrm{n} / \mathrm{a}$ & 0.75 & 0.75 & 0.75 \\
\hline Rigger & 0.75 & 0.5 & 1 & 0.25 & 1 & 0.75 & 0.75 & 0.5 & 0.75 & 0.75 & 0.75 & 0.75 & $\mathrm{n} / \mathrm{a}$ & 1 & 1 \\
\hline Str Steel Erector & 0.75 & 0.5 & 1 & 0.25 & 1 & 0.5 & 0.5 & 0.5 & 0.75 & 1 & 0.5 & 0.75 & 1 & $\mathrm{n} / \mathrm{a}$ & 1 \\
\hline Welder & 0.5 & 0.5 & 0.75 & 0.25 & 0.75 & 0.5 & 0.5 & 0.5 & 0.5 & 0.75 & 0.5 & 0.75 & 1 & 1 & $\mathrm{n} / \mathrm{a}$ \\
\hline
\end{tabular}




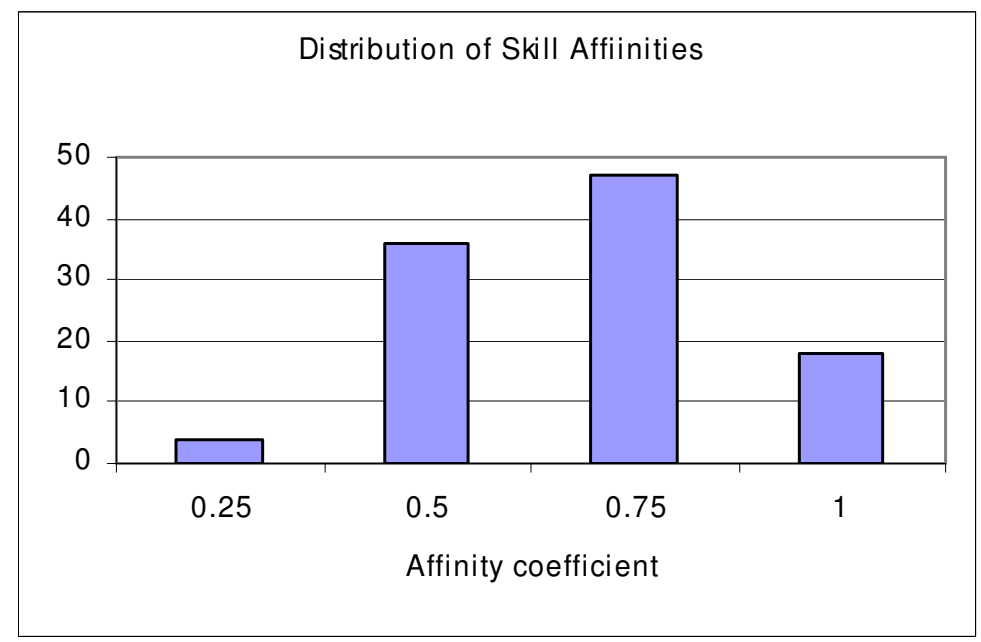

Figure 4.1. Frequency Diagram of Skill Affinity Coefficients.

\subsection{Training Costs}

Training a construction worker to be fully skilled in an additional craft requires a significant investment from the employer. Based on interviews with industry professionals using in-house instructors and NCCER materials, Pappas (2004) estimated a cost of $\$ 2,000-\$ 5,000$ to upgrade a worker from 1.5 to 2 certified crafts. Therefore, the cost of training a worker to be fully skilled in an additional craft is expected to fall in the $\$ 4,000-\$ 10,000$ range.

This study, however, does not call for training workers to be fully skilled in an additional craft. Rather, it calls for training workers in additional crafts in order to effectively contribute to the work without having to possess mastery level skills in the additional craft. Furthermore, as stated in Chapter 3, the cross-training of the workers is not necessarily performed in a formal fashion. Training can be performed through an onthe-job mechanism where the worker with the most expertise in a certain craft can assume the role of the mentor and the remaining members of the crew can assume the role of apprentices or helpers.

For the purpose of this study, the "basic" cost of training a worker to be proficient in an additional craft is assumed to be $\$ 2,000$. This figure is increased depending on the 
affinity coefficient between the worker's original craft and his/her additional craft. The following equation illustrates the simple calculation of the cost to train in skill $j$ a worker who already possesses skill $i$ (trainingcost $t_{i j}$ ) as the basic training cost (traincost $t_{i j}$ ) divided by the corresponding affinity coefficient.

trainingcost $_{i j}=\frac{\text { traincost }_{i j}}{\alpha_{i j}}$

Table 4.12 shows the different training costs that were calculated using both the "basic" \$2,000 cost and the affinity coefficients. It is noted that the cost of training a worker who already possesses skill $i$ in skill $j$ is equal to the cost of training a worker who already possesses skill $j$ in skill $i$. This is attributed to the nature of the statistical analysis (bivariate correlation) which was performed on the different pairs of skills to estimate skill affinities (Table 4.8). However, this might not be a realistic assumption. For example, the cost of training a painter in carpentry skills is expected to be higher than the cost of training a carpenter in painting skills. To overcome this pitfall, the user of the OWIM is recommended to enter company specific data on training costs between pairs of skills if available. 
Table 4.12. Training Costs in US dollars.

\begin{tabular}{|c|c|c|c|c|c|c|c|c|c|c|c|c|c|c|c|}
\hline & 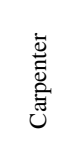 & 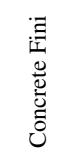 & 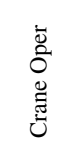 & 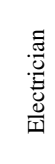 & 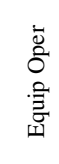 & 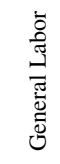 & 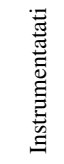 & 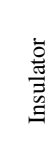 & 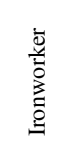 & 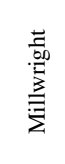 & 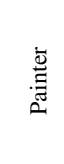 & 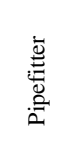 & $\begin{array}{l}\dot{\bar{D}} \\
.00 \\
\overrightarrow{0}\end{array}$ & 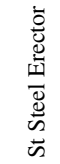 & $\frac{\overline{0}}{\frac{0}{j}}$ \\
\hline Carpenter & $\mathrm{n} / \mathrm{a}$ & 2000 & 2667 & 4000 & 2667 & 2000 & 2667 & 2667 & 2000 & 2667 & 2000 & 4000 & 2667 & 2667 & 4000 \\
\hline Concrete Finisher & 2000 & n/a & 4000 & 4000 & 2667 & 2000 & 4000 & 2667 & 2000 & 4000 & 2000 & 4000 & 4000 & 4000 & 4000 \\
\hline Crane Operator & 2667 & 4000 & $\mathrm{n} / \mathrm{a}$ & 4000 & 2000 & 2667 & 2667 & 4000 & 2667 & 2667 & 2667 & 2667 & 2000 & 2000 & 2667 \\
\hline Electrician & 4000 & 4000 & 4000 & n/a & 4000 & 4000 & 2667 & 4000 & 4000 & 4000 & 4000 & 8000 & 8000 & 8000 & 8000 \\
\hline Equipment Oper & 2667 & 2667 & 2000 & 4000 & $n / a$ & 2667 & 2667 & 2667 & 2667 & 2667 & 2667 & 2667 & 2000 & 2000 & 2667 \\
\hline General Laborer & 2000 & 2000 & 2667 & 4000 & 2667 & $\mathrm{n} / \mathrm{a}$ & 2667 & 2667 & 2000 & 2667 & 2000 & 2667 & 2667 & 4000 & 4000 \\
\hline Instrumentation & 2667 & 4000 & 2667 & 2667 & 2667 & 2667 & $\mathrm{n} / \mathrm{a}$ & 4000 & 4000 & 2667 & 2667 & 2667 & 2667 & 4000 & 4000 \\
\hline Insulator & 2667 & 2667 & 4000 & 4000 & 2667 & 2667 & 4000 & $\mathrm{n} / \mathrm{a}$ & 4000 & 2667 & 2667 & 4000 & 4000 & 4000 & 4000 \\
\hline Iron Worker & 2000 & 2000 & 2667 & 4000 & 2667 & 2000 & 4000 & 4000 & $n / a$ & 4000 & 2667 & 4000 & 2667 & 2667 & 4000 \\
\hline Millwright & 2667 & 4000 & 2667 & 4000 & 2667 & 2667 & 2667 & 2667 & 4000 & $n / a$ & 2667 & 2667 & 2667 & 2000 & 2667 \\
\hline Painter & 2000 & 2000 & 2667 & 4000 & 2667 & 2000 & 2667 & 2667 & 2667 & 2667 & $\mathrm{n} / \mathrm{a}$ & 4000 & 2667 & 4000 & 4000 \\
\hline Pipe Fitter & 4000 & 4000 & 2667 & 8000 & 2667 & 2667 & 2667 & 4000 & 4000 & 2667 & 4000 & $n / a$ & 2667 & 2667 & 2667 \\
\hline Rigger & 2667 & 4000 & 2000 & 8000 & 2000 & 2667 & 2667 & 4000 & 2667 & 2667 & 2667 & 2667 & $\mathrm{n} / \mathrm{a}$ & 2000 & 2000 \\
\hline Str Steel Erector & 2667 & 4000 & 2000 & 8000 & 2000 & 4000 & 4000 & 4000 & 2667 & 2000 & 4000 & 2667 & 2000 & $n / a$ & 2000 \\
\hline Welder & 4000 & 4000 & 2667 & 8000 & 2667 & 4000 & 4000 & 4000 & 4000 & 2667 & 4000 & 2667 & 2000 & 2000 & $n / a$ \\
\hline
\end{tabular}




\subsection{Training CAPACITY}

As explained in Chapter 3, there might be conditions in which there is a limitation on the number of workers that can be trained during a short time. Table 4.13 presents hypothetical values for the maximum number of workers that can be trained in any one of the considered crafts. It is also important to note here that different scenarios of availability of training were tried. The results of this effort are presented in Chapter 5. The model user can set the values in Table 4.13 and the rest of the tables presented in this chapter.

Table 4.13. Maximum Number of Workers that Can Be Trained in an Additional Craft.

\begin{tabular}{|c|c|}
\hline & Capacity \\
\hline Carpenter & 20 \\
\hline Concrete Finisher & 10 \\
\hline Crane Operator & 5 \\
\hline Electrician & 5 \\
\hline Equipment Operator & 10 \\
\hline General Laborer & 0 \\
\hline Instrumentation Worker & 10 \\
\hline Insulator & 20 \\
\hline Iron Worker & 10 \\
\hline Millwright & 15 \\
\hline Painter & 15 \\
\hline Pipe Fitter & 10 \\
\hline Rigger & 5 \\
\hline Structural Steel Erector & 10 \\
\hline Welder & 20 \\
\hline
\end{tabular}




\subsection{HIRING COSTS}

The hiring cost figures that are used in this study were determined based on Burleson et. al (1998)'s proposed labor economic model. They are composed of the following terms:

- Recruiting and Screening Costs: these are incurred for all applicants. The cost is to be $\$ 300$ per worker in addition to a $15 \%$ turnover rate, which results in $\$ 345$ per worker. This figure includes application, interview, reference checks, physicals, respirator tests, drug screening, skill or performance testing, lead level testing, hearing loss tests, asbestos exposure tests, and the indirect costs of administrating any of these items. To adjust for inflation, this current study uses an estimate of $\$ 500$ per worker for recruiting and screening.

- Employee Orientation Costs: these are usually computed based on the total number of hours spent in any type of company or project orientation. Added to that figure are the cost of materials such as handbooks, company packets, badges, etc. that are provided during the orientation session. An 8-hour orientation session was determined to the Model Plant project. Material expense was estimated as $\$ 5$. The full expression for orientation costs per worker is:

Orientation $=($ orientation Hours $)($ Average wage $)+$ materials

This study assumes an employee orientation cost of $\$ 150$ per worker.

- Worker Qualification Costs: these include both owner initiated requirements and state or local regulatory requirements. For example, all individuals working at a project site in the Houston area petro-chemical construction sector must have completed the Houston Safety Council training and examination, which was estimated to cost $\$ 25$. Also, welders are typically required to be certified. The cost was estimated to be $\$ 125$ in 1997 . This study assumes an incurred safety Council 
training cost of $\$ 50$ per worker for all workers. It also assumes that all hired welders will need certification, which costs $\$ 150$ per worker.

- Small Tools and Personal Protective Equipment Costs: Personal Protective Equipment (PPE) includes hardhats, gloves, ear plugs, safety harness, and goggles, which are often provided by the contractor. Contractors sometimes also provide small tools for job use. These are often lost, stolen, or damaged and therefore they must be replaced. These costs increase linearly with each additional hire. PPE costs were estimated to be $\$ 11$ per worker and small tool replacement costs to be $\$ 500$ per worker. This current study uses $\$ 600$ for both terms combined.

In summary, this study assumes a hiring cost of $\$ 1300$ per worker for all hired workers except welders who are assumed to have a $\$ 1450$ hiring cost per worker. Finally, this study does not include any insurance or tax-related costs in the hiring cots. It is assumed that these costs are indirectly reflected in the hourly wages, i.e. the hourly wages that are discussed in section 4.10 of this chapter are assumed to be after tax and insurance wages.

\subsection{Hiring CAPACITY}

As shown in Chapter 3, the model formulation takes into consideration market conditions. The availability of labor, single-skilled and multi-skilled, is represented by a certain hiring capacity. The maximum number of workers that can be hired is input to the optimization model. Even though such parameters are not easily determined in "realworld" conditions, the set of hiring capacity constraints reflect to a certain extent the state of the labor market. For example, there might be shortages of welders in the project area which could imply that there are no available welders to hire. This is represented in the model by a hiring capacity of welders of 0 . The model is expected then to suggest crosstraining other workers in welding. Table 4.14 presents hypothetical hiring capacity figures for the different considered crafts in this study. Different scenarios of hiring 
possibilities were tried. The results of this effort are presented in the following chapter, Chapter 5.

Table 4.14. Maximum Number of Workers with One Skill that Can Be Hired.

\begin{tabular}{|c|c|}
\hline & $\mathrm{N}$ \\
\hline Carpenter & 10 \\
\hline Concrete Finisher & 20 \\
\hline Crane Operator & 5 \\
\hline Electrician & 0 \\
\hline Equipment Operator & 15 \\
\hline General Laborer & 20 \\
\hline Instrumentation Worker & 10 \\
\hline Insulator & 20 \\
\hline Iron Worker & 10 \\
\hline Millwright & 15 \\
\hline Painter & 10 \\
\hline Pipe Fitter & 0 \\
\hline Rigger & 0 \\
\hline Structural Steel Erector & 10 \\
\hline Welder & 20 \\
\hline
\end{tabular}

Similarly, the availability of multiskilled workers is also affected by the conditions of the labor market. Figure 4.15 presents hypothetical hiring capacity figures for multiskilled workers. 
Table 4.15. Maximum Number of Workers with Two Skills that Can Be Hired.

\begin{tabular}{|c|c|c|c|c|c|c|c|c|c|c|c|c|c|c|c|}
\hline Primary Skill & 芯 & 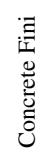 & 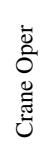 & 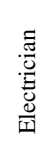 & 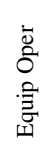 & 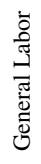 & 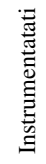 & 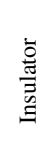 & 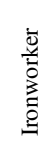 & 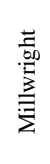 & 预 & 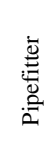 & 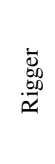 & 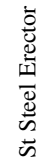 & $\frac{\bar{d}}{\frac{0}{3}}$ \\
\hline Carpenter & & 2 & & & & & & & 1 & & 2 & & & & 1 \\
\hline Concrete Finisher & 1 & & & & & & & & & & 2 & & & & \\
\hline Crane Operator & & & & & 2 & & & & & & & & & & \\
\hline Electrician & & & & & & & 3 & 2 & & & & & & & \\
\hline Equipment Oper & & & 2 & 2 & & & 2 & & & & & & & & \\
\hline General Laborer & & & & & & & & & & & & & & & \\
\hline Instrumentation & & & & 1 & & & & & & & & & & & \\
\hline Insulator & & & & 1 & & & & & & & & & & & \\
\hline Iron Worker & & & & & & & & & & 1 & & & 1 & 2 & 1 \\
\hline Millwright & & & & & & & & & 2 & & & & & & \\
\hline Painter & 1 & 1 & & & & & & & & & & & & & \\
\hline Pipe Fitter & & & & & & & & & & & & & & & 1 \\
\hline Rigger & & & & & & & & & 1 & & & 2 & & & \\
\hline Str Steel Erector & & & & & & & & & 1 & & & & 1 & & 2 \\
\hline Welder & 1 & & & & & & & & & & & 1 & & & \\
\hline
\end{tabular}




\subsection{WAGES}

Table 4.16 summarizes the average hourly wages obtained from the previously described CCIS/CII Survey and from the BLS data. The last column of table summarizes the values that are used in this study. These were assumed to fall between the figures obtained from the CCIS/CII Survey and those obtained from the BLS. The sensitivity of the model to variations in labor wages is studied in the following chapter.

Table 4.16. Hourly Wages in US dollars.

\begin{tabular}{|c|c|c|c|}
\hline & CCIS/CII Survey & BLS Data & Current Study \\
\hline Carpenter & 17.68 & 19.73 & 18.50 \\
\hline Concrete Finisher & 16.75 & 17.05 & 17.00 \\
\hline Crane Operator & 19.00 & 20.89 & 20.00 \\
\hline Electrician & 19.40 & 23.16 & 21.50 \\
\hline Equipment Operator & 18.08 & 20.89 & 19.50 \\
\hline General Labor & 16.50 & 13.54 & 15.00 \\
\hline Instrumentation & 18.65 & 20.29 & 19.50 \\
\hline Insulator & 18.46 & 13.79 & 16.50 \\
\hline Ironworker & 18.39 & 16.56 & 17.50 \\
\hline Millwright & 18.28 & 20.08 & 19 \\
\hline Painter & 16.62 & 16.33 & 16.50 \\
\hline Pipefitter & 18.71 & 20.29 & 19.50 \\
\hline Rigger & 19.27 & 13.42 & 16.50 \\
\hline Str Steel Erector & 18.60 & 21.32 & 20 \\
\hline Welder & 19.30 & 15.48 & 17.50 \\
\hline
\end{tabular}


One of the barriers for implementing multiskilling is the adoption of a wage scale depending on the number of possessed skills. Construction workers can be reluctant to get training in an additional skill unless it reflects in their pay rates. On the other hand, contractors and owners are often reluctant to make significant changes to their wage rates to reward multi-skilled workers. This study assumes that the hourly wage of a worker who possesses skills $i$ and $j$ is the higher of the following two figures: the wage of a worker who possesses skill $i$ only and the wage of a worker who possesses skill $j$ only. For example, the hourly wage of a welder is increased from $\$ 17.50 /$ hour to $\$ 19 /$ hour upon finishing training in pipefitting. Table 4.17 provides a summary of the hourly wages of multiskilled workers that are used in this study. 
Table 4.17. Hourly wages of multiskilled workers in US dollars.

\begin{tabular}{|c|c|c|c|c|c|c|c|c|c|c|c|c|c|c|c|}
\hline Primary Skill & 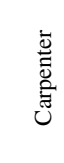 & 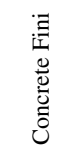 & 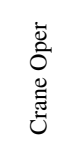 & 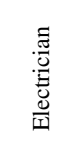 & 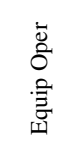 & 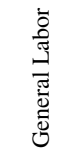 & 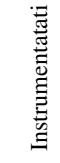 & $\begin{array}{l}\dot{\overline{0}} \\
\frac{\tilde{\sigma}}{\Xi} \\
\bar{\Xi} \\
\Xi\end{array}$ & $\begin{array}{l}\dot{\bar{d}} \\
\stackrel{\bar{d}}{0} \\
\stackrel{0}{0}\end{array}$ & 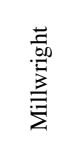 & 离 & $\begin{array}{l}\stackrel{\overrightarrow{0}}{0} \\
\stackrel{0}{0} \\
.\end{array}$ & 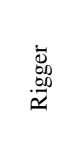 & 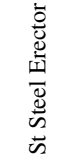 & $\frac{\overline{0}}{\frac{0}{0}}$ \\
\hline Carpenter & 18.5 & 18.5 & 20 & 21.5 & 19.5 & 18.5 & 19.5 & 18.5 & 18.5 & 19 & 18.5 & 19.5 & 18.5 & 20 & 18.5 \\
\hline Concrete Finisher & 18.5 & 17 & 20 & 21.5 & 19.5 & 17 & 19.5 & 17 & 17.5 & 19 & 17 & 19.5 & 17 & 20 & 17.5 \\
\hline Crane Operator & 20 & 20 & 20 & 21.5 & 20 & 20 & 20 & 20 & 20 & 20 & 20 & 20 & 20 & 20 & 20 \\
\hline Electrician & 21.5 & 21.5 & 21.5 & 21.5 & 21.5 & 21.5 & 21.5 & 21.5 & 21.5 & 21.5 & 21.5 & 21.5 & 21.5 & 21.5 & 21.5 \\
\hline Equipment Oper & 19.5 & 19.5 & 20 & 21.5 & 19.5 & 19.5 & 19.5 & 19.5 & 19.5 & 19.5 & 19.5 & 19.5 & 19.5 & 20 & 19.5 \\
\hline General Laborer & 18.5 & 17 & 20 & 21.5 & 19.5 & 15 & 19.5 & 16.5 & 17.5 & 19 & 16.5 & 19.5 & 16.5 & 20 & 17.5 \\
\hline Instrumentation & 19.5 & 19.5 & 20 & 21.5 & 19.5 & 19.5 & 19.5 & 19.5 & 19.5 & 19.5 & 19.5 & 19.5 & 19.5 & 20 & 19.5 \\
\hline Insulator & 18.5 & 17 & 20 & 21.5 & 19.5 & 16.5 & 19.5 & 16.5 & 17.5 & 19 & 16.5 & 19.5 & 16.5 & 20 & 17.5 \\
\hline Iron Worker & 18.5 & 17.5 & 20 & 21.5 & 19.5 & 17.5 & 19.5 & 17.5 & 17.5 & 19 & 17.5 & 19.5 & 17.5 & 20 & 17.5 \\
\hline Millwright & 19 & 19 & 20 & 21.5 & 19.5 & 19 & 19.5 & 19 & 19 & 19 & 19 & 19.5 & 19 & 20 & 19 \\
\hline Painter & 18.5 & 17 & 20 & 21.5 & 19.5 & 16.5 & 19.5 & 16.5 & 17.5 & 19 & 16.5 & 19.5 & 16.5 & 20 & 17.5 \\
\hline Pipe Fitter & 19.5 & 19.5 & 20 & 21.5 & 19.5 & 19.5 & 19.5 & 19.5 & 19.5 & 19.5 & 19.5 & 19.5 & 19.5 & 20 & 19.5 \\
\hline Rigger & 18.5 & 17 & 20 & 21.5 & 19.5 & 16.5 & 19.5 & 16.5 & 17.5 & 19 & 16.5 & 19.5 & 16.5 & 20 & 17.5 \\
\hline St Steel Erector & 20 & 20 & 20 & 21.5 & 20 & 20 & 20 & 20 & 20 & 20 & 20 & 20 & 20 & 20 & 20 \\
\hline Welder & 18.5 & 17.5 & 20 & 21.5 & 19.5 & 17.5 & 19.5 & 17.5 & 17.5 & 19 & 17.5 & 19.5 & 17.5 & 20 & 17.5 \\
\hline
\end{tabular}




\subsection{SUMMARY}

This chapter presented the details of the project to which the OWIM was applied. The CII Model Plant, an industrial-type project used in several CII studies, was selected. The labor profile obtained from the project schedule which extends over 77 weeks is considered. Hourly wages figures were obtained from two different sources: the BLS and the CII/CCIS survey. Affinities between pairs of skills were developed based on a bivariate correlation analysis. Assumptions on training and hiring costs, training and hiring capacities, and labor availability were made. These figures will be changed in the following Chapter which studies the sensitivity of the model to some of its input data through several case studies. 


\section{Chapter 5: Evaluation of Results}

This chapter presents the results obtained from the application of the OWIM on several case studies using the CII Model Plant project. First, the model is applied on an ideal scenario, in which there is a relatively large pool of labor to hire from and a possibility to train workers in any desired craft. Second, the model is applied on the case where cross-training is not available; and therefore, the only option is to hire workers. The third, fourth, and fifth case studies represent an application of the model on cases of severe labor shortages, i.e. no workers can be hired. Then, several sensitivity analyses are discussed. Finally, an analysis of the computing effort is presented.

\subsection{CaSe Studies}

\subsubsection{Case Study 1}

Using the CII Model Plant data presented in Chapter 4 (labor demand profile, labor availability, hiring and training costs, skill affinities, and hourly wages), the formulated model was applied on five different case studies reflecting different realworld scenarios. The first case, case study 1, assumes the availability of a large pool of workers to hire from (both single-skilled and multiskilled) as well as sufficient training facilities.

As shown in Table 5.1, the model recommends hiring workers rather than training. The model suggests training only one general laborer in rigging and hiring several single-skilled and multiskilled workers. This is an expected result since the hiring costs are less than the training cost between any pair of crafts. Also, this result reflects the common practice of cross-training workers in additional skills only if needed. In the "real-world," the preference is often given to hiring additional workers over crosstraining the available ones. Another observation is that the model recommends hiring as 
many multiskilled workers as possible to satisfy job site demands as illustrated by the fact that most of the hiring capacity constraints on multiskilled workers are tight ${ }^{9}$. This indicates that the benefits of employing multiskilled workers outweigh the extra incurred $\operatorname{costs}^{10}$. These benefits are related to the fact that multiskilled workers can be assigned to more than one craft at different time periods, which reduces the need to hire singleskilled workers to fill the gaps between labor demand and supply curves.

Table 5.1. Case Study 1: Hiring and Training Recommendations.

\begin{tabular}{|c|c|c|c|c|c|c|c|}
\hline \multicolumn{5}{|c|}{ Hiring Recommendations } & \multicolumn{3}{|c|}{ Training Recommendations } \\
\hline \multicolumn{2}{|c|}{ Single-skilled workers } & \multicolumn{2}{|c|}{ Multi-skilled workers } & \multirow[b]{2}{*}{$2^{*}$} & $\begin{array}{c}\text { Worker primary } \\
\text { skill }\end{array}$ & \multicolumn{2}{|c|}{$\begin{array}{l}\text { Skill to be } \\
\text { trained in }\end{array}$} \\
\hline Welder & 12 & Crane operator & Equipment operator & & General labor & Rigger & 1 \\
\hline Carpenter & 7 & Equipment operator & Instrumentation & $2^{*}$ & & & \\
\hline Painter & 6 & Equipment operator & Crane operator & $2^{*}$ & & & \\
\hline $\begin{array}{l}\text { Ironworker } \\
\text { Equipment }\end{array}$ & 5 & Carpenter & Concrete finisher & $2^{*}$ & & & \\
\hline operator & 4 & Carpenter & Ironworker & $1^{*}$ & & & \\
\hline \multirow[t]{7}{*}{ Crane operator } & 1 & Ironworker & Welder & $1^{*}$ & & & \\
\hline & & Ironworker & Rigger & $1^{*}$ & & & \\
\hline & & Carpenter & Welder & $1^{*}$ & & & \\
\hline & & Carpenter & Painter & 1 & & & \\
\hline & & Concrete finisher & Carpenter & $1^{*}$ & & & \\
\hline & & Welder & Carpenter & $1^{*}$ & & & \\
\hline & & Rigger & Ironworker & $1^{*}$ & & & \\
\hline
\end{tabular}

Another element of the model output is the worker assignments to the different tasks in order to meet job site demands. The model specifies the following assignment variables:

- $\quad l_{i j t}$ : the number of workers possessing skills $i$ and $j$ working in skill $i$ during time period $t$. This set of output variables consists of a $225 \times 77$ matrix. The rows of the matrix consist of the different combinations of pairs of skills, whereas the columns represent the duration of the project in weeks.

\footnotetext{
9 Rows with an asterisk (*) represent tight constraints

${ }^{10}$ As previously discussed in section 4.10, multiskilled workers generally have higher wages than singleskilled workers (Table 4.17)
} 
- $\quad m_{i j t}$ : the number of workers possessing skills $i$ and $j$ working in skill $j$ during time period $t$. Again, this is a $225 \times 77$ matrix.

- $n_{i t}$ : the number of workers with skill $i$ working during time period $t$. This set of output variables consists of a 15x77 matrix. The rows of the matrix represent the different skills considered in this study.

The three matrices of worker assignments for case study one are presented in Appendix C.

The last part of the model output is a summary of the incurred costs. As shown in Table 5.2, the wages incurred on site represent the highest component in the total labor cost figure. This is due to the size of the project and its relatively long duration (77 weeks). Labor costs, which mainly consist of the incurred wages, typically represent a relatively high percentage of the overall project cost; and therefore, a major portion of the contract amount is directly allocated for them. The other two components of the total labor costs, the direct training and hiring costs, are significantly less; and therefore, they can be handled through the human resources overhead.

Table 5.2. Case Study 1: Summary of Costs.

\begin{tabular}{|l|c|}
\hline Direct Training Costs (\$ U.S) & 2,667 \\
\hline Direct Hiring Costs (\$ U.S) & 68,550 \\
\hline Wages Incurred (\$ U.S) & $8,888,940$ \\
\hline Total Costs (\$ U.S) & $8,960,157$ \\
\hline
\end{tabular}

\subsubsection{Case Study 2}

Case study 2 assumes the same conditions as case study 1 except that it is not possible to train workers. Examples of this situation in the real-world include a project located in an area with no training facilities or a contractor might not have the time to train some of the workers because of tight time constraints. 
Table 5.3 summarizes the hiring recommendations generated by the OWIM. Again, the model recommends hiring as many multiskilled workers as possible to satisfy job site demands, as reflected by the number of tight constraints on the hiring of multiskilled workers (denoted by an asterisk).

Table 5.3. Case Study 2: Hiring Recommendations.

\begin{tabular}{|lr|l:lr|}
\hline \multicolumn{5}{|c|}{ Hiring Recommendations } \\
\hline \multicolumn{2}{|c|}{ Single-skilled workers } & \multicolumn{2}{|c|}{ Multi-skilled workers } \\
\hline Welder & 12 & Carpenter & Painter & $2^{*}$ \\
Carpenter & 8 & Equipment operator & Instrumentation & $2^{*}$ \\
Painter & 6 & Equipment operator & Crane operator & $2^{*}$ \\
Ironworker & 5 & Welder & Carpenter & $1^{*}$ \\
Equipment operator & 4 & Carpenter & Welder & $1^{*}$ \\
Crane operator & 2 & Carpenter & Ironworker & $1^{*}$ \\
& & Painter & Carpenter & $1^{*}$ \\
& & Ironworker & Welder & $1^{*}$ \\
& & Ironworker & Rigger & $1^{*}$ \\
& & Crane operator & Equipment operator & 1 \\
& & Rigger & Pipefitter & 1 \\
& & Rigger & Ironworker & $1^{*}$ \\
\hline
\end{tabular}

Table 5.4 summarizes the hiring costs, training costs, and incurred wages for case study 2 . A comparison between the results of case study 1 and case study 2 shows that, while the training cost of $\$ 2666.67$ was eliminated, the hiring costs increased by $\$ 1,300$ and the wages incurred increased by $\$ 2,420$. Overall, the total cost increased by $\$ 1,053.33$.

Table 5.4. Case Study 2: Summary of Costs.

\begin{tabular}{|l|c|}
\hline Direct Training Costs (\$ U.S) & 0 \\
\hline Direct Hiring Costs (\$ U.S) & 69,850 \\
\hline Wages Incurred (\$ U.S) & $8,891,360$ \\
\hline Total Costs (\$ U.S) & $8,961,210$ \\
\hline
\end{tabular}




\subsubsection{Case Study 3}

Case study 3 assumes the same conditions as case study 1 except that it is not possible to hire multiskilled workers. This might occur in a unionized environment where there is a limited availability of multiskilled workers.

Table 5.5 summarizes the hiring and training recommendations generated by the OWIM. A comparison between the results of case study 1 and case study 3 reveals the need to train more workers in the latter case. This is due to the limitation imposed on the hiring of multiskilled workers.

Table 5.5. Case Study 3: Hiring and Training Recommendations.

\begin{tabular}{|cc|ccc|}
\hline \multicolumn{2}{|c|}{ Hiring Recommendations } & \multicolumn{3}{|c|}{ Training Recommendations } \\
\hline \multicolumn{2}{|c|}{ Single-skilled workers } & Worker primary skill & Skill to be trained in \\
& & & & \\
Welder & 15 & General labor & Carpenter & 4 \\
Instrumentation & 2 & General labor & Rigger & 3 \\
Carpenter & $10^{*}$ & & & \\
Painter & 7 & & & \\
Ironworker & 9 & & & \\
Equipment operator & 9 & & & \\
Crane operator & 4 & & & \\
\hline
\end{tabular}

Table 5.6 summarizes the hiring costs, training costs, and incurred wages for case study 3 . A comparison between case study 1 and case study 3 indicates that the imposed limitation on the hiring of multiskilled workers resulted in a reduction of $\$ 3,300$ in incurred wages, which is expected since the wages of multiskilled workers are higher than the wages of single-skilled workers. Nonetheless, this limitation resulted in an increase in training costs of $\$ 13,333$ and an increase in hiring costs of $\$ 6,500$. This result indicates that the benefits of employing multiskilled workers outweigh the associated costs. 
Table 5.6. Case Study 3: Summary of Costs.

\begin{tabular}{|l|c|}
\hline Direct Training Costs (\$ U.S) & 16,000 \\
\hline Direct Hiring Costs (\$ U.S) & 75,050 \\
\hline Wages Incurred (\$ U.S) & $8,885,540$ \\
\hline Total Costs (\$ U.S) & $8,976,590$ \\
\hline
\end{tabular}

\subsubsection{Case Study 4}

Case study 4 assumes the same conditions as case study 1 except that it is not possible to hire single-skilled workers. Even though this is an unlikely scenario in practice, the purpose of presenting this case study is to compare its results with the results of the other case studies.

Table 5.7 summarizes the hiring and training recommendations generated by the OWIM. Again, the constraints on the hiring of multiskilled workers are tight, indicating the preference to hire multiskilled workers rather than training workers in additional skills. 
Table 5.7. Case Study 4: Hiring and Training Recommendations.

\begin{tabular}{|c|c|c|c|c|c|}
\hline \multirow{2}{*}{\multicolumn{3}{|c|}{$\begin{array}{c}\text { Hiring Recommendations } \\
\text { Multi-skilled workers }\end{array}$}} & \multicolumn{3}{|c|}{ Training Recommendations } \\
\hline & & & Worker primary skill & Skill to be trained & \\
\hline Structural steel & Welder & $2^{*}$ & Structural steel & Welder & 8 \\
\hline Millwright & Ironworker & $2^{*}$ & General labor & Carpenter & 4 \\
\hline Carpenter & Painter & $2^{*}$ & Structural steel & Crane operator & 2 \\
\hline Carpenter & Concrete finisher & $2^{*}$ & General labor & Rigger & 2 \\
\hline Equipment operator & Electric & $2^{*}$ & Structural steel & Equipment operator & 1 \\
\hline Equipment operator & Instrument & $2^{*}$ & Concrete finisher & Carpenter & 1 \\
\hline Equipment operator & Crane operator & $2^{*}$ & Concrete finisher & Ironworker & 1 \\
\hline Concrete finisher & Painter & $2^{*}$ & General labor & Painter & 1 \\
\hline Crane operator & Equipment operator & $2^{*}$ & & & \\
\hline Pipefitter & Welder & $1^{*}$ & & & \\
\hline Welder & Pipefitter & $1^{*}$ & & & \\
\hline Welder & Carpenter & $1^{*}$ & & & \\
\hline Carpenter & Welder & $1^{*}$ & & & \\
\hline Carpenter & Ironworker & $1^{*}$ & & & \\
\hline Painter & Carpenter & $1^{*}$ & & & \\
\hline Painter & Concrete finisher & $1^{*}$ & & & \\
\hline Ironworker & Millwright & $1^{*}$ & & & \\
\hline Ironworker & Welder & $1^{*}$ & & & \\
\hline Ironworker & Rigger & $1^{*}$ & & & \\
\hline Concrete finisher & Carpenter & $1^{*}$ & & & \\
\hline Rigger & Ironworker & $1^{*}$ & & & \\
\hline
\end{tabular}

Table 5.8 summarizes the hiring costs, training costs, and incurred wages for case study 4.

Table 5.8. Case Study 4: Summary of Costs.

\begin{tabular}{|l|c|}
\hline Direct Training Costs (\$ U.S) & $41,333.33$ \\
\hline Direct Hiring Costs (\$ U.S) & 40,050 \\
\hline Wages Incurred (\$ U.S) & $8,908,720$ \\
\hline Total Costs (\$ U.S) & $8,990,103$ \\
\hline
\end{tabular}

\subsubsection{Case Study 5}

Case study 5 assumes it is not possible to hire any outside or additional workers (single-skilled or multiskilled) and therefore cross-training is the only solution to meet 
job-site demands. This scenario is likely to happen on projects in remote areas with limited availability of labor. Table 5.9 summarizes the training recommendations generated by the OWIM.

Table 5.9. Case Study 5: Training Recommendations.

\begin{tabular}{|l|ll|}
\hline \multicolumn{3}{|c|}{ Training Recommendations } \\
\hline Worker primary skill & Skill to be trained in \\
\hline Structural steel & Equipment operator & 9 \\
General labor & Ironworker & 8 \\
Pipefitter & Welder & 6 \\
General labor & Painter & 6 \\
Millwright & Welder & 5 \\
Structural steel & Welder & 4 \\
Millwright & Carpenter & 4 \\
General labor & Carpenter & 4 \\
Ironworker & Carpenter & 3 \\
Insulator & Carpenter & 3 \\
Pipefitter & Instrumentation & 2 \\
Equipment operator & Crane operator & 2 \\
General labor & Rigger & 2 \\
Structural steel & Crane operator & 1 \\
Pipefitter & Crane operator & 1 \\
Painter & Rigger & 1 \\
Concrete finisher & Painter & 1 \\
Concrete finisher & Ironworker & 1 \\
\hline
\end{tabular}

Table 5.10 summarizes the hiring costs, training costs, and incurred wages for case study 2 . A comparison between case study 1 and case study 4 indicates that the strict limitation on the hiring of workers results in an increase of $\$ 91,583$ in the overall labor costs.

Table 5.10. Case Study 5: Summary of Costs.

\begin{tabular}{|l|c|}
\hline Direct Training Costs (\$ U.S) & 142,000 \\
\hline Direct Hiring Costs (\$ U.S) & 0 \\
\hline Wages Incurred (\$ U.S) & $8,909,740$ \\
\hline Total Costs (\$ U.S) & $9,051,740$ \\
\hline
\end{tabular}




\subsubsection{Summary of Five Cases}

Table 5.11 summarizes the outcomes of the application of the OWIM on the five case studies.

Table 5.11. Comparison of Results from Five Case Studies.

\begin{tabular}{|l|c|c|c|c|c|}
\hline & Case Study 1 & Case Study 2 & Case Study 3 & Case Study 4 & Case Study 5 \\
\hline Description & $\begin{array}{c}\text { Training \& } \\
\text { hiring available }\end{array}$ & Can't Train & $\begin{array}{c}\text { Can't hire } \\
\text { multiskilled }\end{array}$ & $\begin{array}{c}\text { Can't hire } \\
\text { single-skilled }\end{array}$ & Can't hire at all \\
\hline Training Costs (\$ U.S) & $2,666.67$ & 0 & 16,000 & $41,333.33$ & 142,000 \\
\hline Hiring Costs (\$ U.S) & 68,550 & 69,850 & 75,050 & 40,050 & 0 \\
\hline $\begin{array}{l}\text { Wages Incurred (\$.S) } \\
\text { U.S) }\end{array}$ & $8,888,940$ & $8,891,360$ & $8,885,540$ & $8,908,720$ & $8,909,740$ \\
\hline Total Costs (\$ U.S) & $8,960,157$ & $8,961,210$ & $8,976,590$ & $8,990,103$ & $9,051,740$ \\
\hline
\end{tabular}

As shown in Figure 5.1, the training costs increase significantly only when it is not possible to hire single-skilled workers (case 4) or when it is not possible to hire workers, single-skilled or multiskilled (case 5), which confirms the aforementioned observation that training is only recommended when hiring is not possible.

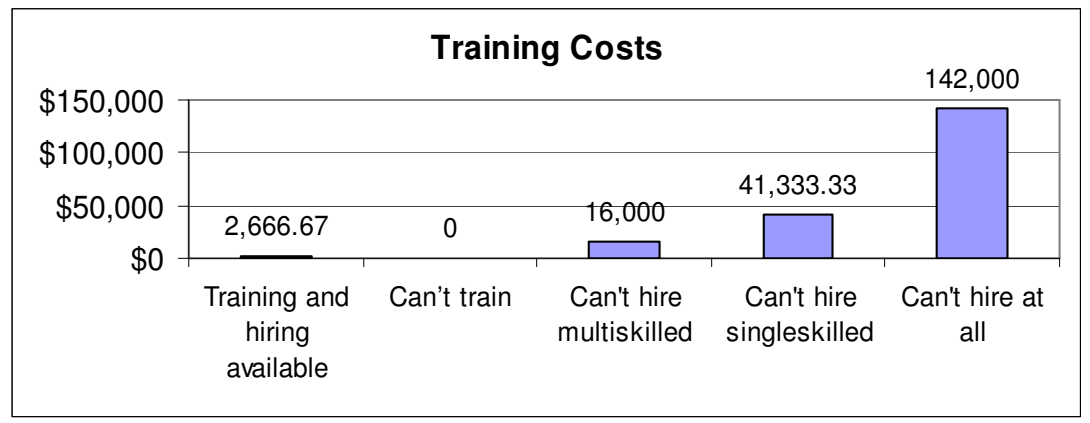

Figure 5.1. Summary of Training Costs in the Five Case Studies.

Conversely, the hiring costs decrease significantly only when it is not possible to hire single-skilled workers or when it is not possible to hire workers, single-skilled or multiskilled (Figure 5.2). 


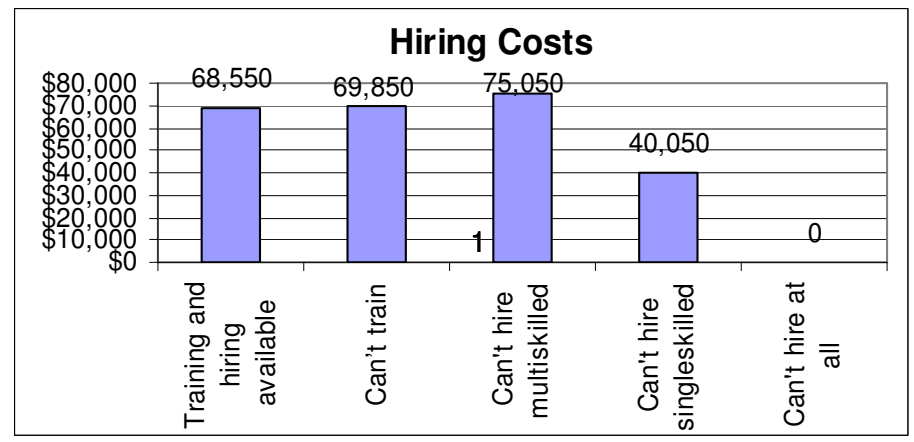

Figure 5.2. Summary of Hiring Costs in the Five Case Studies.

The relatively high increase in the wages incurred in the last two case studies is due to the fact that the wages of multiskilled workers are generally higher than the wages of single-skilled workers (Figure 5.3).

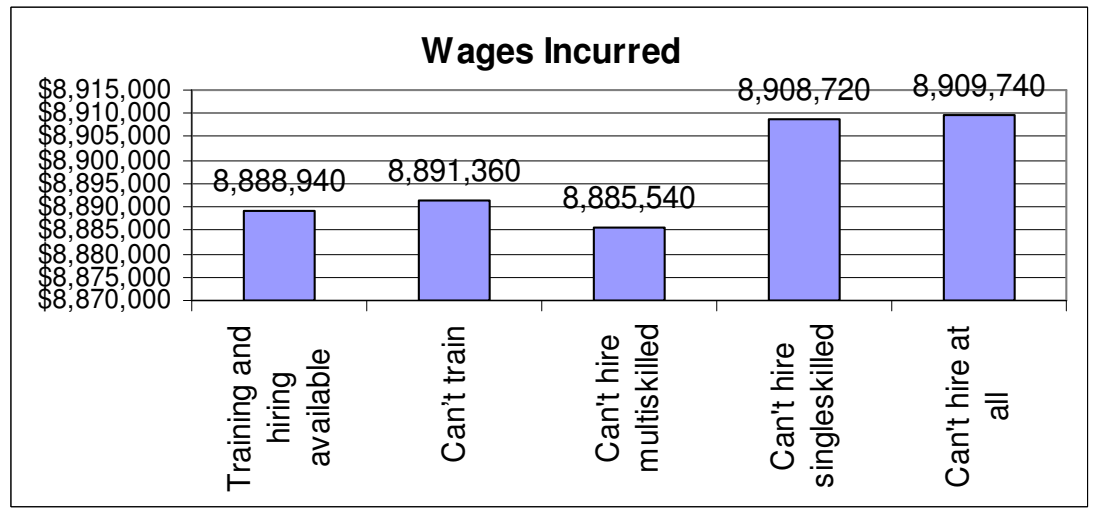

Figure 5.3. Summary of Wages Incurred in the Five Case Studies.

As shown in Figure 5.4, the total costs in cases 2, 3, 4, and 5 are higher than the total cost in case 1. This is an expected result, since each of these cases represents a constrained version of case study 1 . Case 5 has the highest increase in total costs as compared to case 1 , whereas case 2 has the least increase in total costs as compared to case 1 . This indicates that the impact of not being able to hire workers is more significant than the impact of not being able to train workers. 


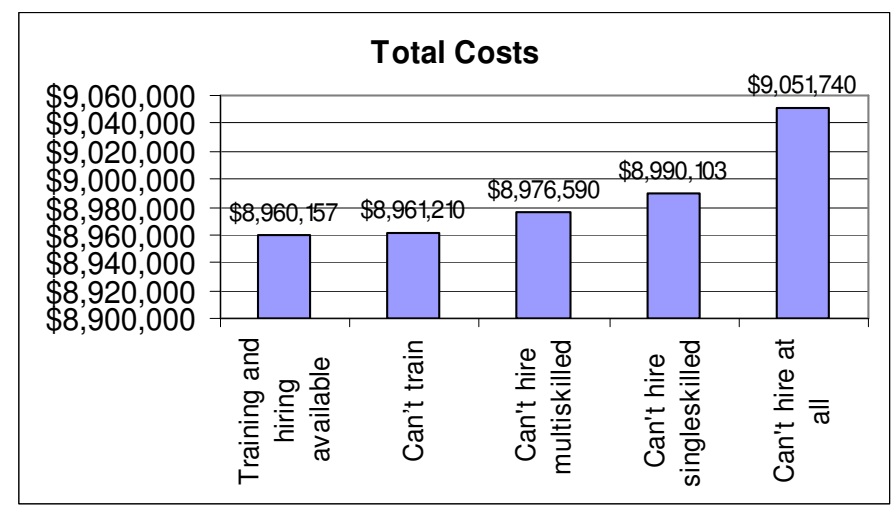

Figure 5.4. Summary of Total Costs in the Five Case Studies.

The following section studies the sensitivity of the OWIM to some of the input data: basic training cost per worker, hiring cost per worker, and wages. The impact of changing these input data on the model results (training, hiring, wages incurred, and total costs) is presented.

\subsection{SENSITIVITY ANALYSES}

\subsubsection{Sensitivity to Training Costs}

Figure 5.5 presents the variation in the number of workers to train or hire, as recommended by the OWIM, resulting from running the model on Case Study 1 while varying the basic training cost per worker (initially set at $\$ 2,000$ per worker). As expected, training becomes a less attractive option than hiring as the training cost per worker increases. Both options are equally attractive when the training cost is $\$ 1,000$ per worker ${ }^{11}$.

Figure 5.6 presents the variation in the total labor costs, the objective function of the OWIM, resulting varying the basic training cost. As expected, the total cost increases with increasing values of training cost (everything else kept constant) until it reaches a certain point where training is not recommended anymore. This phenomenon occurred at

\footnotetext{
${ }^{11}$ A basic training cost of $\$ 1,000$ translates into a training cost of $\$ 1,000-\$ 4,000$ per worker after adjusting for skill affinity.
} 
the point of $\$ 3,000$ of basic training cost. Beyond this point, the model does not recommend training any worker; instead, it recommends hiring workers, single-skilled and multiskilled.

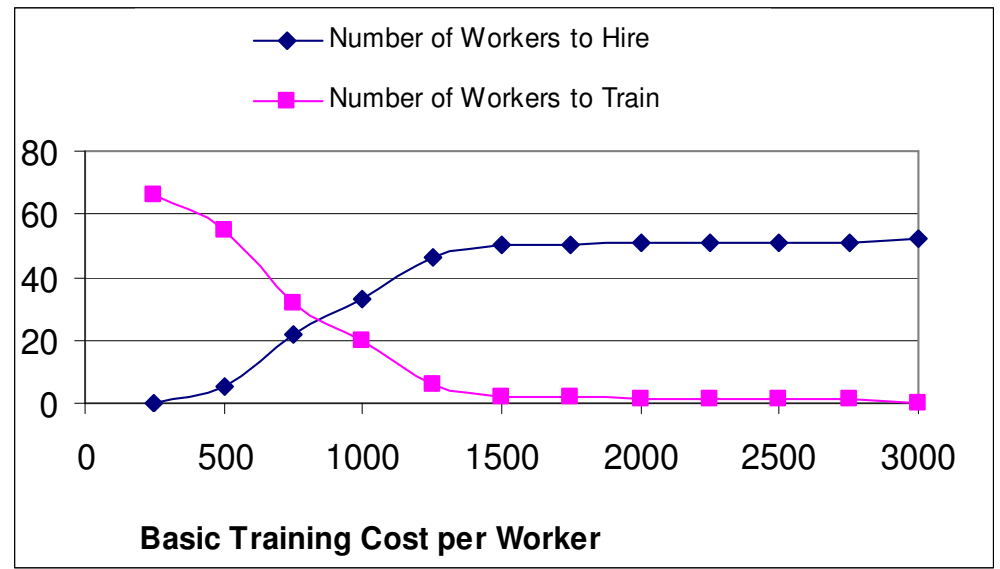

Figure 5.5. Number of Workers to Hire or Train Versus Basic Training Cost per Worker.

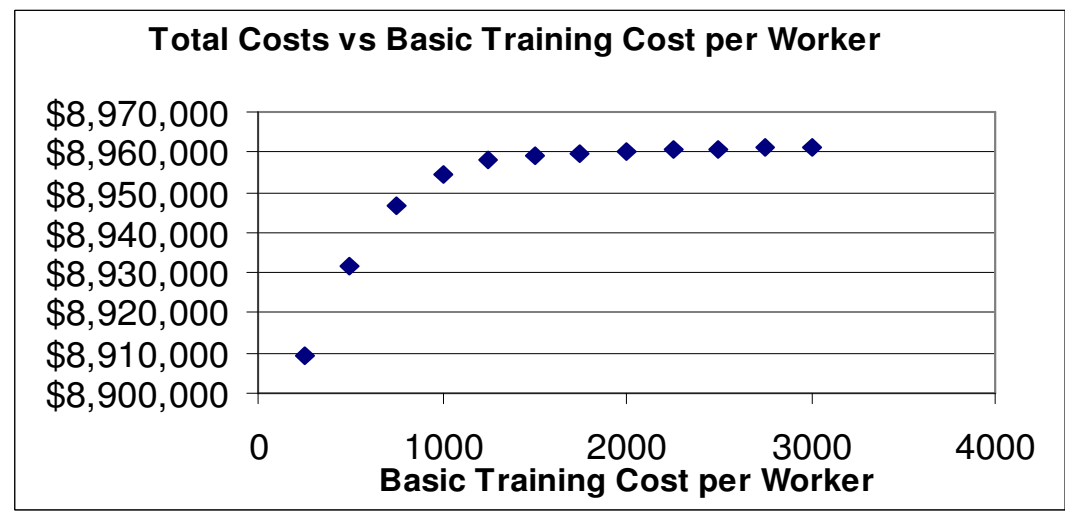

Figure 5.6. Sensitivity of the Total Costs to the Basic Training Cost per Worker.

Figure 5.7 presents the variation in one of the components of the OWIM's objective function, namely the overall training costs, as a result of changing the basic training cost. An increase in basic training cost up to $\$ 500$ per worker results in an increase in overall training costs. This can be explained by the fact that up to this point training is more economical than hiring; hence the model is recommending more training 
than hiring. Beyond this point, hiring starts becoming more competitive and therefore less training is needed as depicted by the decreasing values of overall training costs. Finally, as previously discussed, training is not recommended at all beyond the $\$ 3,000$ point, as depicted by the training costs of $\$ 0$.

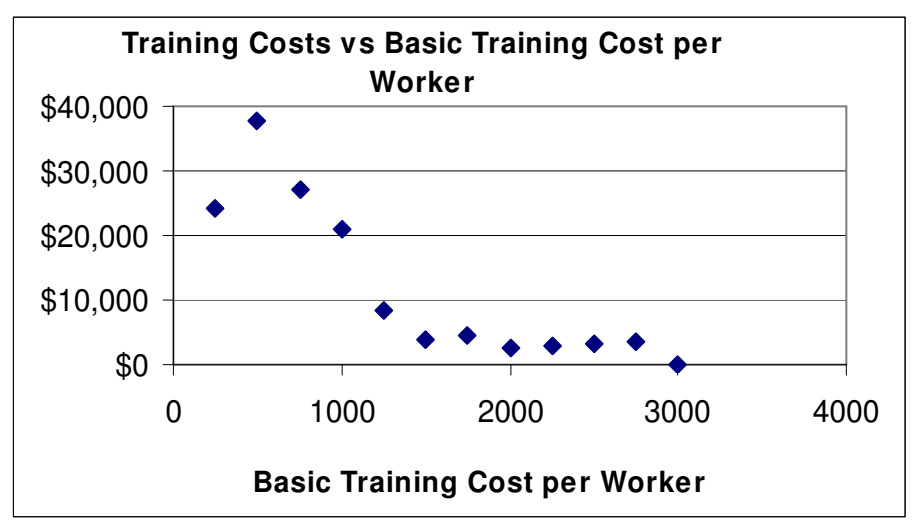

Figure 5.7. Sensitivity of the Training Costs to the Basic Training Cost per Worker.

The following figure presents the variation in another component of the OWIM's objective function, namely the overall hiring costs, as a result of the variation in the basic training cost per worker. The S-shaped curve indicates that hiring costs increase up to a certain point $(\sim 70,000)$, beyond which any increase in the basic training cost does not affect the output of the model (i.e. the hiring and training recommendations) or even the summary of cost figures.

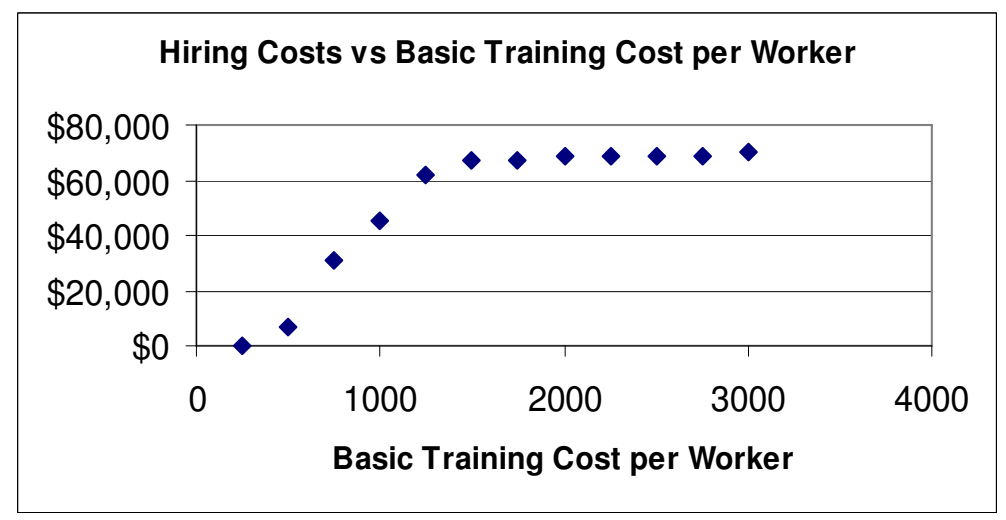

Figure 5.8. Sensitivity of the Hiring Costs to the Basic Training Cost per Worker. 
The last figure in this section, Figure 5.9, shows the variation in wages incurred as a result of the variation in the basic training cost. The general trend of the curve is that an increase in the training cost is accompanied by an increase in wages.

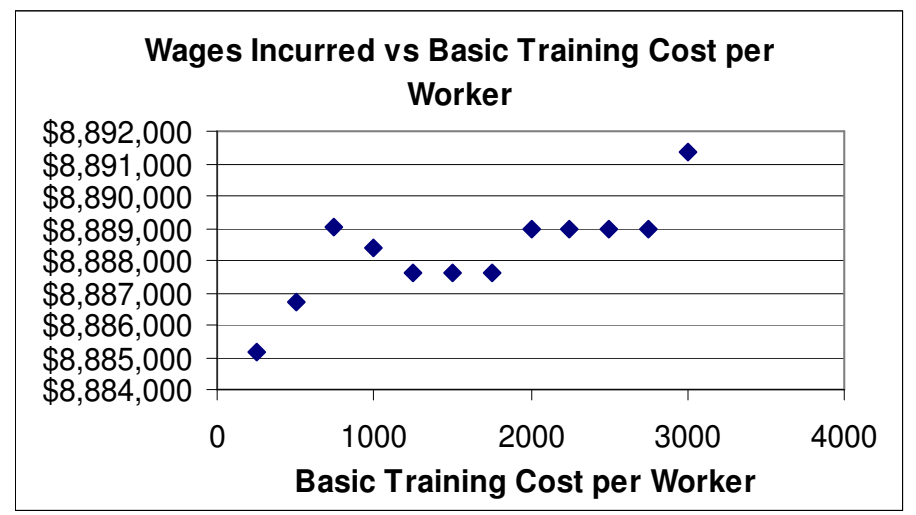

Figure 5.9. Sensitivity of the Incurred Wages to the Basic Training Cost per Worker.

\subsubsection{Sensitivity to Hiring Costs}

Figure 5.10 presents the variation in the number of workers to train or hire as recommended by the OWIM, resulting from running the model on Case Study 1 while varying the basic hiring cost per worker, initially set at $\$ 1300$ for all workers except welders $^{12}$. As expected, hiring becomes a less attractive option than training as the hiring cost per worker increases. Both options are equally attractive when the hiring cost is in the vicinity of $\$ 2,500$ per worker.

Figure 5.11 presents the variation in total labor costs (i.e. objective function of the OWIM) as a result of varying the hiring cost per worker. The total costs increase up to a certain point $(\sim \$ 9,050,000)$ obtained at the hiring cost of $\$ 7,000$ per worker. At this point, the OWIM does not recommend hiring any worker; instead, it recommends only cross-training workers in additional skills. Beyond this point, the solution of the model and the cost figures do not change.

\footnotetext{
12 Hiring cost of a welder $=$ hiring cost of any other type of worker + certification fees (estimated at \$150)
} 


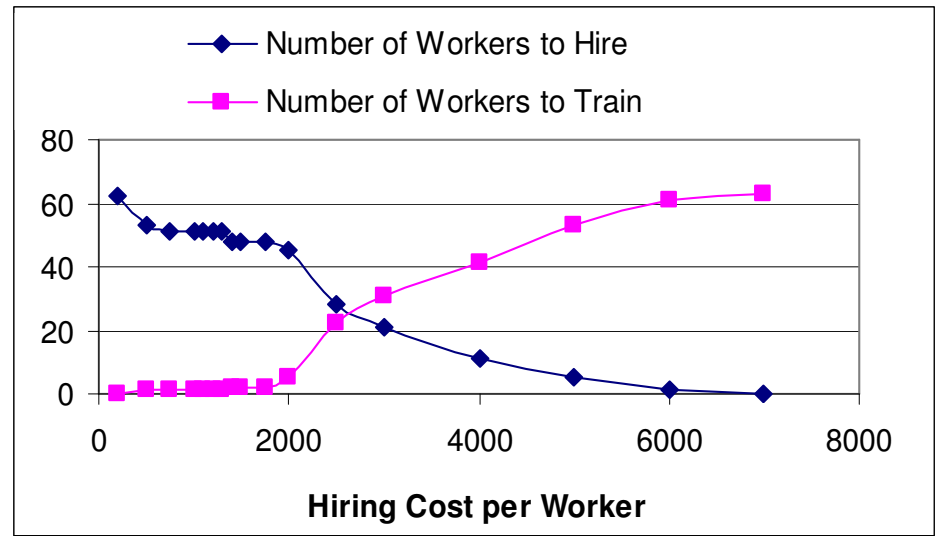

Figure 5.10. Number of Workers to Train or Hire versus Hiring Cost per Worker.

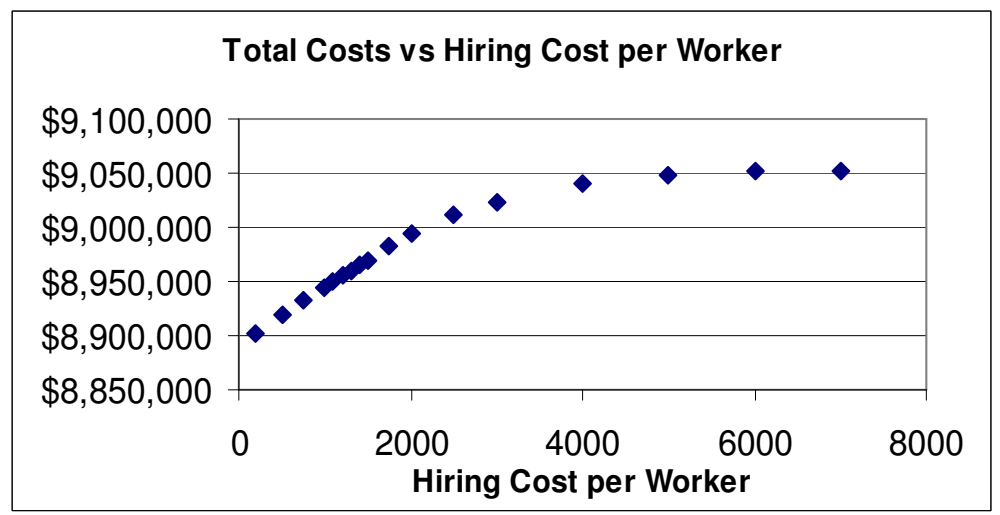

Figure 5.11. Sensitivity of the Total Costs to the Hiring Cost per Worker.

Figures 5.10 and 5.12 indicate that training is not recommended when the hiring cost is less than $\$ 2,000$ per worker. The increase in the hiring cost beyond this point results in a significant increase in the training cost up to the point of $\$ 7,000$ of hiring cost per workers. Beyond this point, the solution provided by the OWIM does not change and therefore the training costs curve tapers off at a value of approximately $\$ 150,000$. 


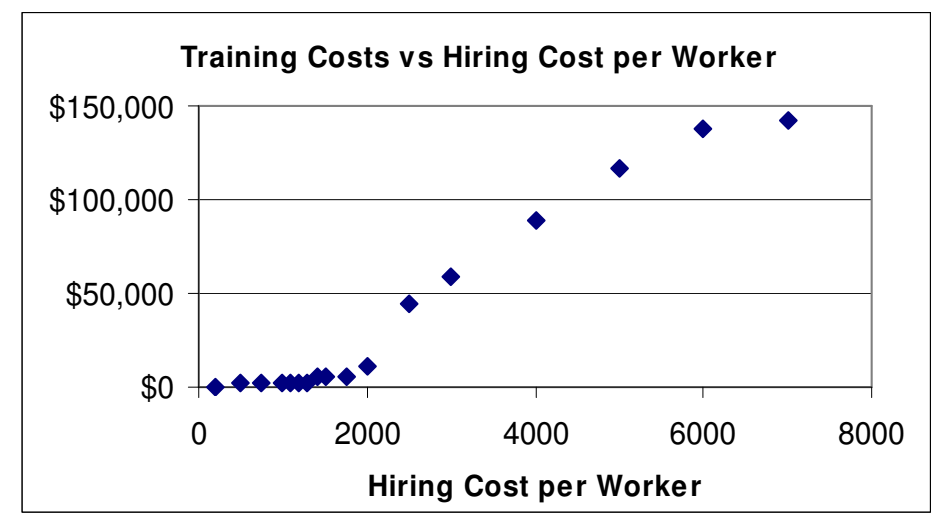

Figure 5.12. Sensitivity of the Training Costs to the Hiring Cost per Worker.

The following figure presents the variation in the overall hiring costs as a result of the variation in the hiring cost per worker. An increase in the hiring cost up to $\$ 2,000$ per worker results in a continuous increase in overall hiring costs. This can be explained by the fact that up to this point training is less economical than hiring; hence the solution of the model does not change, i.e. only hiring is recommended. Beyond the $\$ 2,000$ point, training starts becoming a more competitive option and therefore less hiring is required, which results in a decrease in the overall hiring costs. Finally, as previously discussed, hiring is not recommended beyond the $\$ 7,000$ point, as depicted by the hiring costs of $\$ 0$.

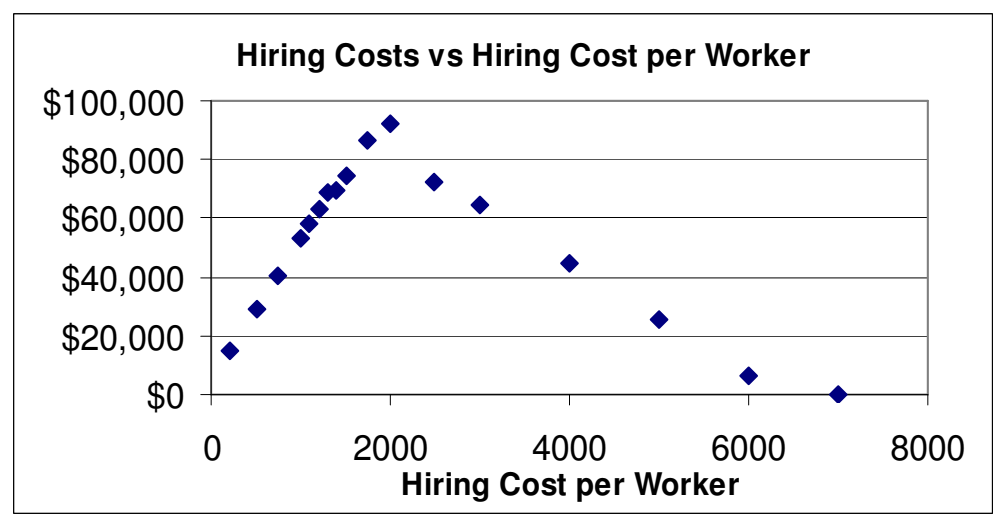

Figure 5.13. Sensitivity of the Hiring Costs to the Hiring Cost per Worker. 
The last figure in this section, Figure 5.14, shows the variation in wages incurred as a result of the variation in the hiring cost per worker. The general trend of the curve is that an increase in the hiring cost is accompanied by an increase in wages.

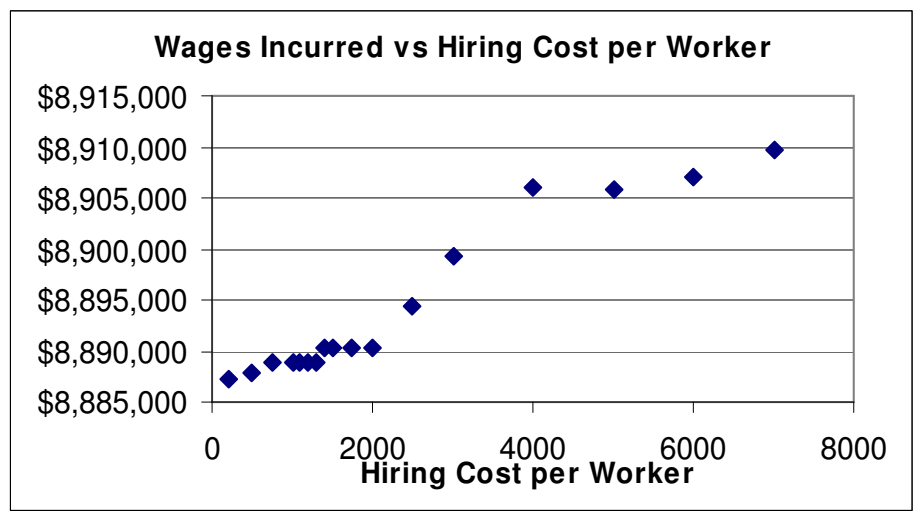

Figure 5.14. Sensitivity of the Incurred Wages to the Hiring Cost per Worker.

\subsubsection{Sensitivity to Wages}

This section presents the impact of changing the wage figures used in this study on the solution provided by the OWIM. The hourly wages that were presented in Chapter 4 of this document were changed by a multiplication factor varying from 0.5 to 2.5 .

Figure 5.15 presents the variation in the number of workers to hire or train as a result of varying the hourly wages. This variation is minimal indicating that the recommendations provided by the model, i.e. the numbers of workers to hire or train, are not very sensitive to changes in the hourly wages. It is also noted that the model consistently recommends more hiring than training since the hiring costs are generally lower than the training costs between pairs of skills. 


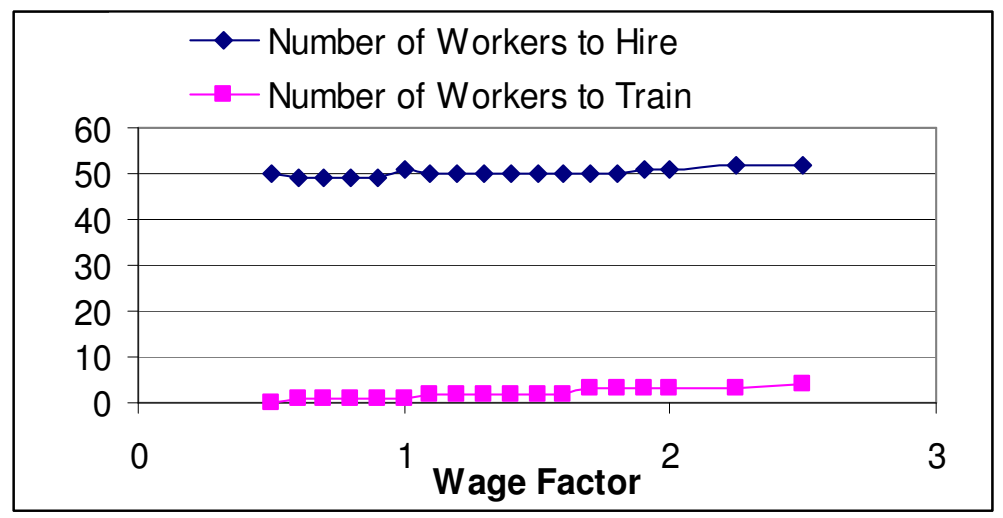

Figure 5.15. Number of Workers to Hire or Train versus Hourly Wages.

Figure 5.16 shows the variation in overall labor costs as a resulting of changing the hourly wage figures. The linear shape of the curve can be explained by the fact that the expression of the overall labor costs is a linear function of 3 terms: hourly wages, training costs and hiring costs. However, as previously discussed, the wages incurred is the highest component in the overall labor costs $(\sim 98 \%$ - section 4.2 of Chapter 4 of this document). The incurred wages expression is linearly dependent on the hourly wages. Hence, a linear change in the hourly wages will always result in a linear change in the incurred wages (Figure 5.17) and an approximately linear change in the overall labor costs (Figure 5.16) since the incurred wages term is the largest component of the overall labor costs expression.

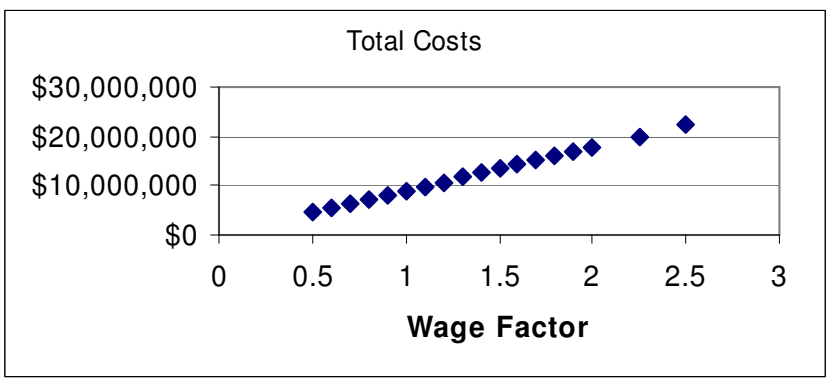

Figure 5.16. Sensitivity of the Total Costs to the Hourly Wages. 


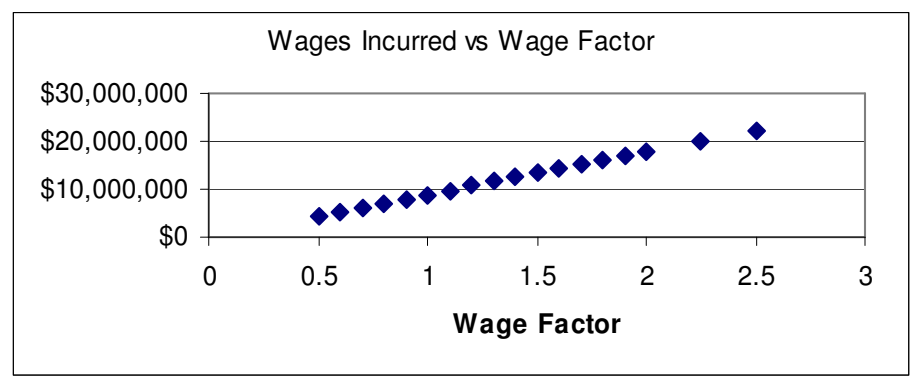

Figure 5.17. Sensitivity of the Incurred Wages to the Hourly Wages.

Figure 5.18 presents the variation in overall training costs as a result of the variation in hourly wages. Training is not recommended when the wages are reduced to $50 \%$ of the values considered in Chapter 4 (wage factor of 0.5 ). Training starts becoming recommended when the wage factor is increased to a value of 0.6. As depicted by the constant value of the training costs afterwards, the solution provided by the OWIM does not change up until the wage factor is increased to 1.1 , i.e. $10 \%$ increase of the values used in Chapter 4. This trend of unchanged solution followed by an increase in training recommendations repeats itself afterwards.

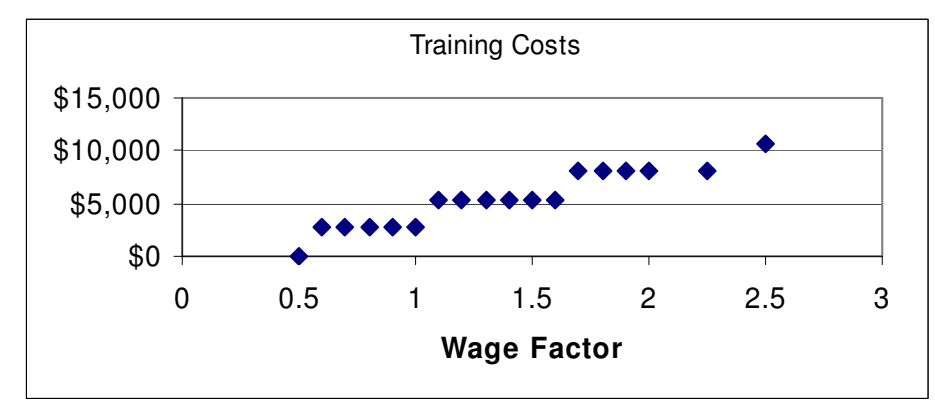

Figure 5.18. Sensitivity of the Training Costs to the Hourly Wages.

A similar trend was obtained for the variation in overall hiring costs as a result of the variation in the hourly wages (Figure 5.19). While increasing the wage factor from 0.5 to 0.6 , less hiring (and more cross-training) is recommended as reflected by the decrease in the total hiring costs. The solution provided by the OWIM does not change up until the wage factor is increased to 1.0 , where more hiring is recommended. 


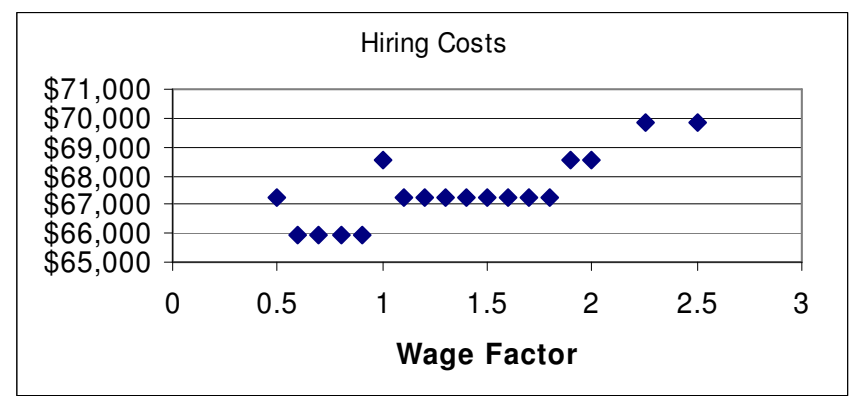

Figure 5.19. Sensitivity of the Hiring Costs to the Hourly Wages.

The following section discusses the computing effort resulting from running the OWIM on the different cases presented in this chapter.

\subsection{COMPUTING EFFORT}

In addition to the recommendations, i.e. the number of workers to hire and the number of workers to train in the different skills, the solution of the model provides summary statistics on the computing effort resulting from running the OWIM. These include:

- Number of equations or rows: this is equivalent to the total number of constraints generated by the model. The value is 19,891 for the OWIM when applied to the CII Model Plant,

- Number of single variables or columns: this is equivalent to the total number of variables generated by the model. The value is 36,271 for the OWIM when applied to the CII Model Plant,

- Number of non-zero elements: the number of non-zero coefficients in the problem matrix. The value is 161,476 for the OWIM when applied to the CII Model Plant,

- Number of iterations used by the Solver to arrive to the optimal solution. The default limit on the number of iterations in GAMS, which can be changed for larger problems, is 10,000 . For example, the value obtained for case study 1 is 6,836 , 
- Resource Usage: the amount of Central Processor Unit (CPU) time in seconds taken by the Solver. The default limit in GAMS is 1,000 seconds. For example, the value obtained for case study 1 was 1.28 , and

- Execution Time: the execution time to solve any of the case studies presented in this Chapter is in the vicinity of 1 second. For example, the time spent by GAMS and CPLEX to solve case study 1 is 0.909 seconds.

One of the reasons that explain the relatively short time required to solve the OWIM is the fact that GAMS has a "presolve" option, which has the ability to reduce the size of the formulated problem. For the OWIM, this option eliminated 6,288 rows or equations and 17,337 columns or variables prior to calling the CPLEX Solver. Another reason behind the short execution time is the fact that only a small number of the constraints are tight. For example, the set of constraints relating the demand for workers with skill $i$ during time period $t$ to the number of workers with skill $i$ available during the same period are tight only for a few weeks out of the 77-week project schedule. This phenomenon happens around the peak of the bell-shaped labor demand curves. 


\section{Chapter 6: Benefits and Costs of Implementing the OWIM}

This chapter presents an assessment of the benefits and costs associated with

implementing the OWIM. Based on the assumptions made in Chapter 4, a new case study was developed. The results obtained from the application of the OWIM on this new case study are compared to two likely approaches representing what an industry practitioner might opt for without referring to the OWIM. Additional non-quantifiable benefits and costs are also presented.

\subsection{BENEFITS OF IMPLEMENTATION}

When faced with the problem of shortages in some trades and with surpluses in others, industry practitioners typically opt for one of the following two options (without referring to the OWIM), named Approach 1 and Approach 2 respectively:

- Approach 1: hire workers to fill the gaps between the labor demand and the labor supply profiles.

- Approach 2: cross-train workers from the trades facing surpluses in order to allow them to work in the trades facing shortages.

Based on the input data presented in Chapter 4 (labor demand profile, labor availability, hiring and training costs, skill affinities, and hourly wages), a new case study, entitled Case Study 6, was developed to allow for the comparison of the results obtained from the application of the OWIM with the results obtained from approach 1 and approach 2 respectively. Case study 6 assumes the same labor profile, wage figures, hiring costs, and skill affinities that were previously described in Chapter 4 . The basic training cost was assumed to be $\$ 1,000$ per worker, which implies that the training cost between any pair of skills falls in the $\$ 1,000-\$ 4,000$ range (after adjusting for the skill affinities between pairs of skills). This assumption was made to present training as an equally favorable option as hiring (hiring costs fall in the $\$ 1,300-\$ 1,450$ range). 
The only other difference between Case Study 6 and the data that was used in Chapters 4 and 5 resides in the training and hiring capacity figures, which were increased to avoid infeasibility of the solution. In other words, the training and hiring capacity values were increased to make sure there is a sufficient pool of workers to hire from or sufficient training facilities to cross-train workers in order to fill the gaps between the labor demand and supply curves. Table 6.1 presents the new figures of the maximum number of workers that can be trained in an additional skill and the maximum number of workers that can be hired.

Table 6.1. Maximum Number of Workers that Can Be Trained in an Additional Skill and Maximum Number of Workers that Can Be Hired.

\begin{tabular}{|c|c|c|}
\hline & $\begin{array}{c}\text { Training } \\
\text { Capacity }\end{array}$ & Hiring Capacity \\
\hline Carpenter & 20 & 20 \\
\hline Concrete Finisher & 10 & 10 \\
\hline Crane Operator & 10 & 10 \\
\hline Electrician & 5 & 5 \\
\hline Equipment Operator & 15 & 15 \\
\hline General Laborer & 0 & 0 \\
\hline Instrumentation & 10 & 10 \\
\hline Insulator & 20 & 20 \\
\hline Iron Worker & 15 & 15 \\
\hline Millwright & 15 & 15 \\
\hline Painter & 15 & 15 \\
\hline Pipe Fitter & 10 & 10 \\
\hline Rigger & 10 & 10 \\
\hline Structural Steel & 10 & 10 \\
\hline Welder & 20 & 20 \\
\hline
\end{tabular}




\subsubsection{Solution Using Approach 1}

In approach 1, the industry practitioner decides the fill the gaps in the labor profile by hiring additional workers. This process could be done without using the OWIM. The following table summarizes the decisions the practitioner would make to fill these gaps.

Table 6.2. Approach 1: Hiring Recommendations.

\begin{tabular}{|c|c|}
\hline Craft & Number \\
\hline Structural steel & 1 \\
\hline Welder & 20 \\
\hline Instrumentation & 5 \\
\hline Carpenter & 19 \\
\hline Painter & 11 \\
\hline Ironworker & 12 \\
\hline Equipment operator & 11 \\
\hline Concrete finisher & 3 \\
\hline Crane operator & 7 \\
\hline Rigger & 8 \\
\hline
\end{tabular}

Table 6.3 summarizes the training, hiring, wages, and total costs incurred following approach 1 .

Table 6.3. Approach 1: Cost Figures.

\begin{tabular}{|c|c|}
\hline & Approach 1 \\
\hline Training Costs & $\$ 0$ \\
\hline Hiring Costs & $\$ 129,110$ \\
\hline Wages Incurred & $\$ 8,877,480$ \\
\hline Total & $\$ 9,006,580$ \\
\hline
\end{tabular}

\subsubsection{Solution Using Approach 2}

In approach 2, the industry practitioner decides the fill the gaps in the labor profile by cross-training workers from the trades facing surpluses in order to allow them to work in the trades facing shortages. This process could be done without using the 
OWIM. While it is relatively easy to determine the training needs in each skill, the identification of the number of workers with skill $i$ to be trained in skill $j$ is less evident. The OWIM was used to generate the "best decision" that the industry practitioner can make, in order to meet job site demands by only cross training workers. This "best decision" is associated with the lowest possible total labor costs. The industry practitioner is expected to make a decision which yields a total cost equal or higher than the one obtained here. The following table summarizes the decisions the practitioner could make to fill these gaps.

Table 6.4. Approach 2: Training Recommendations.

\begin{tabular}{|c|c|c|}
\hline Worker Primary Skill & Skill to be Trained in & N \\
\hline Ironworker & Welder & 12 \\
\hline Millwright & Carpenter & 11 \\
\hline Insulator & Painter & 11 \\
\hline Structural steel & Equipment operator & 10 \\
\hline General labor & Ironworker & 9 \\
\hline General labor & Rigger & 6 \\
\hline Pipe fitter & Instrumentation & 5 \\
\hline Structural steel & Welder & 4 \\
\hline Equipment operator & Crane operator & 4 \\
\hline Pipe fitter & Crane operator & 3 \\
\hline Painter & Concrete finisher & 3 \\
\hline Insulator & Carpenter & 3 \\
\hline Rigger & Welder & 3 \\
\hline Painter & Rigger & 2 \\
\hline Concrete finisher & Ironworker & 2 \\
\hline General labor & Carpenter & 2 \\
\hline Millwright & Structural steel & 1 \\
\hline Millwright & Welder & 1 \\
\hline Pipe fitter & Equipment operator & 1 \\
\hline Instrumentation & Carpenter & 1 \\
\hline Carpenter & Ironworker & 1 \\
\hline Painter & Carpenter & 1 \\
\hline Concrete finisher & Carpenter & 1 \\
\hline
\end{tabular}

Table 6.5 presents a summary of the training, hiring, wages, and total costs incurred following approach 2. 
Table 6.5. Approach 2: Cost Figures.

\begin{tabular}{|c|c|}
\hline & Approach 2-Best Case \\
\hline Training Costs & $\$ 123,667$ \\
\hline Hiring Costs & $\$ 0$ \\
\hline Wages Incurred & $\$ 8,889,100$ \\
\hline Total Costs & $\$ 9,012,767$ \\
\hline
\end{tabular}

\subsubsection{Solution Using the OWIM}

Finally, Case Study 6 was solved using the OWIM. The following table presents the number of workers to hire (single-skilled and multiskilled) and the number of worker to cross-train obtained from the running the OWIM on the Case Study 6.

Table 6.6. OWIM Solution: Hiring and Training Recommendations.

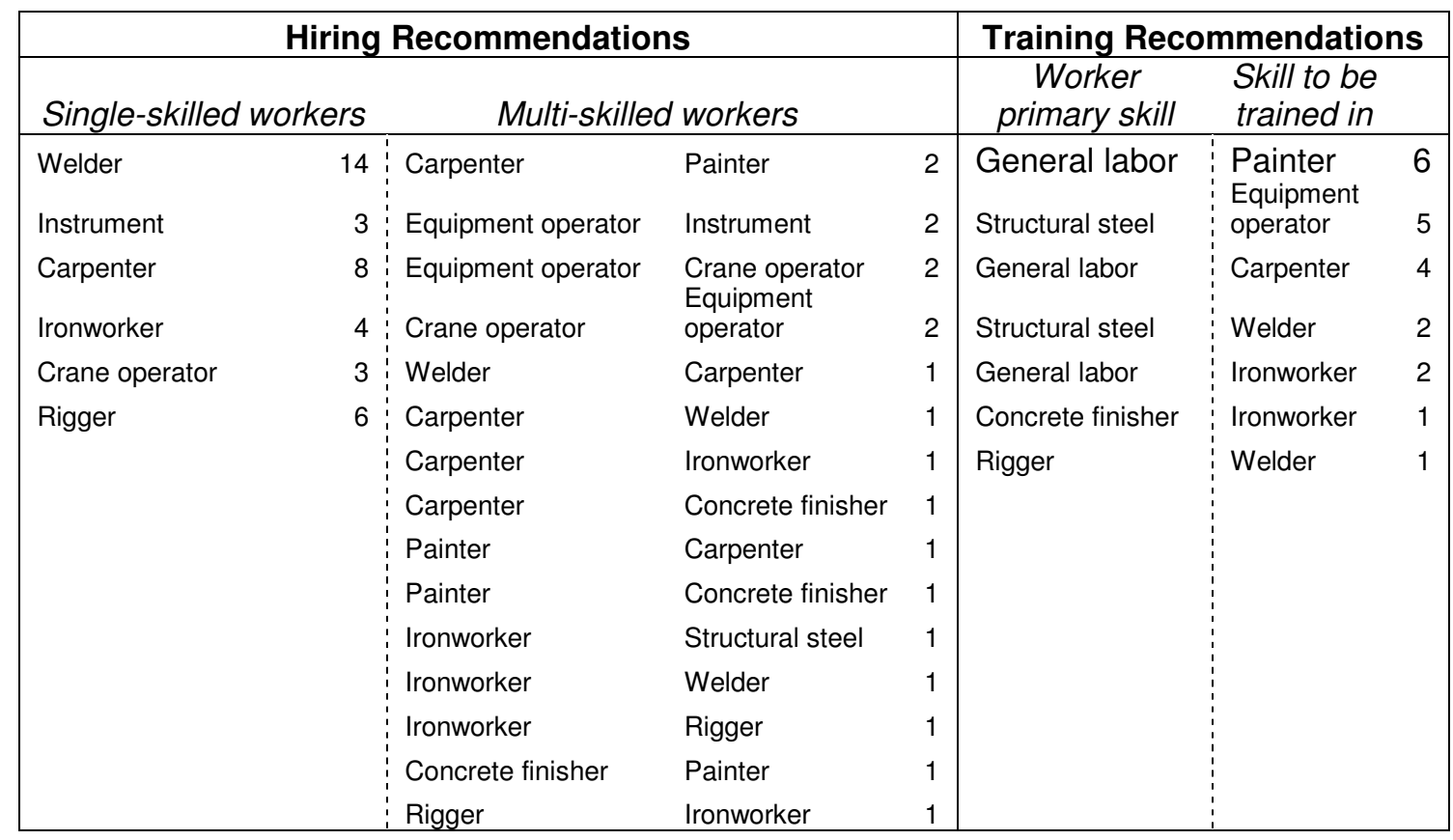

Table 6.7 presents a summary of the training, hiring, wages, and total costs incurred using the OWIM. 
Table 6.7. OWIM Solution: Cost Figures.

\begin{tabular}{|l|c|}
\hline & OWIM solution \\
\hline Training Costs & $\$ 21,000$ \\
\hline Hiring Costs & $\$ 76,650$ \\
\hline Wages Incurred & $\$ 8,883,400$ \\
\hline Total Costs & $\$ 8,981,050$ \\
\hline
\end{tabular}

\subsubsection{Comparison between OWIM and Approaches 1 and 2}

Figures 6.1 and 6.2 present the training, hiring, wages, and total costs incurred using Approach 1, Approach 2, and the OWIM.

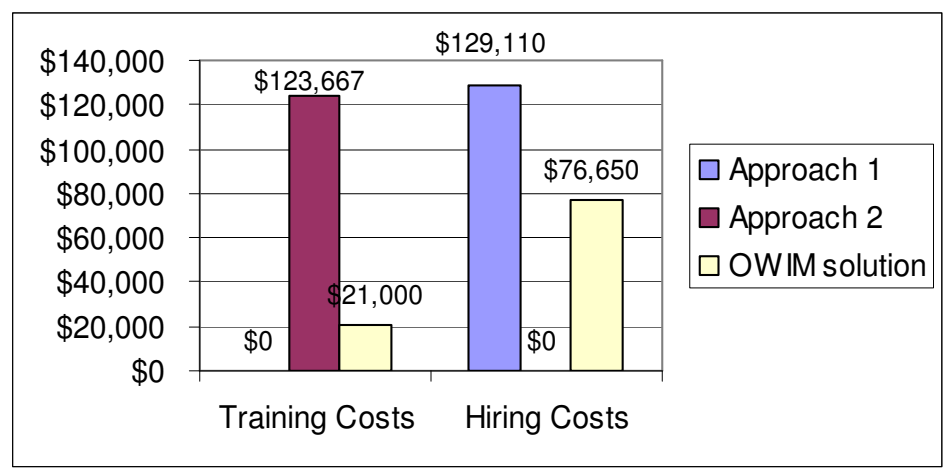

Figure 6.1. Summary of Training and Hiring Costs Using Approach 1, Approach 2, and the OWIM.

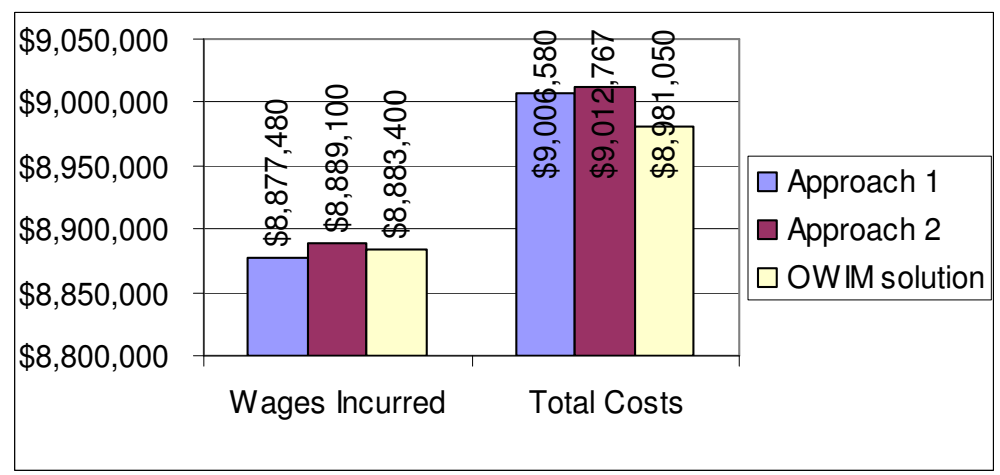

Figure 6.2. Summary of Wages Incurred and Total Costs Using Approach 1, Approach 2, and the OWIM. 
As shown in Figures 6.1 and 6.2, the OWIM provides $\$ 52,460$ of savings in the hiring costs $(\$ 129,110-\$ 76,650)$ as compared to Approach $1, \$ 21,000$ of additional costs in training, and $\$ 5,920$ of additional costs in wages $(\$ 8,883,400-\$ 8,877,480)$. Hence, the overall savings obtained by using the OWIM instead of Approach 1 are $\$ 25,540$ $(\$ 9,006,580-\$ 8,981,050)$.

As compared to Approach 2, the OWIM provides $\$ 102,667$ (i.e. $\$ 123,667$ $\$ 21,000)$ savings in training costs, $\$ 76,650$ additional costs in hiring, and $\$ 5,700$ savings in wages $(\$ 8,889,100-\$ 8,883,400)$. The overall savings obtained by using the OWIM instead of Approach 2 are $\$ 31,717$ (i.e. \$9,012,767-\$8,981,050).

The following section presents the costs associated with the implementation of the OWIM. It is important to note that some of these items are harder to quantify than others.

\subsection{COSTS OF IMPLEMENTATION}

The implementation of the OWIM in the real world has some associated cost elements. An easily quantified element is the cost incurred in purchasing the required software package in which the OWIM can be formulated and then solved. The cost to purchase a copy of GAMS, the program used in this study in which the OWIM was formulated, is $\$ 3,200$ (GAMS 2004). This copy of GAMS is intended for commercial use, which explains why it is more expensive than the cost to purchase a copy of the same program intended for academic use. Also, this copy does not include any associated solver. As it was previously explained in Chapter 3, GAMS does not solve the formulated problem. This task is accomplished by a separate program referred to as a "solver." A combination of GAMS and CPLEX with the possibility of solving linear programs only can be purchased for the price of $\$ 6,000$ (GAMS 2004).

Therefore, the overall cost to purchase the technology required to implement the OWIM is less than the aforementioned savings in overall labor costs of approximately $\$ 30,000$ (\$25,540 and $\$ 31,717$ using approach 1 and approach 2 respectively section 6.1 
of this Chapter). However, this cost figure of $\$ 6,000$ does not include the cost of training an employee of the company in operating the required technology, the cost of changing the administrative procedures within the company in order to integrate the OWIM into the current human resources system, and the cost of using the model on a real project.

The job of the operator includes entering the model input data such as labor demands over the considered time period, labor availability, training capacity, and hiring capacity. Also, the operator should have the ability to run the model and present the output to the decision maker in the company. The training of a staff member in using the OWIM is estimated to take two to three working days, which yields an approximate cost of $\$ 2,000$.

The process of altering the administrative procedures within the company in order to integrate the OWIM into the current human resources system entails developing the required databases of workforce profile (single-skilled and multiskilled), skill affinity coefficients, hiring costs, training costs, hourly wages, estimates of worker availability for hiring, and estimates of training capacities. This process is estimated to take one to two weeks or approximately $\$ 8,000$.

The aforementioned cost elements associated with the implementation of the OWIM represent a one-time investment of $\$ 16,000$ regardless of the number of projects on which the OWIM will be implemented. The last cost element, however, depends on the number of projects on which the OWIM will be implemented. This relates to the process of entering data to the OWIM, running the model, and analyzing the results (training and hiring recommendations and summary costs). This process is estimated to take 4 hours per project or $\$ 400$. 


\subsection{BENEFIT TO COST ANALYSIS}

This section presents a summary of a benefit-to-cost analysis for the implementation of the OWIM by a large construction firm. This assumes that the construction company is in the process of planning for its labor strategies across 10 projects approximately similar in size to the CII Model Plant.

Table 6.8 summarizes the benefits and costs of implementing the OWIM on 10 projects of the size of the CII Model Plant. The benefit-to-cost ratio, which is based on quantifiable elements only, was computed using the following expression:

$$
\text { Benefit }- \text { to }- \text { Cost Ratio }=\frac{\text { Total Benefits or Cost Savings }}{\text { Total Costs }}
$$

Table 6.8. Summary of Savings in Overall Labor Costs and Additional Cost.

\begin{tabular}{|c|c|}
\hline Benefits & $\$ 30,000 \times 10=\$ 300,000$ \\
\hline Technology Costs & $\$ 6,000$ \\
\hline Staff Training Costs & $\$ 2,000$ \\
\hline Administrative Procedures Costs & $\$ 8,000$ \\
\hline Data Input, Model Running, and Analysis of Results & $\$ 400 \times 10=\$ 4,000$ \\
\hline Benefit-to-Cost Ratio of implementing the OWIM & $\$ 300,000 / \$ 20,000=15 / 1$ \\
\hline
\end{tabular}

Note that this summary illustrates the following finding: the benefits of implementing the OWIM increase, relative to the associated costs, with an increase in the number of projects on which the model is applied. In other words, higher benefit-to-cost ratios are obtained when the number of projects on which the OWIM is applied increases. 


\subsection{ADDITIONAL BENEFITS AND COSTS}

As explained in Chapter 3, the OWIM provides the most cost effective solution to meeting job site demands through an optimal strategy of hiring and training the existing workforce. This is illustrated in the expression of the objective function, i.e. minimize the overall labor costs.

In addition to this, the implementation of the OWIM improves the skill set of the existing workforce through the cross-training of workers in additional skills which have some affinity with their primary skill. This, in turn, improves the employability of the workers, who can stay on-site for longer periods. A guaranteed extended employment is likely to be an additional source of motivation from the stand point of the workers themselves. An increased motivation often results in an increase in productivity, a reduction in turnover and absenteeism, and an improvement in safety performance. These, in turn, have a direct positive impact on the overall project costs.

Based on a study of four multiskilling strategies that were applied on the CII Model Plant, Burleson et. al (1998) estimated the benefits of improving the skill sets of the construction workforce. These benefits include a $35 \%$ reduction in the required workforce, a 9\% increase in the employment duration for the existing labor force, and an increase in the annual earning power of the multiskilled workers.

Improving the skill set of the available workforce has also some intangible effects on the workers such as increased morale and satisfaction, increased retention, attraction of more workers to the company, and enhanced career development.

Finally, the benefits of improving the skill set of the existing workforce extend beyond a single project provided that contractors are able to retain the majority of their workers and move them to other jobs once the project is completed.

An intangible cost element associated with implementing the OWIM, which can be looked at as a barrier, is the resistance of the industry to use what is often referred to 
as "complicated mathematical programs." Managers in the construction industry trust their experience and judgment more than they trust computer generated results.

\subsection{SUMMARY}

In summary, the implementation of the OWIM is associated with several benefits and cost elements. Some of these elements are tangible and therefore easily quantified such as the savings in labor costs and the purchase cost of the required technology. Other

elements such as improved morale and productivity or resistance of the industry to computer generated results are less tangible. The results of this study indicate that, at least in terms of tangible elements, the benefits of implementing the OWIM outweigh the associated costs. 


\section{Chapter 7: Conclusions and Recommendations}

\subsection{CONCLUSIONS}

A review of the relevant body of knowledge and interviews with industry practitioners revealed the need for optimization techniques to address the issue of investment in the construction workforce. These techniques have the potential to alleviate problems of skilled labor shortages. A linear programming model was developed to provide an optimization-based framework for matching supply and demand of construction labor through training, recruitment, and allocation. The model entitled OWIM serves as a useful tool for planning using commercially available projects. The OWIM was applied on data obtained from the CII Model Plant and a recent survey conducted by the CCIS and CII.

The developed model is coded in an optimization software entitled GAMS and solved using the CPLEX solver. GAMS permits the expression of optimization problems independently of the data. This separation of logic (or mathematical equations) and data is useful in large and complex problems which may require some revisions before arriving to the final version of the formulated problem. Also, it allows construction contracting firms, which are intended to be the final users of the OWIM, to input their own data to GAMS in the forms of Microsoft Excel tables without having to change any mathematical equation.

The results of the application of the OWIM on several case studies based on data obtained from the CII Model Plant and the CII/CCIS survey revealed that, typically, both the cost of training and the cost of hiring workers are significantly less than the wages incurred on-site.

When applied on an ideal scenario, i.e. assuming the availability of a large pool of workers to hire from (both single-skilled and multiskilled) as well as sufficient training facilities, the model recommends hiring workers rather than training. This is an expected 
result since the hiring costs are less than the training cost between any pair of crafts. Also, this result reflects the common practice of cross-training workers in additional skills only if needed.

The sensitivity of the model results to variation in the input data was also studied. The variations in the number of workers to train or hire, training costs, hiring costs, incurred wages, and overall labor costs as a result of varying the training cost per worker, the hiring cost per worker, and the hourly wages were studied. As expected, the overall labor cost figure increases with increasing values of training cost per worker (everything else kept constant) until it reaches a certain point where training is not recommended anymore. This phenomenon occurred at the point of $\$ 3,000$ of basic training cost per worker (i.e. $\$ 3,000$ to $\$ 12,000$ after adjusting for skill affinities). Beyond this point, the model does not recommend training any worker; instead, it recommends hiring workers, single-skilled and multiskilled. The results of varying the hiring cost per worker, initially set at $\$ 1,300$ for all workers except welders, indicate that the overall labor costs increase up to a certain point obtained at the hiring cost of $\$ 7,000$ per worker. Beyond this point, the OWIM does not recommend hiring any worker; instead, it recommends only crosstraining workers in additional skills. Finally, since the wages incurred is the highest component in the overall labor costs $(\sim 98 \%)$ and since it is linearly dependent on the hourly wages, a linear change in the latter resulted in a linear change in the wages incurred and in an approximately linear change in the overall labor costs.

When compared with possible approaches taken by an industry practitioner faced with the problem of shortages in some trades with surplus in others, the OWIM provided savings of approximately $\$ 30,000$ in overall labor costs, as compared to the approximately $\$ 9$ Million total labor costs.

A comparative study of the benefits and costs associated with the implementation of the OWIM by a large construction company in the process of planning for its labor strategies across 10 projects of the size of the CII Model Plant revealed a benefit-to-cost 
ratio of 15 to 1 . It is important to note here that this value would significantly increase if the model is applied on additional projects. This is due to the fact that most of the cost elements are incurred only once. These include the cost to purchase GAMS and a solver such as CPLEX $(\sim \$ 6,000)$, the cost of training a staff member on using the OWIM $(\sim 2,000)$, and the cost of changing administrative procedures to integrate the OWIM into the current human resources system $(\sim 8,000)$. The only cost element which depends on the number of projects on which the OWIM is applied is the cost of entering data, running the model, and analyzing the results ( $\$ 400$ per project).

This study confirms the conclusion made in previous studies (Burleson et. al 1998, Gomar et. al 2002 and others) that multiskilling can provide significant savings in project labor costs. The results presented in Chapter 5 and Chapter 6 of this document indicate that the benefits of employing a multiskilled workforce outweigh the cost of cross-training singled-skilled workers in additional skills. Looking beyond the scope of the considered project, these benefits are expected to increase provided that the trained workers keep their employment status with their firm. A temporal dimension can be added to the OWIM, in which the benefits of multiskilling are tracked over several consecutive projects performed by the same contractor. Based on the current formulation, a new model can be built in which several projects are considered. This might be beneficial for a company which is in the process of planning for several projects, moving workers internally from region to region and thus changing per diem costs.

The following section discusses other recommendations for future work in this area.

\subsection{RECOMMENDATIONS}

While developing a computerized model with a relatively large amount of input and output data, the first recommendation that comes to mind is to improve the aesthetics of the model. The process of making the model more user-friendly entails providing more flexibility in the data entering process. For example, work could be done to allow the 
model to automatically read the input data from Excel. The user could be given the option to use his/her company input data such as training and hiring costs or use the default data provided by the OWIM. Also, the model could be altered to allow for reading the labor demand profile from scheduling software such as Primavera Project Planner. There is room for improving the output of the model as well. For example, work can be done to give the user the option of plotting labor assignments over a certain period of the project.

The skill affinity coefficients used in this study were derived from a bivariate correlation analysis of actual skill combinations as observed in a survey of approximately 1,000 workers at 19 project sites across the US. However, in practice, these coefficients might differ from a company to another. It is recommended that a company which is planning to use the OWIM on a specific project uses its own historical data on skill affinities, if available.

The current formulation of the OWIM can be easily altered to incorporate elasticities. For example, the task of finding skilled workers becomes harder once a certain number of workers are hired. In this case, the cost of hiring a worker is expected to rise. This phenomenon can be captured in the OWIM by splitting the number of workers to hire variable into two separate variables, one representing the number of workers to hire at a certain cost and the other representing the number of workers to hire at a higher cost or at higher hourly wages. In addition to this new variable, constraints representing the maximum number of workers that can be hired at both costs are needed.

The formulation of the OWIM assumes that the workers currently employed will be offered a chance to get basic training in only one additional skill. This assumption was based on previous studies which indicated limited benefits for cross-training workers in more than one additional skill (Gomar et. al 2002, Campbell 1999, and Burleson et. al 1998). One of the conclusions of Gomar's study is that the benefits of extended employment duration are marginal after workers possess skills in two or three crafts. It 
will still be beneficial to extend the formulation to allow for the option of training in more than one additional skill.

This paper also recommends adding a skill level dimension to the formulation. This can be done by dividing the workers into helpers/apprentices, journeymen and foremen. The model would offer the option of training a helper with skill $i$ to become a journeyman in the same skill, training a helper with skill $i$ in an additional skill $j$, or training a journeyman with skill $i$ in becoming a helper in skill $j$. It is also recommended to change the model formulation in order to allow for training workers in administrative or management skills.

Due to the availability of data, the developed model was applied on an industrial project. With minor modifications, the model can be applied to any type of construction project that is facing a skilled labor shortage.

Finally, future studies in this field can benefit from previous work in agent-based modeling, "a methodology in which a simulation experiment is constructed around a set of autonomous agents that interact with each other and their underlying environment to mimic the real-world scenario that the replicate" (Sawhney et. al 2003). A model can be developed at a corporate level or for a certain region such as the Gulf Coast Area where there is sufficient construction work for the local labor pool. Hence, workers don't need to leave the region to get employed. The different projects in this region can be looked at as independent agents interacting with a common pool of labor. Long-term demand curves for this area need to be generated. The model can incorporate potential elasticities in supply and demand of labor. The investment in the available labor pool can come from a regional organization such as the Houston Business Roundtable which is interested in improving the skill sets of its labor pool in order to meet job site demands in the most cost-effective fashion. In this context, several questions arise: is there a breakpoint at which all the firms start training? Will the training be provided by contractors, owners, or both? When will the workers themselves recognize the benefits of cross-training? 


\subsection{CONTRIBUTIONS}

This study extends the CCIS workforce research effort through the following contributions:

- It describes the characteristics of today's US construction workforce based on a recent survey, discusses the main challenge faced by this workforce (i.e. skilled labor shortages) and some of the innovative solutions, and presents major labor management elements, namely multiskilling.

- It provides a framework for the implementation of one of the components of the Tier II strategy, namely how to improve workers' skill sets using mathematical modeling. The developed model, entitled the OWIM, makes the best use of the available workforce and its skills set using an optimization-based approach. This is accomplished by matching supply and demand of construction labor most efficiently through training, recruitment, and allocation. The model provides a simple and useful tool for labor planning using commercially available projects.

- It presents a case study, the CII Model Plant, on which the model is tested and validated. The results of applying the model on several case-study scenarios are also discussed.

- It illustrates some of the benefits and costs associated with the implementation of the OWIM. 
Appendix A: Workforce Assessment Package Questionnaires 


\section{WORKFORCE ASSESSMENT TOOL INDIVIDUAL SKILL ASSESSMENT}

1. In how many crafts are you certified?

Please list those crafts and who provided the certification:

In the next 12 months, how many additional crafts will you be certified in?

Please list those crafts:

2. How many years of experience, in your primary craft, do you have at the certified craft level? yrs

3. How many hours of craft training and craft skill updating have you had in the last 3 years? (including recertification and safety) Hrs

4. Please check all of the following administrative skills in which you are proficient*:

$\square$ Cost Management $\quad \square$ Request for Information $\square$ Material Management

$\square$ Scheduling $\square$ Estimating

5. Please check all of the following computer skills in which you are proficient*:

$\square$ E-mail/internet $\square$ Scheduling $\square \quad$ Material Management

$\square \quad$ Word processing $\quad \square \quad$ Estimating

$\square$ Spreadsheet $\quad \square$ Computer Aided Design (CAD)

6. How many total hours of training do you have in planning skills? (Material, equipment, tools and information request, short-term planning, and scheduling) (Include FORMAL on-the-job training) Hrs

Are you certified in planning? $\square$ yes $\square$ no

Are you proficient* in planning skills? $\square$ yes $\square$ no

7. How many combined hours of training do you have in job management skills? (Crew coordination, inter-and intra- craft coordination, selection of work packages, and leadership) (Include FORMAL on-the-job training) Hrs

Are you certified in job management? $\square$ yes $\square$ no Are you proficient* in job management skills? $\square$ yes $\square$ no

8. Have you worked for this company before this project? $\square$ yes $\square$ no

*Proficient- a skill in which you are competent and capable with little or no supervision 
9. For the last year, please rate the your personal performance record (including safety, attendance, quality, productivity, and initiative) on a scale from 0 to 10 with 0 being weak, 5 being modest and 10 being superior.

\begin{tabular}{lccccccccccc} 
& Weak & \multicolumn{4}{c}{ Modest } & & & Superior \\
Performance & 0 & 1 & 2 & 3 & 4 & 5 & 6 & 7 & 8 & 9 & 10 \\
Record & & & & & & & & & & &
\end{tabular}

10. Do you have any experience in training unskilled workers in tasks as an instructor or a mentor?

$\square$ yes $\square$ no

If yes, have you ever been certified as an instructor?

yes $\square$ no

11. How many people are on your crew (not including the foreman)?

How many journeymen are on your crew?

How many helpers are on your crew? 


\section{WORKFORCE ASSESSMENT TOOL INDIVIDUAL BACKGROUND QUESTIONNAIRE}

1. What is your age?

2. What is your gender? $\square$ Female Male

3. What is your country of origin? $\square$ USA $\square$ Other (please specify)

4. What is your level of education?

0-8 years of school

Some high school

High school diploma

GED equivalent

Completed vocational or technical program

Some college (No degree)

$\square \quad$ Associate degree (2 year program)

$\square$ Bachelors degree (4 year program)

$\square$ Some post graduate education (Masters, Ph.D.)

$\square$ Masters degree

Ph.D.

Other (please specify)

5. What is your present job title? (Check one)
$\square$ Project Manager
Assistant Project Manager
Superintendent
Assistant Superintendent
Craft Superintendent
General Foreman
Foreman
Craftsman / Journeyman
Apprentice/Helper
Other (please specify)

6. In what crafts do you work at the journeyman level? (Check all that apply)
$\square$ Boilermaker
$\square$ Carpenter
$\square$ Concrete Finisher
$\square$ Crane Operator
$\square$ Equipment Operator
$\square$ Electrician
$\square$ Instrument Fitter
$\square$ Glass/Glazing Worker
$\square$ Instrument Technician
$\square$ Insulation Worker
$\square$ Laborer
Mason

$\square$ Welder
$\square$ Millwright
$\square$ Operating Engineer
$\square$ Plumber
$\square$ Painter
$\square$ Pipe fitter
$\square$ Roofer
$\square$ Reinforcing Rodman
$\square$ Rigger
$\square$ Structural Ironworker
$\square$ Sheetmetal Worker
$\square$ Other (list)

If you checked more than one, please indicate which is you primary craft:

7. How did you receive your craft training? (Check all that apply)
$\square$ Passed NCCER Wheels of Learning Program in your craft
$\square$ Basic military training in construction
$\square$ Military "C" school training in a craft
Vocational program

$\square$ Graduate of union sector apprenticeship program

$\square$ Graduate of company non-union apprenticeship program

$\square$ Graduate of company craft certification program

$\square$ On the job training only

$\square$ Other (specify)

8. In your current job, do you have supervisory responsibility? $\square$ Yes $\quad \square$ No 
9. What is your current pay rate, not including overtime ? $\$$ per hour

If you are not paid by the hour but you are salaried, what is your salary $\$$ per year

10. How many total weeks did you work in construction in year 2001 ? weeks

On average, how many hours per week did you work in construction in year 2001?

11. How long have you been with your present firm? Years Months

12. For how many different construction companies have you worked?

13. On what type of construction projects have you normally worked ?

$\square$ Union $\quad \square$ Open Shop $\quad \square$ Both

14. How many years of experience in construction do you have in each of the following categories?

\begin{tabular}{|c|c|}
\hline Years & Position \\
\hline & Apprentice / Helper \\
\hline & Journeyman \\
\hline & Foreman \\
\hline & General Foreman \\
\hline & Assistant Superintendent \\
\hline & Superintendent \\
\hline & Assistant Project Manager \\
\hline & Project Manager \\
\hline
\end{tabular}

Your Total years of experience in construction

15. Do you know how to use a computer? $\square$ Yes $\square$ No (if "No" jump to question 18)

16. How long have you been using a computer? years

17. Where did you acquire your computer skills?

Self-taught off the job

By on-the-job use

Through company sponsored training

Formal education / schooling

Other (please specify)

18. Do you have any job planning, management or administrative skills ? 
Yes $\quad \square$ No (if "No" jump to question 20)

19. Where did you acquire those planning, management and administrative skills ?

$\square$ Self-taught off the job

$\square$ By on-the-job use

$\square$ Through company sponsored training

$\square$ Formal education / schooling

$\square$ Other (please specify)

Example of skills: - Cost and materials management, Scheduling, Estimating, RFI, crew coordination, selection of work packages, leadership

20. Are you satisfied with your pay? $\square$ Yes $\square$ No

For the following question, please indicate your response on a scale from 1 to 5.

21. How satisfied do you feel with your career in the construction industry?

$\begin{array}{ccccc}1 & 2 & 3 & 4 & 5 \\ \text { Very } & & \text { Neutral } & & \text { Very } \\ \text { Dissatisfied } & & & & \text { Satisfied }\end{array}$

Why? 
Appendix B: Case Study 1-An Example Formulation of the WOIM in GAMS 
\$ TITLE Real size Problem for the Optimal Invesment Model

$\$$ Offlisting

\$OFFUPPER OFFSYMXREF OFFSYMLIST INLINECOM \{ $\}$

OPTIONS SOLPRINT=OFF, LIMCOL $=0$, LIMROW=0, LP=CPLEX;

SETS

I sets of skills /Strctsteel, Millwright, Pipefitter, Welder, Electric, Instrument, Carpenter, Painter, Ironworker, Equipoper, Concrfin, Craneoper, Genlabor, Insulator, Rigger/ T time periods /WK $1 *$ WK77/;

ALIAS (I,J);

PARAMETER S(I) available workers with skill i currently employed

/Carpenter 35

Concrfin 7

Craneoper 9

Electric 30

Equipoper 24

Genlabor 45

Instrument 5

Insulator 30

Ironworker 22

Millwright 36

Painter 17

Painter 17

Pipefitter 66

Rigger 5
Strctseel 14

Welder $40 /$;

PARAMETER WAGE(I) hourly wage of a worker who possesses skill

/Carpenter 18.50

Concrfin 17

Craneoper 20

Electric 21.50

Equipoper 19.50

Genlabor 15

Instrument 19.50

Insulator 16.50

Ironworker 17.5

Millwright 19

Painter 16.50

Pipefitter 19.50

Rigger 16.50

Strctsteel 20

Welder 17.50 /;

PARAMETER HIRECOST(I) cost to hire a worker who possesses skill i ; HIRECOST $(i)=1300$

HIRECOST('Welder') $=1450$ 
PARAMETER HIRECAP(I) maximum number of workers with skill $i$ that can be hired /Carpenter 10

Concrfin 20

Craneoper 5

Electric 0

Equipoper 15

Genlabor 20

Instrument 10

Insulator 20

Ironworker 10

Millwright 15

Millwright 15

Painter 10

$\begin{array}{ll}\text { Pipefitter } & 0 \\ \text { Rigger } & 0\end{array}$

$\begin{array}{ll}\text { Rigger } & 0 \\ \text { Strctsteel } & 10\end{array}$

Welder 20

PARAMETER TRAINCAP(I) maximum number of workers that can be trained in skill i /Carpenter 20

Concrfin 10

Craneoper 5

Electric 5

Equipoper 10

Genlabor 0

Instrument 10

Insulator 20

Ironworker 10

Millwright 15

Painter 15

Pipefitter 10

Rigger 5

Strctsteel 10

Strctsteel 10

Welder 20 /; 
TABLE D(I,T) number of needed workers with skill i during time period $t$

WK34 WK35 Wk36 WK37 WK38 WK3 WK4 WK5 WK6 WK7 Wk8 Wk9 WK10 WK11 WK12 WK13 WK14 WK15 WK16 WK17 WK18 WK19 WK20 WK21 WK22 Wk23 Wk24 WK25 Wk26 WK27 Wk28 WK29 WK30 WK31 WK32 WK33 WK69 WK5 WK1 WK37 WK38 WK39 Wk40 Wk41 WK42 Wk43 WK44 WK45 WK46 WK47 Wk48 Wk49 Wk50 WK51 WK52 WK53 WK54 WK55 WK56 WK57 WK58 WK59 WK60 WK61 WK62 WK63 WK64 WK65 WK66 WK67 WK68

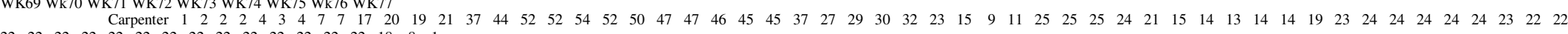

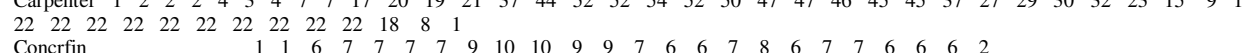

$\begin{array}{lllllllll}6 & 8 & 8 & 2\end{array}$

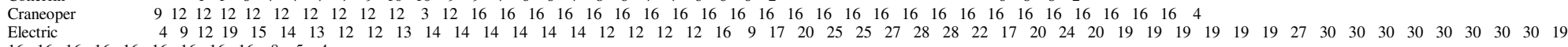

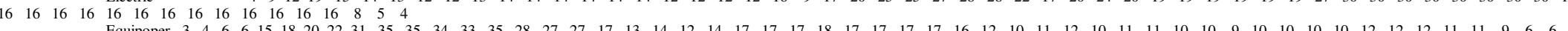

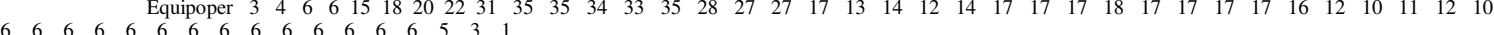

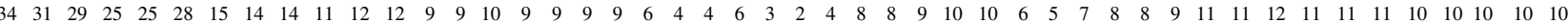

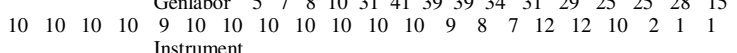

$\begin{array}{lllllll}3 & 3 & 3 & 3 & 1 & \text { Instrument }\end{array}$

$\begin{array}{llllllllllllllllllllllllllllllll}3 & 3 & 3 & 3 & 3 & 3 & 3 & 5 & 5 & 9 & 10 & 10 & 6 & 5 & 5 & 5 & 5 & 5 & 5 & 5 & 5 & 5 & 5 & 5 & 5 & 5 & 5 & 5 & 5 & 5 & 4 & 1\end{array}$

$23 \quad 3$

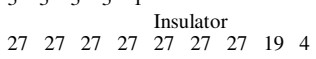

$27 \quad 27 \quad 27$
Ironworker

$\begin{array}{lllllllllllllllllllllll}2 & 2 & 2 & 2 & 1 & 1 & 4 & 4 & 4 & 4 & 4 & 4 & 12 & 15 & 15 & 15 & 14 & 23 & 27 & 27 & 27 & 27 & 27\end{array}$ $\begin{array}{lllllllllllllllllllllllllllllllllllllllllllllllll}\text { lronworker } & 5 & 6 & 15 & 18 & 18 & 19 & 26 & 29 & 32 & 31 & 30 & 29 & 31 & 33 & 34 & 34 & 32 & 29 & 20 & 18 & 18 & 16 & 17 & 10 & 5 & 4 & 4 & 5 & 5 & 5 & 5 & 5 & 5 & 4 & 3 & 3 & 3 & 3 & 3 & 3 & 3 & 3 & 3 & 2\end{array}$

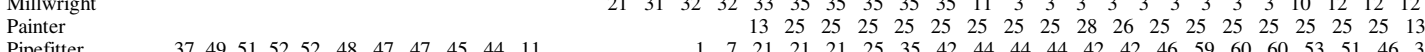
\begin{tabular}{lllllllllllllllll}
\hline & 3 & 3 & 3 & 3 & 3 & 3 & 3 & 1 & 2 & 3 & 2 & 1 & 1 & 1 & 1
\end{tabular}

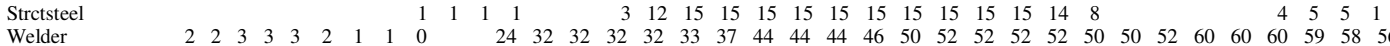

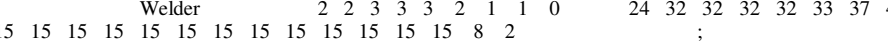
TABLE P(I,J) number of currently employed workers with skill i \& J

Carpenter Concrfin Craneoper Electric Equipoper Genlabor Instrument Insulator Ironworker Millwright Painter Pipefitter Rigger Strctsteel Welder

Carpenter

Concrfin

Craneoper

Electric

2

Equipoper

2

Instrument

Insulator

Ironworker

Ironworker

Mainter

Pipefitter

Rigger

Rigger
Strctsteel

Welder

PARAMETER W(I,J) hourly wage of a worker who possesses skills i \& $\mathrm{j}$;

$\mathrm{W}(\mathrm{I}, \mathrm{J})=\max (\mathrm{WAGE}(\mathrm{I}), \mathrm{WAGE}(\mathrm{J}))$;

PARAMETER HCOST (I,J) cost to hire a worker who possesses skills i \& j;

$\operatorname{HCOST}(i, j)=1300$;

$\operatorname{HCOST}($ 'Welder', $\mathrm{j})=1450$

$\operatorname{HCOST}\left(\mathrm{i},{ }^{\prime} W e l d e r '\right)=1450$; 
TABLE HCAP (I,J) maximum number of workers with skills i \& $j$ that can be hired

Carpenter Concrfin Craneoper Electric Equipoper Genlabor Instrument Insulator Ironworker Millwright Painter Pipefitter Rigger Strctsteel Welder

Carpenter

Concrfin 2

Craneoper

Electric

Equipoper

2

Genlabor

Insulator

Ironworker

Ironworker

Millwrig
Painter

Pipefitter

Rigger

Rigger
Strctsteel

Welder

22

1

2

PARAMETER TRAINCOST(I,J) cost to train a worker who possesses skill i in skill $\mathrm{j}$;

TRAINCOST $(\mathrm{I}, \mathrm{J})=2000$;

TRAINCOST(I,'Genlabor')=1;

TABLE a(I,J) affinity coefficient between skill $i$ and $j$

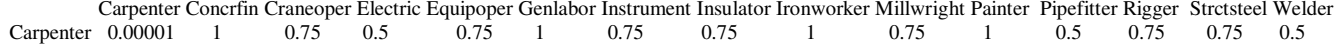

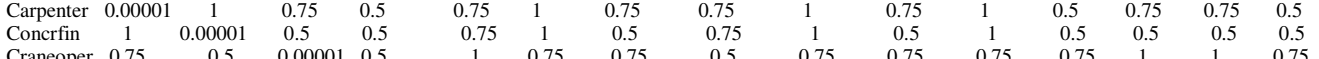

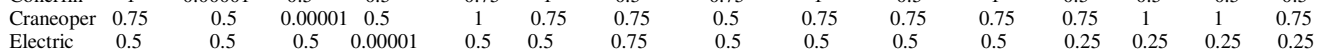

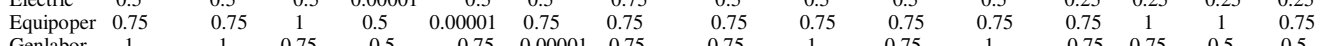

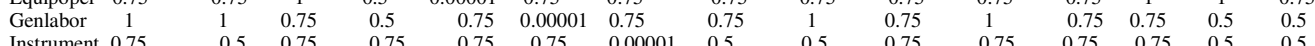

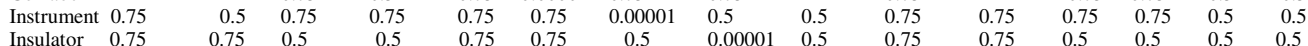

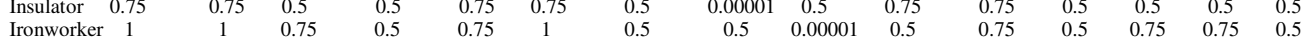

$\begin{array}{lllllllllllllll}\text { Millwright } 0.75 & 0.5 & 0.75 & 0.5 & 0.75 & 0.75 & 0.75 & 0.75 & 0.5 & 0.00001 & 0.75 & 0.75 & 0.75 & 1 & 0.75\end{array}$

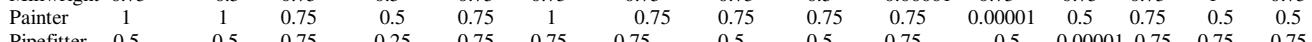

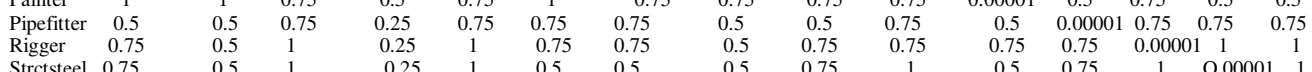

$\begin{array}{llllllllllllllll}\text { Strctsteel } & 0.75 & 0.5 & 1 & 0.25 & 1 & 0.5 & 0.5 & 0.5 & 0.75 & 1 & 0.5 & 0.75 & 1 & 0.00001 & 1 \\ \text { Welder } & 0.5 & 0.5 & 0.75 & 0.25 & 0.75 & 0.5 & 0.5 & 0.5 & 0.5 & 0.75 & 0.5 & 0.75 & 1 & 1 & 0.00001 \text {; }\end{array}$

SCALAR HRSPERWEEK number of hours of work per week /40/;

POSITIVE VARIABLES

$X(I, J)$ number of workers with skill $i$ to be trained in skill $j$

Y(I) number of workers with skill $i$ to be hired

$\mathrm{Z}(\mathrm{I}, \mathrm{J})$ number of workers with skills $\mathrm{i}$ and $\mathrm{j}$ to be hired

$\mathrm{L}(\mathrm{I}, \mathrm{J}, \mathrm{T})$ number of workers with skills $\mathrm{i}$ and $\mathrm{j}$ working in skill $\mathrm{i}$ in time period $\mathrm{t}$

$\mathrm{M}(\mathrm{I}, \mathrm{J}, \mathrm{T})$ number of workers with skills $\mathrm{i}$ and $\mathrm{j}$ working in skill $\mathrm{j}$ in time period $\mathrm{t}$

$\mathrm{N}(\mathrm{I}, \mathrm{T})$ number of workers with skill $\mathrm{i}$ working during time period $\mathrm{t}$

FREE VARIABLE

TOTALCOST total labor costs;

EQUATIONS

OBJ defines the objective function - minimize total labor cost 


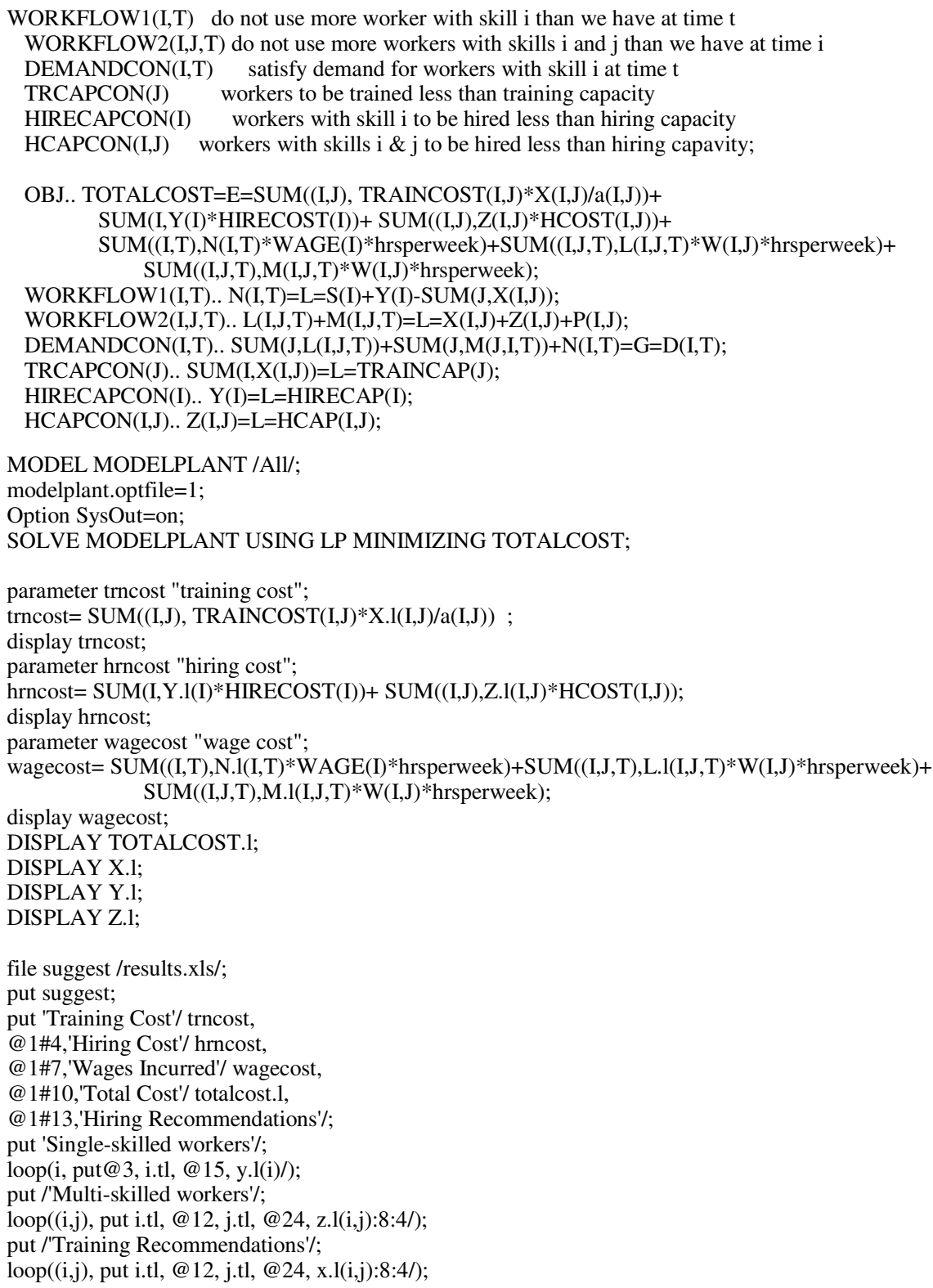


Appendix C: Sample Output of Worker Assignment Resulting from Running the WOIM on Case Study 1 
Note: "LEVEL" indicates the value of the variable, i.e. the number of workers with the corresponding skills working during the indicated week. For example, the number of workers who possess both structural steel and pipefitting skills working during week 58 is 0 and the number of workers who possess structural steel and welding skills working during week 18 is 1 .

The size of the full L Matrix, which is equivalent to the number of rows, is equal to: $15 \times 15 \times 77=17,325$.

VAR $L$ number of workers with skills $i$ and $j$ working in skill $i$ in time period $t$

LEVEL

Strctsteel.Pipefitter.WK58

Strctsteel.Pipefitter.WK59

Strctsteel.Pipefitter.WK60

Strctsteel.Pipefitter.WK61

Strctsteel.Pipefitter.WK62

Strctsteel.Pipefitter.WK63

Strctsteel.Pipefitter.WK64

Strctsteel.Pipefitter.WK65

Strctsteel.Pipefitter.WK66

Strctsteel.Pipefitter.WK67

Strctsteel.Pipefitter.WK68

Strctsteel.Pipefitter.WK69

Strctsteel.Pipefitter.WK70

Strctsteel.Pipefitter.WK71

Strctsteel.Pipefitter.WK72

Strctsteel.Pipefitter.WK73

Strctsteel.Pipefitter.WK74

Strctsteel.Pipefitter.WK75

Strctsteel.Pipefitter.WK76

Strctsteel.Pipefitter.WK77

Strctsteel.Welder .WK

Strctsteel.Welder .WK2

Strctsteel.Welder .WK3

Strctsteel.Welder .WK4

Strctsteel.Welder .WK5

Strctsteel.Welder .WK6

Strctsteel.Welder .WK7

Strctsteel.Welder .WK8

Strctsteel.Welder .WK9

Strctsteel.Welder .WK10

Strctsteel.Welder .WK11

Strctsteel.Welder .WK12

Strctsteel.Welder .WK13

Strctsteel.Welder .WK14

Strctsteel.Welder .WK15

Strctsteel.Welder .WK16

Strctsteel.Welder .WK17

Strctsteel.Welder .WK18

Strctsteel.Welder .WK19

Strctsteel.Welder .WK20

Strctsteel.Welder .WK21

Strctsteel.Welder WK22

Strctsteel.Welder .WK23

Strctsteel.Welder .WK24

Strctsteel.Welder .WK25

Strctsteel.Welder .WK26

Strctsteel.Welder .WK27

Strctsteel.Welder .WK28

Strctsteel.Welder .WK29
1.0000

1.0000

1.0000

1.0000

1.0000

1.0000

1.0000 
The size of the full $\mathrm{M}$ matrix, which is equivalent to the number of rows, is equal to: $15 \times 15 \times 77=17,325$.

VAR M number of workers with skills $\mathrm{i}$ and $\mathrm{j}$ working in skill $\mathrm{j}$ in time period $\mathrm{t}$

LEVEL

$\begin{array}{lll}\text { Pipefitter.Rigger } & \text {.WK25 } & \\ \text { Pipefitter.Rigger } & \text {.WK26 } & \\ \text { Pipefitter.Rigger } & \text {.WK27 } & 1.0000 \\ \text { Pipefitter.Rigger } & \text {.WK28 } & 1.0000 \\ \text { Pipefitter.Rigger } & \text {.WK29 } & 1.0000 \\ \text { Pipefitter.Rigger } & \text {.WK30 } & 1.0000 \\ \text { Pipefitter.Rigger } & \text {.WK31 } & 1.0000\end{array}$

Pipefitter.Rigger .WK33

Pipefitter.Rigger .WK34

Pipefitter.Rigger .WK35

Pipefitter.Rigger .WK36

Pipefitter.Rigger .WK37

Pipefitter.Rigger .WK38

Pipefitter.Rigger .WK39

Pipefitter.Rigger .WK40

Pipefitter.Rigger .WK41

Pipefitter.Rigger .WK42

Pipefitter.Rigger .WK43

Pipefitter.Rigger .WK44

Pipefitter.Rigger .WK45

Pipefitter.Rigger .WK46

Pipefitter.Rigger .WK47

Pipefitter.Rigger .WK48

Pipefitter.Rigger .WK49

Pipefitter.Rigger .WK50

Pipefitter.Rigger .WK51

Pipefitter.Rigger .WK52

Pipefitter.Rigger .WK53

Pipefitter.Rigger .WK54

Pipefitter.Rigger .WK55

Pipefitter.Rigger .WK56

Pipefitter.Rigger .WK57

Pipefitter.Rigger .WK58

Pipefitter.Rigger .WK59

Pipefitter.Rigger .WK60

Pipefitter.Rigger .WK61

Pipefitter.Rigger .WK62

Pipefitter.Rigger .WK63

Pipefitter.Rigger .WK64

Pipefitter.Rigger .WK65

Pipefitter.Rigger .WK66

Pipefitter.Rigger .WK67

Pipefitter.Rigger .WK68

Pipefitter.Rigger .WK69

Pipefitter.Rigger .WK70

Pipefitter.Rigger .WK71

Pipefitter.Rigger .WK72

Pipefitter.Rigger .WK73 
The size of the full $\mathrm{N}$ matrix, which is equivalent to the number of rows, is equal to: $15 \mathrm{x} 77=1155$.

VAR N number of workers with skill $\mathrm{i}$ working during time period $\mathrm{t}$

LEVEL

Millwright.WK22

21.0000

Millwright.WK23

31.0000

32.0000

$\begin{array}{ll}\text { Millwright.WK25 } & 32.0000 \\ \text { Millwright.WK26 } & 33.0000\end{array}$

$\begin{array}{ll}\text { Millwright.WK26 } & 33.0000 \\ \text { Millwright.WK27 } & 35.0000\end{array}$

Millwright.WK28 35.0000

Millwright.WK29 35.0000

Millwright.WK30 35.0000

Millwright.WK31 35.0000

Millwright.WK32 $\quad 11.0000$

Millwright.WK33 3.0000

Millwright.WK34 3.0000

Millwright.WK35 3.0000

Millwright.WK36 1.0000

Millwright.WK37 1.0000

Millwright.WK38 $\quad 3.0000$

Millwright.WK39 $\quad 1.0000$

Millwright.WK40 3.0000

Millwright.WK41 3.0000

Millwright.WK42 10.0000

Millwright.WK43 12.0000

Millwright.WK44 10.0000

Millwright.WK45 12.0000

Millwright.WK46 10.0000

Millwright.WK47 $\quad 5.0000$

Millwright.WK48 2.0000

Millwright.WK49

Millwright.WK50

Millwright.WK51

Millwright.WK52

Millwright.WK53

Millwright.WK54

Millwright.WK55

Millwright.WK56

Millwright.WK57

Millwright.WK58

Millwright.WK59

Millwright.WK60

Millwright.WK61

Millwright.WK62

Millwright.WK63

Millwright.WK64

Millwright.WK65

Millwright.WK66

Millwright.WK67

Millwright.WK68

Millwright.WK69

Millwright.WK70 


\section{GLOSSARY}

\begin{tabular}{ll} 
ABC & Associated Builders and Contractors \\
BEA & Bureau of Economic Analysis, US Department of Commerce \\
BLS & Bureau of Labor Statistics, US Department of Labor \\
BRT & The Business Roundtable \\
CCIS & Center for Construction Industry Studies \\
CEH & Compass Educational Holdings \\
CII & Construction Industry Institute \\
CINESTA & Construction Industry Network for Essential Training in Alberta \\
COAA & Construction Owners Association of Alberta \\
CPWR & The Center to Protect Workers' Rights \\
CURT & The Construction Users Roundtable \\
CWDFC & Construction Workforce Development Forecasting Committee \\
GAMS & General Algebraic Modeling System \\
IBB & International Brotherhood of Boilermakers \\
NCCER & National Center for Construction Education and Research \\
OWIM & Optimal Workforce Investment Model \\
P3 & Primavera Project Planner \\
SDHPT & State Department of Highways and Public Transportation \\
\hline
\end{tabular}




\section{References}

Allen, S. 1994. "Developments in Collective Bargaining in Construction in the 1980s and 1990s." National Bureau of Economic Research, working paper No. 4674.

Associated Builders and Contractors (ABC). 2002. ABC Today, Vol. 9, No. 9, June 2000.

Aykin, T. 1996. "Optimal Shift Scheduling with Multiple Break Windows." Management Science, 42(4), 591-602.

Beaumont, N. 1997. "Scheduling Staff Using Mixed Integer Programming." European Journal of Operational Research, 98, 473-484.

Bechtold, S.E. and Jacobs, L.W. 1990. "Implicit Optimal Modeling of Flexible Break Assignments in Labor Staffing Decisions for Service Operations." Management Science, 36(11), 1339-1351.

Bertsimas, D. and Tsitsiklis, J.N. 1997. "Introduction to Linear Optimization." Athena Scientific, Belmont, Massachusetts.

Brandenburg, S. 2004. “The Tier I Workforce Management Strategy: Concept and Application." Dissertation, The University of Texas at Austin, Austin, TX.

Brooke, A., Kendrick, D., Meeraus, A., and Raman, R. 1998. "GAMS A User's Guide." GAMS Development Corporation. Washington, DC.

Bureau of Economic Analysis (BEA). 2004. Website. Available online: http://www.bea.doc.gov/ Accessed on June, 03, 2004.

Bureau of Labor Statistics (BLS). 2004. "2002 National Industry-Specific Occupational Employment and Wage Estimates: NAICS 237900 - Other Heavy and Civil Engineering Construction." U.S. Department of Labor: The Bureau of Labor Statistics, http://www.bls.gov/oes/2002/naics4_237900.htm Accessed on January 27, 2004.

Burleson, R. 1997. "Multiskilled Labor Utilization Strategies in Construction." Dissertation, The University of Texas at Austin, Austin, TX.

Burleson, R., Haas, C., Tucker, R. and Stanley, A. 1998. "Multiskilled Labor Utilization Strategies in Construction." Journal of Construction Engineering and Management, 124(6), 480-489. 
Business Roundtable (BRT). 1983. "More Construction for the Money." Construction Industry Cost Effectiveness Project, Summary Report. The Business Roundtable.

Business Roundtable (BRT). 1997. "Confronting the Skilled Construction Work Force Shortage: A blueprint for the future." Construction Cost Effectiveness Task Force, Summary Report. The Business Roundtable.

Campbell, G.M. 1999. "Cross-Utilization of Workers Whose Capabilities Differ." Management Science, 45(5), 722-732.

Carley, L.A., Goodrum, P., Haas, C.T. and Borcherding J.D. 2003. "Experiences with Multiskilling among Non-Union Craft Workers in U.S. Industrial Construction Projects." Construction and Architectural Management, Vol. 10, p374-381.

Castaneda, J. 2002. "Workers' Skills and Receptiveness to Operate Under the Tier II Construction Management Strategy." Dissertation, The University of Texas at Austin, Austin, TX..

Center to Protect Workers' Rights (CPWR). 2002. "The Construction Chart Book: The U.S. Construction Industry and Its Workers." $3^{\text {rd }}$ Edition. Washington, D.C.

Chang, S.W. 2002. "Development and Assessment of the Tier II Workforce Strategy Implementation Index." Dissertation, The University of Texas at Austin, Austin, TX.

Chapman, K. and Gerson, G. 1999. "High-Performance Teams in the Construction Industry." In Action: Developing High-Performance Work Teams. J.J. Philips, S.D. Jones, and M.M. Beyerlein, editors. Vol. 1, 229-250.

Construction Industry Institute (CII). 1986. "The CII Model Plant." Source Document 23, Construction Industry Institute, The University of Texas at Austin, Austin, TX.

Construction Industry Institute (CII). 2000. "Attracting and Maintaining a Skilled Construction Workforce." Research Summary 135-1, The University of Texas at Austin, Austin, TX.

COAA. 2004. "Tools for Essential Skills Training in Alberta." Edmonton: Construction Owners Association of Alberta.

Construction User Round Table (CURT). 2001. "CURT Work Force development survey results." The Construction User Round Table.

Construction Workforce Development Forecasting Committee (CWDFC). 2002. "The Construction Workforce Development Forecasting Committee 2002 Construction Trades Outlook." The Construction Owners Association of Alberta, Canada. 
Contren®. 2004. “Contren® Learning Series.” http://www.prenhall.com/crafttraining.

Dantzig, G.B. 1954. "A Comment on Edie's Traffic Delays at Toll Booths." Operation Research, 2(3), 339-341.

Diekmann, J.E., and Peppler, S.E. 1984., "Union and Open Shop Labor Cost Differences." Journal of Construction Engineering and Management, 110(1), 8799.

Edie, L.C. 1954. "Traffic Delays at Toll Booths.” Operations Research, 2(2), 107-138.

Franke W. and Sobel I. 1970. "The Shortage of Skilled Technical Workers." Lexington, MA, Heath-Lexington Books.

Gann, D. and Senker, D. 1998. "Construction Skills Training for the Next Millenium." Construction Management and Economics, 16, 569-580.

General Algebraic Modeling System (GAMS). 2004. Sales, Commercial Price List, http://www.gams.com/sales/commercialp.htm, accessed on 12/05/2004, 11:20am.

Gomar, J.E. 1999. "Assignment and Allocation Optimization of a Partially Multiskilled Workforce." Master's Thesis, The University of Texas at Austin, Austin, TX.

Gomar, J.E., Haas, C.T., and Morton, D.P. 2002. "Assignment and Allocation Optimization of a Partially Multiskilled Workforce." Journal of Construction Engineering and Management, March-April, 103-109.

Goodrum, P. 2004. "Occupational Injuries, Illnesses, and Fatalities: Differences among Hispanic and non-Hispanic Construction Workers." 2004 Specialty Conference on Leadership and Management in Construction.

Goodrum, P. and Gangwar, M. 2004. "The Relationship Between Changes in Equipment Technology and Wages in the US Construction Industry." Construction Management and Economics, 22, 291-301.

Haas, C.T., Rodriguez A.M., Glover R., and Goodrum P. 2001. "Implementing a multiskilled workforce." Construction Management and Economics, 19, 633-641.

Hancock, H. 1960. "Theory of Maxima and Minima.” Dover Publications, Inc., New York.

Hegazy, T. and Wassef, N. 2001. "Cost Optimization in Projects with Repetitive NonSerial Activities." Journal of Construction Engineering and Management, ASCE, 127(3), 183-191. 
Hyatt, B.A., Pappas, M.P., and Haas, C.T. 2004. "Comparison of Naval Construction Force Personnel and Civilian Construction Workers in the United States Utilizing the Workforce Assessment Package." Proceedings of the Specialty Conference on Management and Leadership in Construction, Hilton Head, South Carolina, ASCE, March 25-26.

International Brotherhood of Boilermakers (IBB). 2004.

http://www.commonarc.com/welcome.htm\#top, accessed on 03/05/2004, 10:30am.

Kiplinger. 2002. "Labor Market Outlook.” Kiplinger Letter. 79(20).

Levitt, R. E. 1979. "Union Versus Nonunion Construction in the U.S.” Journal of the Construction Division, Proceedings of the American Society of Civil Engineers, 105 (CO4), 289-301.

Mackenzie S., Kilpatrick A.R. and Akintoye A. 2000. "UK Construction Skills Shortage Response Strategies and an Analysis of Industry Perceptions." Construction Management and Economics, 18, 853-862

Maloney, W. and McFillen, J. 1995. "Job Characteristics: Union-Nonunion Differences." Journal of Construction Engineering and Management, ASCE, 121(1), 43-54.

Maloney, W.F. 1997. "Strategic Planning for Human Resource Management in Construction." Journal of Management in Engineering, ASCE, vol 13 (3).

Marshall, R. 1992. "Key Elements of High Performance Work and Learning Systems.” In High Performance Work and Learning Systems: Crafting a Worker-Centered Approach. Proceedings of a Conference Sponsored by the AFL-CIO Human Resources Development Institute, September 1991, Daniel Marshall, editor: 3-14.

Mattila, K.G. and Abraham, D.M. 1998. "Resource Leveling of Linear Schedules Using Integer Linear Programming." Journal of Construction Engineering and Management, ASCE, 124(3), 232-244.

McFillen, J. and Maloney W. 1986. "Human Resource Data in the Construction Industry." Journal of Construction Engineering and Management, ASCE, 112(1), 22-32.

Mital, K.V. 1979. “Optimization Methods.” Wiley Eastern Limited.

Moondra, S.L. 1976. “An L.P. Model for Work Force Scheduling for Banks.” Journal of Bank Research, 7(4), 299-301.

NCCER. 2003. "Innovative Program Builds Workforce." Construction Education Newsline, National Center for Construction Education and Research, 7(2), 1. 
Newman, K.D., and Hancher, D.E. 1991. “Workers' Compensation Issues in Construction." Journal of Professional Issues in Engineering Education and Practice, 117(3), 228-243.

Pappas, M.P. 2004. "An Assessment of Implementation Requirements for the Tier II Construction Workforce Strategy." Dissertation, The University of Texas at Austin, Austin, TX.

Paulson, B.C. 1976. "Estimation and Control of Construction Labor Costs." Journal of the Construction Division, Proceedings of the American Society of Civil Engineers, 101 (CO3), 623-633.

Philips, S.D., McCutcheon, R.T., Emery, S.J., Little, R., and Kwesiga, M.B., 1995, "Technical Analysis of Employment Potential of a National Public Works Programme." Journal of the South African Institution of Civil Engineers, 37(3), $18-24$.

Pike, R.W. 1986. "Optimization for Engineering Systems." Van Nostrand Reinhold Company: New York.

Postel-Vinay F., and Robin, J.M. 2002. "Equilibrium Wage Dispersion with Worker and Employer Heterogeneity." Econometrica, 70(6), 2295-2350.

Reid, J. 1997. "Challenges for the Construction Industry.” Construction Business Review, $7(1), 30-31$.

Rowings, J. and Federle, M. 1996. "Characteristics of the Craft Workforce." Journal of Construction Engineering and Management, ASCE, 122(1), 83-90.

Sawhney, A., Walsh, K., and Mulky A. 2003. "Agent-Based Modeling and Simulation in Construction." Proceedings of the 2003 Winter Simulation Conference, S. Chick. P.J Sanchez, D. Ferrin, and D.J. Morris, eds.

Srour, I.M., Saillard J., Haas, C.T., Tucker R. L. 2003. "Skill Standards for the Construction Industry." Proceedings of the Specialty Conference on Management and Leadership in Construction, Hilton Head, South Carolina, ASCE, March 2526.

Srour, I.M., Haas, C.T., Borcherding J.D. 2004. "What Does the Construction Industry Value in its Workers." Submitted to the Journal of Construction Engineering and Management, The American Society of Civil Engineers.

State Department of Highways and Public Transportation (SDHPT), 1989, "Research Pays Off." TR News (Transportation Research Board), 142, 28-29.

Stewart, B.D., Webster, D.B., Ahmad, S., and Matson, J.O. 1994. "Mathematical Models for Developing a Flexible Workforce." Journal of Production Economics, 36, 243-254. 
Tam, C.M., Tong, T.K., Cheung, S.O. and Chan, A.P. 2001. "Genetic Algorithm Model in Optimizing the Use of Labour." Journal of Construction Management and Economics, Vol 19, p207-215.

Tarumi, H., 1994, "Review of Research on Ballast and Roadbed." Quarterly Report of RTRI (Railway Technical Research Institute), 35(1), 15-18.

Thompson, G.M. 1995. "Improved Implicit Optimal Modeling of the Labor Shift Scheduling Problem.” Management Science, 41(4), 595-607.

Tucker, R.L., Haas, C.T., Glover, R.W., Alemany, C., Carey, L.A., Rodriguez, A., and Shields, D. 1999. "Key Workforce Challenges Facing the American Construction Industry: An Interim Assessment." Report No. 3, Center for Construction Industry Studies, The University of Texas at Austin, Austin, TX.

Veneri, C.M. 1999. "Can Occupational Labor Shortages Be Identified Using Available Data?" Monthly Labor Review, 15-22.

Villalobos, J.A. 1997. "Implementation of Multiskilling in the Construction Industry." Masters Thesis, The University of Texas at Austin, Austin, TX.

Wilde, D.J. and Beightler, C.S. 1967. "Foundations of Optimization." Prentice Hall, Inc., Englewood Cliffs, N.J.

Winston, W. 1995. "Introduction to Mathematical Programming: Applications and Alogrithms." International Thomson Publishing.

Wolters, R.S., and Burleson, R.C. 1996. "Merit Shop Recruitment and Selection Practices in Alabama." Journal of Construction Engineering and Management, 122(2), 152-157. 


\section{Vita}

Issam Mounir Srour was born in Beirut, Lebanon on March 17, 1977, the son of Mounir Srour and Hassiba Jezzini Srour. After completing his studies at Carmel SaintJoseph High School, Beirut, Lebanon, in 1995, he entered the American University of Beirut where he received a Bachelors of Engineering in Civil and Environmental Engineering in July 1999. In the fall of 1999, he started his compulsory military service by working as a Lieutenant Engineer with the Lebanese Army. In the fall of 2000, he entered the Graduate School at the University of Texas at Austin where he earned a Masters of Science in Civil Engineering with a specialty in Transportation in December 2001. In the spring of 2002, he started working towards a PhD in Civil Engineering with a specialty in Construction Engineering and Project Management at the University of Texas at Austin. He completed a Graduate Portfolio Program in Dispute Resolution in the spring of 2004.

Permanent address: Al-Qouzi Building, Al-Jaza'er Street, Al-Malla, Beirut, Lebanon This dissertation was typed by the author. 